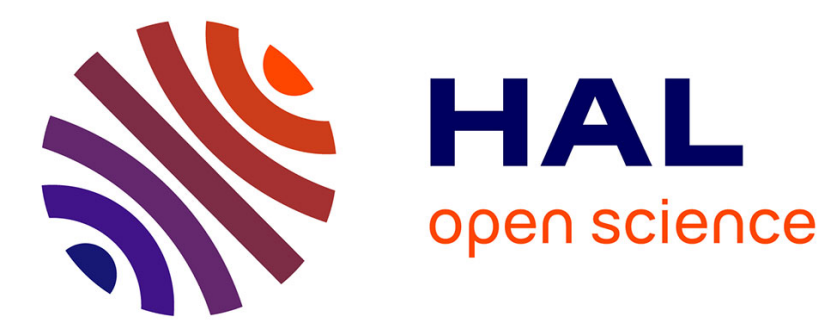

\title{
A review of subtidal benthic habitats and invertebrate biota of the Strait of Georgia, British Columbia
}

\author{
B.J. Burd, P.A.G. Barnes, C.A. Wright, R.E. Thomson
}

\section{To cite this version:}

B.J. Burd, P.A.G. Barnes, C.A. Wright, R.E. Thomson. A review of subtidal benthic habitats and invertebrate biota of the Strait of Georgia, British Columbia. Marine Environmental Research, 2008, 66, 10.1016/j.marenvres.2008.09.004 . hal-00563056

\section{HAL Id: hal-00563056 https://hal.science/hal-00563056}

Submitted on 4 Feb 2011

HAL is a multi-disciplinary open access archive for the deposit and dissemination of scientific research documents, whether they are published or not. The documents may come from teaching and research institutions in France or abroad, or from public or private research centers.
L'archive ouverte pluridisciplinaire HAL, est destinée au dépôt et à la diffusion de documents scientifiques de niveau recherche, publiés ou non, émanant des établissements d'enseignement et de recherche français ou étrangers, des laboratoires publics ou privés. 


\section{Accepted Manuscript}

A review of subtidal benthic habitats and invertebrate biota of the Strait of Georgia, British Columbia

B.J. Burd, P.A.G. Barnes, C.A. Wright, R.E. Thomson

PII:

S0141-1136(08)00212-2

DOI:

10.1016/j.marenvres.2008.09.004

Reference:

MERE 3288

To appear in:

Marine Environmental Research

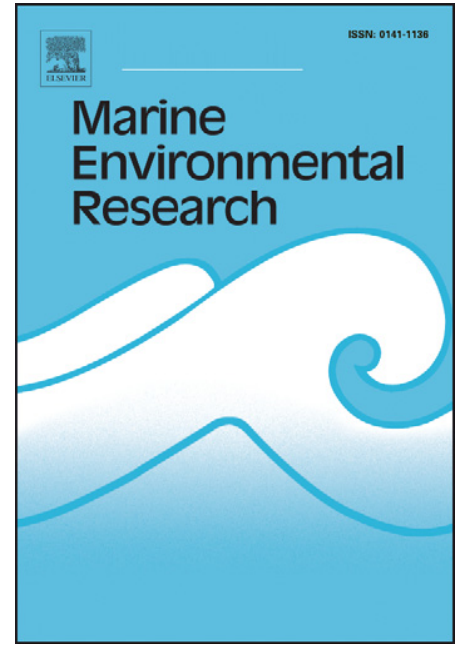

Received Date: $\quad 14$ November 2007

Revised Date: $\quad 28$ August 2008

Accepted Date: $\quad 20$ September 2008

Please cite this article as: Burd, B.J., Barnes, P.A.G., Wright, C.A., Thomson, R.E., A review of subtidal benthic habitats and invertebrate biota of the Strait of Georgia, British Columbia, Marine Environmental Research (2008), doi: 10.1016/j.marenvres.2008.09.004

This is a PDF file of an unedited manuscript that has been accepted for publication. As a service to our customers we are providing this early version of the manuscript. The manuscript will undergo copyediting, typesetting, and review of the resulting proof before it is published in its final form. Please note that during the production process errors may be discovered which could affect the content, and all legal disclaimers that apply to the journal pertain. 
A review of subtidal benthic habitats and invertebrate biota of the 5 Strait of Georgia, British Columbia

B.J. Burd', P.A.G. Barnes ${ }^{2}$, C. A. Wright ${ }^{3}$, R.E. Thomson ${ }^{3}$

${ }^{1}$ Ecostat Research Ltd., 1040 Clayton Rd. North Saanich, B.C. V8L 5P6

${ }^{2}$ Barnes Marine Research Ltd., 942 Sunset Drive, Salt Spring Island, B.C. V8K 1E6

${ }^{3}$ Institute of Ocean Sciences, Box 6000, Sidney, B.C. V8L 4B2

\section{6} (2) (1) 


\section{Abstract}

34 The initial phase of a collaborative Ambient Monitoring Program (AMP) for the Strait of

35 Georgia (SoG) (Marine Environmental Research Vol. x, pp. ) has focused on the benthos,

36 sedimentary regimes, organic and contaminant cycling in subtidal regions of the strait. As part

37 of that project, we review the primarily subtidal benthic invertebrate faunal communities found

38 in the SoG, with particular reference to habitats and sediment conditions. This topic has not been

39 addressed in the primary literature for over 20 years. Benthic biota are the baseline sentinels of

40 the influence of natural and anthropogenic inputs to sediments. They are also a fundamental

41 component of the food chain at the seafloor, and their community ecology must be clearly

42 understood in order to predict how anthropogenic activities and climate change will affect our

43 coastal oceans. The purpose of this review is to provide context on habitats and biota in the SoG,

44 and to highlight topics and geographic areas where our knowledge of the benthos is limited or 45 lacking.

47 Keywords: benthos; Strait of Georgia; subtidal communities; intertidal communities;

48 British Columbia; anthropogenic influences

\section{1. Introduction}

52 The introduction (Section 1) includes the background to this review (Section 1.1), plus

53 overviews of the oceanography (Section 1.2) and sedimentary regimes (Section 1.3) of the SoG.

54 Section 2 reviews information available on the SoG's benthic habitats and invertebrate 
55 communities, with specific sections on intertidal (Section 2.1) and subtidal (Section 2.2)

56 communities and habitats. Section 2.2 is further divided into subsections based on subtidal depth

57 range and substrate type. Anthropogenic influences on benthic environments and invertebrates

58 of the SoG are summarized in Section 3; case studies of each type of anthropogenic influence are

59 also presented. Section 4 provides a brief summary of the review paper.

60

\section{$61 \quad \underline{1.1 \text { Background }}$}

62 Sources, and availability, of information for this review depended largely on the depth range of

63 interest. For example, one source of information on intertidal habitats and biotic conditions for

64 the SoG includes broad-scale mapping, or monitoring, studies with the purpose of managing

65 broader geographic regions for multi-user inputs and conservation. Mapping data are limited to

66 intertidal zone and the shallow subtidal $(<30 \mathrm{~m})$ habitats that have broad aerial, or ground survey

67 coverage. Unfortunately, at depths $>30 \mathrm{~m}$, such mapping and survey data do not exist for the

68 SoG. Rather, information for these depths comes primarily from ship-board sampling as part of

69 studies designed to address specific questions for limited geographic areas. These studies tend,

70 therefore, to be focused on a defined area, a specific anthropogenic influence and/or on data

71 collection in support of fisheries and/or environmental management. Similar sources of

72 information are also available for intertidal and shallow subtidal (0-30 m) habitats for the SoG.

73 While most marine habitats are discussed, at least briefly, in this review, the paper was

74 conceived within the context of a project which was biased towards subtidal, sedimentary

75 habitats, and hence it is these latter habitats that are the focus of this review. 
77 In temperate coastal areas world-wide, most benthic biological research and monitoring

78 programs focus on macrobenthic invertebrates (those captured with $\geq 500 \mu \mathrm{m}$ mesh screens). For

79 this reason, macrobenthic invertebrate communities are the main subject of this review. In

80 addition to size, the life histories, responses to natural and anthropogenic conditions and changes,

81 and trophic strategies of macrobenthic invertebrates are far better understood and documented

82 than those of smaller invertebrates and protozoans. For example, many commercially important

83 macroinvertebrate species live within the sediments (e.g., clams) or on the surface of the

84 sediments or hard substrata (e.g., crabs). In addition, benthic macroinvertebrates have often been

85 the subject of antropogenic impact studies; as a result of being largely sedentary, these organisms

86 are exposed to ambient conditions and may serve as the first-line sentinels reflecting localized

87 impacts (c.f. Warwick and Clark, 1993; Pohle et al., 2001). It should be noted that many benthic

88 macroinvertebrates have a pelagic larval development stage and, as a result, are part of an

89 extensive and intricate food chain which is not limited to the benthos but which can extend

90 throughout the water column.

92 Benthic invertebrates process the particulate, organic materials (detritus, small organisms) that

93 are deposited on the seafloor or that are suspended within reach of the organisms, using a wide

94 range of feeding strategies such as deposit feeding, suspension feeding, filter feeding, or

95 scavenging. Benthic invertebrates may also be predators, herbivores (grazing on living plant

96 material) or they may rely, at least partially, on chemoautotrophy via symbioses with bacteria for

97 their nutrition (Barnes, 1987). Schwinghamer (1983) estimated that, in soft sediments in

98 temperate coastal regions, macroinvertebrates constitute approximately $95 \%$ of the total

99 invertebrate biomass. Similarly, Rowe et al. (1991) found that in coastal areas in global 
100 temperate regions, benthic macroinvertebrates tend to dominate the benthic biomass (excluding

101 fish) in mid-depth subtidal areas (i.e. below the euphotic zone) followed by the other two major

102 benthic consumer groups, the meiofauna (interstitial invertebrates sized $42 \mu \mathrm{m}$ to $1 \mathrm{~mm}$ ) and the

103 single-celled organisms (primarily bacteria). While single-celled organisms are beyond the

104 scope of this review, meiofaunal community studies, where applicable, have been incorporated.

105 With the exception of foraminifera (for which taxonomy based on shell morphology has been

106 extensively used in modern and ancient sediments for interpolation of biological and

107 environmental conditions), however, the availability of information on meiofaunal taxonomy,

108 life histories, and environmental tolerances is limited.

109 In contrast to diversity and biomass patterns, Schwinghamer (1981) estimates that, because of

110 their small size, approximately $95 \%$ of the total abundance of benthic invertebrates consists of

111 nematodes and harpacticoid copepods. Included in this total abundance estimate are the larvae of

112 larger invertebrates and a series of less common phyla, typically captured only by $63 \mu \mathrm{m}$ mesh

113 screens, which prey on benthic bacteria, flagellates, ciliates, foraminifera, and diatoms or blue-

114 green algae in shallower muds (Schwinghamer, 1981; Gerlach et al., 1985). The importance of

115 meiofauna as the base heterotrophs in the food chain varies depending on habitat type and depth

116 (Coull and Bell, 1979). Certainly, components of the meiofauna can be very important in

117 intertidal, and shallow subtidal (i.e. photic zone) benthos where there is considerable primary

118 production occurring in the sediments (Schwinghamer, 1981, 1983; Rowe et al., 1991).

119 Copepods, in particular, can be a vital food resource for juvenile fish in near-shore nursery areas

120 (for review see Tito de Morais and Bodiou, 1984). Harpacticoid copepods in sediment core

121 samples from Zostera marina beds in the Nanaimo River Estuary and the Cowichan Estuary

122 were diverse (over 50 species from the Nanaimo River Estuary) and abundant (Levings et al., 
123 1983). In contrast to their global findings for mid-depth subtidal coastal areas, Rowe et al.

124 (1991) suggest that meiofauna may be a more important component of deep subtidal biomass

125 than are macroinvertebrates. In the SoG, a moderately deep coastal area, it is reasonable to

126 assume, therefore, that benthic macroinvertebrates are the primary consumers at the base of the

127 (benthic) food chain and are more important than meiofauna in this regard.

128 The SoG is part of the broader coastal region of southwest BC and northwest Washington State.

129 Therefore, biological reference materials for the Pacific northwest (e.g. Carefoot 1977; Kozloff

130 1987) have general applicability to the SoG. The most recently published review of the benthos

131 of the SoG is Levings et al. (1983). This review included reference to broad-scale, historical

132 biological surveys from the 1960s and 1970s that were based primarily in intertidal and shallow

133 subtidal areas; at the time of the review, there was very little available research on mid-subtidal

134 to deep subtidal benthic invertebrate fauna. These surveys included a few studies of soft

135 substrate infaunal invertebrates (Ellis, 1967a, b, 1968a, b, c) and descriptions of an extensive

136 trawl survey of larger epifauna (Bernard 1978). A general description of fjord cliff fauna, based

137 on submersible surveys from three contiguous fjords, was also included in the review of Levings

138 et al. (1983). Although not included in the subject matter of this review, intertidal research on

139 algal and marine vascular plant communities in the SoG was reviewed by Levings et al. (1983)

140 and, more recently, by Watson (1998). In addition to the general lack of research on subtidal

141 invertebrate fauna, Levings et al. (1983) point out that there were no data at all from the deep

142 basin of the SoG and also that little was known about the type, source or composition of

143 sediments, or sedimentation rates, in the SoG. In the past twenty-five years, a great deal of effort

144 has been expended to map biophysical conditions in the substrates of the intertidal and shallow

145 subtidal zones in the SoG; this information is reviewed in Sections 2.1 and 2.2. However, this 
146 review concentrates, primarily, on the less accessible and less well understood, subtidal regions 147 of the SoG.

148 From 1986 to 1992, a series of primarily deeper (>30 m) subtidal benthic surveys were

149 conducted by the Canadian Department of Fisheries and Oceans and Environment Canada in the

150 SoG and surrounding areas (Burd and Brinkhurst, 1990; Cross and Brinkhurst, 1991; Burd and

151 Brinkhurst, 1992). Only one study, carried out in Boundary Bay, conducted both intertidal and

152 shallow subtidal benthic surveys (Burd et al., 1987). These surveys were briefly referred to in

153 Brinkhurst et al. (1994) and Watson (1998). The original data, and a meta-analysis for these

154 coastal surveys, are provided in Burd (1992). Wilson et al. (1994) edited a trans-boundary

155 (Canada-USA) symposium report reviewing the marine environment and biota of the SoG, Puget

156 Sound and Juan de Fuca Strait. Several research papers from this report are included in this

157 review. A broadly based trans-boundary trawl survey of macroinvertebrates and bottom fish

158 species, which included the southern SoG (Canadian and US), was conducted in 2001 by the

159 Washington State Department of Fish and Wildlife (Palsson et al., 2003). Although 117 taxa of

160 large invertebrates were enumerated from trawls, the focus of the survey was on fish stocks,

161 historical trends, and exploitation rates. However, the distributions of commercial invertebrates

162 (notably Dungeness crab and pandalid shrimp) were highlighted.

163

164 Aside from a small number of government studies focused on historical environmental issues

165 (e.g. the Brittania Mine in Howe Sound (G3 Consulting, 2003; Hagan et al., 2004; Levings et al.,

166 2004; Zis et al., 2004), the remaining benthic subtidal habitat and invertebrate sampling has been

167 carried out, primarily, as part of monitoring programs (data collection either for establishing a 
168 baseline or as part of an ongoing program) related to specific anthropogenic inputs into the SoG

169 or its fjords.

170

171 Much of the benthic infaunal data available from the SoG since 1986 has been collated into a

172 taxonomically coded and consistent meta-database which includes data from background (or

173 reference) areas, data from areas of known anthropogenic input, and accompanying sediment

174 physical and geochemical data (Burd et al., in press). Burd et al. (in press) also provide a

175 detailed discussion of the biotic responses of benthic invertebrate communities in the SoG to

176 sedimentation rate and organic flux.

178 1.2. Oceanography

179 The oceanography of the SoG, and a number of surrounding fjords and inlets, is described by

180 Thomson (1981), LeBlonde (1983), Crean et al. (1988), and Stacey et al. (1991), with updates by

181 Thomson (1994, 1998), Li et al. (1999), and Masson and Cummings (2004). Early numerical

182 tidal current models for the SoG were reported by Thomson (1981) and Crean et al. (1988); more

183 recent tidal current models are described in Foreman et al. (1995, 2004). Models of current

184 variability due to wind, river discharge (estuarine circulation), winter cooling and other non tidal

185 factors, as well as bio-physical aspects of the water column variability, are currently being

186 developed by scientists at the University of British Columbia, (through the STRATOGEM

187 project (http://www.stratogem.ubc.ca/), the University of Victoria (VENUS project;

188 http://www.venus.uvic.ca/index.html) and the Canadian Department of Fisheries and Oceans

189 Institute of Ocean Sciences (IOS) (Masson and Cummings, 2004).

190 
191 The SoG is $222 \mathrm{~km}$ long and approximately $28 \mathrm{~km}$ wide with a mean depth of roughly $155 \mathrm{~m}$

192 (Thomson, 1981; Davenne and Masson, 2001). Additional characteristic features of the SoG,

193 taken from England et al. (1996), Thomson (1998), and Thomson and Foreman (1998) are

194 summarized in Table 1. Fig. 1 shows the depth topography, sills and surrounding inlets of the 195 Strait.

197 The two primary components of circulation in the SoG, and the dominant factors determining the

198 rate of basin flushing and exchange, are the diurnal and semidiurnal tidal currents and the

199 seasonally variable estuarine circulation driven by fresh water fluxes into the strait. The strength

200 of estuarine circulation in the SoG is affected seasonally by the volume of runoff discharge from

201 the major rivers (mainly the Fraser River) which enter mostly in late spring to early summer,

202 with a secondary surge in late fall. Estuarine circulation is strongly affected by the intensity of

203 vertical tidal mixing which becomes maximal in the narrow channels leading into the strait.

204 Winds, surface heating and cooling, intrusions from adjoining Juan de Fuca Strait and Discovery

205 Passage, and variations in offshore oceanic conditions also affect the circulation in the strait.

206 Other factors influencing the circulation are the shape of the coastline and slope of the bottom

207 topography, bottom and internal friction, inertial forces and external factors related to up-strait

208 propagation of oceanic "events" originating over the outer continental margin. These factors are

209 discussed in Thomson (1998) and outlined in detail in Griffin and LeBlonde (1990), Thomson

210 (1994), and Thomson et al. (2007). Detailed discussion on the estuarine circulation in the SoG

211 can be found in Marinone and Pond (1996), Li et al. (1999), Pawlowicz (2001) and Masson

212 (2002).

213 
214 There are a number of distinct oceanographic regimes in the SoG (Thomson, 1998). These

215 include the three main basin oceanographic regimes (delineated in Fig. 1) that are described by

216 Thomson $(1981,1998)$ as follows:

217 1) the Southern SoG, which has vigorous flow exchange and mixing between the

Connecting oceanographic regimes include Juan de Fuca Strait, which extends from the Pacific continental shelf to the entrance to the southern end of Haro and Rosario straits (two tidally active channels with very similar temperature and salinity structure (Thomson, 1998). The northern end of the SoG is connected to the Pacific Ocean through Discovery Passage and Johnstone Strait (Harrison and Yin, 1998). These oceanic connections at the northern and

232 enhanced through the narrow adjoining channels (Thomson, 1981). At the southern end of the

233 SoG, for example, a complex topography of islands and sills creates strong vertical and lateral 234 tidal mixing (Masson and Cummings, 2000; Pawlowicz, 2002; Thomson et al., 2007), which is 235 also evident in the vertically mixed particulate distributions in this region (Johannessen et al., 236 2005b). There is nominal surface outflow at both ends of the SoG, with approximately 85-95\% 
237 of the flow volume through Haro and Rosario straits and the remaining flow through Johnstone

238 Strait. Thomson (1981) examined the cross-sectional areas of all channels leading into the SoG

239 and found that the southern channels account for $93 \%$ of the cross-sectional area and the

240 northern channels only 7\%. The major inlets adjoining the SoG are Burrard Inlet, Howe Sound,

241 Jervis Inlet (including Sechelt Inlet), Bute Inlet and Saanich Inlet (Harrison and Yin, 1998).

242 Knight Inlet and Toba Inlet connect through a northern island-strewn archipelago, so can be

243 considered a separate oceanographic regime. Surface outflow of riverine water strongly affects

244 the water property structure in this region (Thomson, 1998).

246 The southern SoG is defined as the area extending south from the main arm of the Fraser River

247 to the eastern end of Juan de Fuca Strait (Thomson, 1981; Harrison and Yin, 1998; Thomson,

248 1998). This oceanographic regime is dominated by the Fraser River plume when it moves

249 southward (e.g. during northwest winds and an ebb tide) and is significantly influenced by tidal

250 mixing over the shallow sills of Rosario and Haro straits during spring tides. Tidal mixing

251 injects nutrient-rich water into the southern Strait which lessens the occurrence of nitrogen

252 limitation episodes in the summer. It is, therefore, considered a highly productive area even

253 though it has not been well studied (Harrison and Yin, 1998). Haro Strait, which separates the

254 southern Gulf Islands and Vancouver Island from the San Juan Islands, is the most important of

255 these channels. The flow exchange through this channel is strongly three-dimensional, with

256 variation over multiple time scales (Pawlowicz, 2002). The exchange undergoes marked

257 variability at fortnightly, monthly and seasonal time scales due to corresponding variations in the

258 intensity of the tidal mixing in the channels (i.e., the hydraulic control mechanism outlined by

259 Griffin and LeBlonde, 1990). During the neap tide portion of the fortnightly cycle, when the 
260 tidal currents in Haro Strait are minimal, surface brackish waters from the SoG are able to

261 "slide" seaward over the more dense oceanic waters entering at intermediate to near-bottom

262 depths from Juan de Fuca Strait. In summer (July to October), the deep estuarine inflow in Juan

263 de Fuca Strait carries warm, salty (high density), low-oxygen, high nutrient water inward from

264 the coastal ocean. This water is then able to penetrate to the bottom of the SoG in a series of

265 monthly pulses, renewing the deep water nutrient levels in the region; in winter (November to

266 March), this subsurface inflow occurs only to intermediate depths (Masson and Cummings,

267 2004). Deep water oxygen levels are increased during deep water intrusions of cold highly

268 oxygenated water in spring. During the spring tidal portion of the fortnightly cycle, when tidal

269 currents are maximal, turbulent vertical mixing in Haro Strait and other passages prevents the

270 simple exchange of brackish SoG water with deeper oceanic water. In this case, there is a reflux

271 of water from the passages back into the SoG at intermediate depths. Additional details on the

272 exchange processes through Haro Strait are found in Griffin and LeBlonde (1990), Thomson

273 (1994), Pawlowicz (2002), Masson and Cummings (2004), and Thomson et al. (2007).

275 The central SoG is defined herein as the area from the south end of Texada Island to a line

276 drawn from Point Roberts to the Saanich Peninsula (Waldichuk, 1957; Thomson, 1981, 1998).

277 This oceanographic regime is complex due to the seasonal influences of the Fraser River plume,

278 which is characterized by low salinity, very high light-extinction coefficients, high $\mathrm{SiO}_{4}^{-4}$, low

279 chlorophyll and low primary productivity. During freshet, the sediment-laden surface plume is

$280 \quad 2-10 \mathrm{~m}$ thick (Thomson, 1981), thus reducing the depth of the euphotic zone and primary

281 production within the surface waters, while greatly enhancing primary (Stockner et al., 1979) and

282 secondary (Mackas and Louttit, 1988) production at the plume margins. Surprisingly, 
283 chlorophyll levels and the abundance of zooplankton and fish are frequently high under the 284 plume (Harrison and Yin, 1998). Bacterioplankton production is greatly enhanced within the 285 brackish plume water (Albright, 1983). The area of the Fraser River plume undergoes marked 286 seasonal variability, with the maximum variations in extent, as well as chemical and biological 287 parameters, occurring in June, at which time the plume can dominate the central SoG. At any 288 given time, the distribution of the plume is influenced by the stage of the tidal currents (flood 289 verus ebb tide) and by surface wind speed and direction (Harrison and Yin, 1998). After wind 290 and tidal mixing, the third largest mechanism for transporting deep nutrient inputs into the 291 surface layer of the SoG is the entrainment of nitrate-rich salt-wedge water directly into the base 292 of the Fraser River outflow (Harrison and Yin, 1998). Seasonal cycles in nutrients, chlorophyl 293 and primary productivity are relatively predictable in the central SoG (Harrison et al., 1983) but 294 the day-to-day variation is high, with values ranging over one order of magnitude in some 295 months (e.g. June). Nitrogen limitation frequently occurs in July and August, depending on the 296 magnitude of the wind events. As a consequence, it is difficult to draw a reliable map of annual 297 primary productivity for the SoG (Harrison and Yin, 1998). Modelling surface layer

298 productivity is also a major component of the STRATOGEM project

299 (http://web.uvic.ca/ dower/dowerlab/research.html).

301 As with the southern passages, flow through the northern passages of Discovery Passage and 302 Johnstone Strait is strongly tidal with a pronounced estuarine circulation component driven by 303 runoff from the Fraser River. Hydraulic processes again modify the fortnightly, monthly and 304 seasonal exchange of waters through this region. Although the flow dynamics in the northern 305 passages are similar to those in the southern passages, the flow tends to have a weaker cross- 
channel component and experiences less variability in water properties due to the greater narrowness of the channels (Thomson, 1981, 1994). Considerable oceanographic information is available for this region as a result of current and water property surveys conducted in the region in the 1970s. For data on currents and estuarine-type circulation see Thomson $(1976,1977)$, Huggett et al. (1980), Thomson and Huggett, (1980), and Thomson et al. (1980a, b). Haigh and

311 Taylor (1991) studied microplankton communities in the northern SoG and determined that,

312 because of the long wind fetch and weak halocline (relatively little influence of the Fraser River

313 compared to the southern regions), wind mixing is likely to prolong or prevent pronounced

314 bloom formation. By late summer, the west side of the SoG is diatom-dominated and more

315 productive due to a nutrient-rich tidal jet flowing out of Discovery Passage during a flood tide.

316 The east side is more stratified due to surface heating and a somewhat lower salinity due to the

317 Fraser River plume (mainly in June and July) (Haigh and Taylor, 1991).

319 The fjords adjoining the SoG represent a separate oceanographic domain due to the relative 320 isolation of their water masses from the rest of the strait (Thomson, 1998). The mainland fjords

321 include Howe Sound, Jervis Inlet, Bute Inlet, Toba Inlet, Knight Inlet, and Saanich Inlet (the

322 latter being the only fjord on the eastern side of Vancouver Island). Toba and Knight inlets are 323 not always considered to be part of the SoG (Harrison and Yin, 1998). All fjords are separated 324 from the main basin by sills shallower than the fjord basin. Only Burrard Inlet, discussed later in 325 this section, lacks a sill and is not a fjord. Behind the sills, the fjords have glacially-carved 326 basins which are often far deeper than the SoG itself; the deepest fjord basin (700 $\mathrm{m})$ is found in 327 Jervis Inlet. Tidal and estuarine currents over the sills provide for an exchange of material with 328 the SoG, including the possibility of intermittant deep-water exchange events dependent on 
329 conditions inside and outside of the silled basins. The sill regions are characterized by enhanced

330 tidal currents due to restricted openings and shallow depths; this is particularly true in Knight

331 Inlet (Farrow et al., 1983; Tunnicliffe and Wilson, 1988) and at the famous Skookumchuk

332 Narrows opening into Jervis Inlet (Thomson, 1981). However, inlets with especially shallow sills

333 at the mouth tend to have low bottom currents in the deep basins located behind the sill, which

334 can lead to stagnation resulting in low dissolved oxygen levels in bottom waters and sediments

335 (Thomson, 1981). Basic features of basin topography and oceanography for the SoG fjords are

336 described by D. Stucchi (IOS, Sidney, BC) (http://www.pac.dfo-

337 mpo.gc.ca/sci/osap/projects/bcinlets/default_e.htm).

339 Saanich Inlet, the best studied of the SoG inlets in terms of sediments (note that this is not true

340 with respect to physical oceanography, where Knight Inlet is better understood), is smaller than

341 most of the mainland fjords and has a relatively minor freshwater input but a substantial

342 freshwater source just outside the sill (Cowichan River). The Inlet has a shallow sill at $70 \mathrm{~m}$

343 depth and a maximum basin depth of $225 \mathrm{~m}$. Saanich Inlet is unique in that it is the only marine

344 fjord in the SoG system with bottom water ( $>120-140 \mathrm{~m})$ that is anoxic for most of the year.

345 These conditions are due to high primary production, in addition to restricted bottom water

346 exchange that occurs over extremely limited duration (Gargett et al., 2003). During fall

347 upwelling conditions, Saanich Inlet bottom waters are oxygenated for a short time interval only,

348 with anoxic conditions returning rapidly and extensively throughout the deep waters and

349 sediments (Anderson and Devol, 1973). Fall upwelling in the SoG usually pushes the bottom

350 anoxic layer up to mid-water depths prior to complete flushing. Deep water renewal in Saanich

351 Inlet is described in detail by Anderson and Devol (1973). 
353 Howe Sound, a fjord located just north of Vancouver, has the second largest freshwater

354 discharge into the SoG. The Squamish River, along with the Cheakamus River and some input

355 from the Fraser River plume, creates low surface salinities in the head of the fjord, along with a

356 strongly stratified water column with moderate oxygen in the top $30 \mathrm{~m}$. These conditions, in

357 combination with the heavy glacial silt load carried by the Squamish River from May to

358 September, result in a high, near-surface, suspended silt load and brackish surface layer that

359 greatly restrict light penetration (McDaniel, 1973; Hoos and Vold, 1975). Similar conditions are

360 present in other glacially-fed fjords, such as Bute Inlet and Knight Inlet, although fresh water

361 input is lower in these latter two fjords (http://www.pac.dfo-mpo.gc.ca/sci/osap/projects/

362 bcinlets/references_e.htm). Deep water $(>180 \mathrm{~m})$ in Howe Sound tends to be seasonally hypoxic,

363 with flushing of bottom water occurring at the time of seasonal upwelling (Levings, 1980a, b).

365 Knight Inlet has a maximum depth of $540 \mathrm{~m}$ and two basins; the sill to the inner basin is located

366 at $48 \mathrm{~m}$ depth and the sill to the outer basin, at the mouth of the inlet, at $60 \mathrm{~m}$ depth. Bottom

367 water oxygen levels are higher than most of the mainland fjords ( $\sim 3 \mathrm{ml} / \mathrm{L})$, indicating frequent

368 renewals and exchange of a large fraction of the deep water (http://www.pac.dfo-

369 mpo.gc.ca/sci/osap/projects/bcinlets/knight_inlet_e.htm). Bute Inlet has a maximum depth of

$370650 \mathrm{~m}$, with a relatively deep sill at $370 \mathrm{~m}$ depth and good bottom water oxygenation and

371 renewal. Bute Inlet has two rivers at the head, with mainly glacial sedimentation (D. Stucchi,

372 (http://www.pac.dfo-mpo.gc.ca/sci/osap/projects/bcinlets/references_e.htm). 
374 As noted earlier, the deepest mainland fjord is Jervis Inlet, with a maximum depth of $670 \mathrm{~m}$. The

375 sill to the outer basin in Jervis Inlet is relatively deep (240 m) and bottom water exchange is

376 sufficient to maintain reasonable oxygen levels in the deep basin all year. This inlet also has the

377 lowest freshwater input of all the mainland fjords (D. Stucchi, http://www.pac.dfo-mpo.gc.ca/sci/

378 osap/projects/bcinlets/references_e.htm). The oceanographic energetics of Jervis Inlet are

379 described by Freeland and Farmer (1980). Haigh et al. (1992) and Taylor et al. (1994) described

380 the seasonal cycle of temperature, salinity, nutrients, chlorophyll, and phytoplankton species for

381 Sechelt Inlet, an arm of Jervis Inlet. Sechelt Inlet is composed of the well mixed Skookumchuck

382 Narrows, and the more stratified waters of the main inlet and Salmon Inlet.

383 Burrard Inlet, composed of Vancouver Harbour, Indian Arm and Port Moody Arm, receives

384 moderate runoff from the Indian River, with the outer section of the inlet influenced by the

385 Capilano and Seymour Rivers (Harrison and Yin, 1998). Burrard Inlet is located within the

386 Greater Vancouver Regional District and is the most heavily industrialized inlet in British

387 Columbia. The inlet has a maximum depth of $90 \mathrm{~m}$ and the main basin, as well as the shallow,

388 isolated arms, are well oxygenated throughout the year and flush rapidly (Levings and Samis,

389 2001; Stacey and Pond, 2003). During a large part of the phytoplankton growing season (May to

390 July), high-silt water from the Fraser River decreases light penetration in the surface layer and

391 hence, primary productivity is reduced (Harrison and Yin, 1998). Although it does not have a

392 sill at the mouth, Burrard Inlet does have several constrictions within the Inlet which create high

393 currents (Thomson, 1981). Partially as a result of the lack of sill, fine silt sediments in the outer

394 inlet flow out into the main basin of the SoG. Indian Arm, located at the far northeastern end of

395 Burrard Inlet, is more fjord-like in structure with a $220 \mathrm{~m}$ deep basin and a shallow sill (15 $\mathrm{m}$ to

$39625 \mathrm{~m})$. 


\section{1.3. Sedimentary Regime}

\section{1.3.1 Shoreline Description}

400 For the SoG, both the total shoreline length inclusive of fjords $(3721 \mathrm{~km})$, and the area of benthic

401 habitat (substrate) types were estimated by Levings et al. (1983). The authors note that, for their

402 estimates, data from hydrographic charts on bottom type was sufficiently detailed only for

403 intertidal and subtidal habitats down to $20 \mathrm{~m}$. The authors use "shoreline" to represent intertidal

404 and subtidal habitats down to $20 \mathrm{~m}$ and note that rocky and sandy shores make up $88 \%$ of the

405 total shoreline length. However, when area is calculated, sand and mud substrates account for

$40666.8 \%\left(832 \mathrm{~km}^{2}\right)$ of the total $1245 \mathrm{~km}^{2}$ of intertidal and shallow subtidal habitats. In contrast,

407 rocky shores contribute only $320 \mathrm{~km}^{2}$ or $25.7 \%$ to the total area. Using Natural Resources Maps,

408 Levings et al. (1983) computed subtidal areas at depths $>20 \mathrm{~m}$. While only $11 \%$ of the subtidal

409 area of the SoG is in the $20-50 \mathrm{~m}$ depth range, approximately $71 \%$ of the subtidal area is within

410 the 50-300 m depth range, encompassing most of the main basin of the Strait, with the majority

411 of the substrate soft sediments (see Figs. 2, 3). Only $18 \%$ of the subtidal area is $>300 \mathrm{~m}$ deep

412 and the majority of these areas are in the mainland fjords (Levings et al., 1983).

413

414 Zacharias et al. (1998a) used the BC Physical Shorezone Mapping System (Howes et al., 1993)

415 as the basis of an analysis that provides an estimate of the total shoreline length of the SoG,

416 including fjords (4107 km). The SoG's intertidal length is estimated to be composed of $26 \%$

417 rocky cliffs, $16 \%$ rock with gravel beach, $11 \%$ sand/gravel flats, $9.5 \%$ rock with sand/gravel

418 beach and an additional 10 representative types each composing $\leq 7 \%$ of the shoreline; flats are

419 those areas with slopes $<5^{\circ}$, while beaches have slopes from $5^{\circ}-20^{\circ}$ or higher (Zacharias et al. 
420 1998b). The same authors estimate that the intertidal area of the SoG consists of 34\% estuary

421 wetland, 17\% sand/gravel flat, 9\% sand/gravel beach and an additional 11 types, each composing

$422 \leq 6 \%$ of the intertidal area.

423

424 A review of marine ecosystem, or habitat, classification systems available for the SoG benthos, 425 from the intertidal to the deep subtidal areas, is provided by Watson (1998). One of these, the 426 British Columbia Marine Ecosystem Classification (BCMEC) system, was first developed in 4271995 (Zacharias et al., 1998b, http://ilmbwww.gov.bc.ca/ cis/coastal/bcmec/index.html).

428 BCMEC uses a tiered hierarchical system to define ecological boundaries for planning and 429 administrative purposes (Howes et al., 1996). There are 12 ecosections in British Columbia, 430 based on differences in ocean circulation, mixing, salinity, temperature, primary and total 431 productivity, continental slope and shelf influence and freshwater influence (Harper et al., 1993a,

432 b; Howes et al., 1996; Zacharias et al., 1998a). The SoG represents one ecosection, which is

433 divided into smaller ecounits (ecological regions) based on a combination of five physical

434 characters: wave exposure, depth, subsurface relief, current regime, and substrate type (Table 3-

435 Wainwright et al., 1995; Howes et al., 1996; Zacharias et al., 1998a). Salinity and temperature

436 data were later incorporated at the ecounit level into the SoG ecosection (Zacharias and Howes,

437 1998), as were stratification and slope (http://ilmbwww.gov.bc.ca/cis/coastal/bcmec/index.html).

438 Depth, current and relief data used to develop BCMEC came from Canadian Hydrographic

439 Service charts (depth, current, relief) (Lamb and Edgell, 1986; Wainwright et al., 1995), models

440 (exposure) (Harper, 1995), and Geological Survey of Canada mapping of benthic sediments

441 (substrate) (see Zacharias and Howes, 1998 for more detail) with intermittent ground-truthing

442 (Howes et al., 1994; http://ilmbwww.gov.bc.ca/risc/). Fig. 2 illustrates the coarse resolution 
443 classification of the SoG, based on the system described above and using much of the collected

444 data from the Provincial Physical Shore Zone Mapping System (Howes et al., 1994).

446 The subtidal components of the ecounits (Fig. 2) are based on extrapolation from data on the 447 intertidal to shallow subtidal zones $(\leq 20 \mathrm{~m})$. This method produces a simplistic rendering of 448 substrate types; the soft substrate areas are typically much more of a mosaic, frequently with 449 mixtures of mud and sand, than are depicted, for example, in Fig. 2. This simple scheme is not 450 designed, therefore, to capture the complexity of substrate types, but rather to provide a general 451 perspective. Much more accurate and detailed information on subtidal slope, topography and 452 substrate diversity is available from multibeam data (Fig. 3), as well as from collated sediment 453 core and grab samples from a variety of sources (see Fig. 4). For example, the multibeam data 454 show the deep subtidal reefs which have been found, using video transects, to be relic (or living) 455 sponge and coral reefs (Conway et al., 2007; Cook, in press). Similarly, multibeam data have 456 shown the complex delta structure and sedimentation around the mouth of the Fraser River and 457 the southern portion of the Strait (Hill et al. in press). Although, the multibeam data is not useful 458 at shallower depths $(<30 \mathrm{~m})$ (see Fig. 3), in combination with the physical and biological shore 459 zone data (Howes et al., 1994; Frith et al., 1994), it provides a fairly comprehensive and reliable 460 overview of the full range of benthic habitat depths in the SoG (Fig. 4) (see Burd et al, in press; 461 Cook et al., in press; Hill et al., in press; Macdonald et al., in press).

463 Figure 4 shows a plot of sediment percent fines (silt+clay $<63 \mu \mathrm{m}$ particle size) to illustrate 464 sediment types in the SoG. A more detailed map of the near-shore sediment types around the 465 Fraser River delta north to Burrard Inlet is shown in Hart et al. (1998). Note that the greater 
466 detail in Fig. 4 can aid in identifying localized "anomalies". For example, coarse sand is evident

467 around the Iona outfall (source unclear), at sand heads just south of the mouth of Burrard Inlet,

468 and at the mouth of the south arm of the Fraser River.

\section{1.3.2. Sedimentary Processes}

470 The sedimentary regime for the SoG is extremely complex, particularly around the Fraser River

471 delta and associated areas receiving maximum deposition from the river (see Hart et al., 1998).

472 Sedimentary features of this area are described in detail by Hill et al. (in press). Sedimentation

473 rates, organic and inorganic fluxes for the Strait are described in more detail in Burd et al. (in

474 press). For the sake of simplicity, this section on sedimentary processes divides the SoG into

475 two equal regions north and south of the deepest part of the main basin ( 400 $\mathrm{m})$ which is

476 located just south of Texada Island. North of this dividing line (which includes the northern

477 basin regime; Section 1.2), the basin rapidly becomes narrower and much shallower $(<200 \mathrm{~m})$

478 creating a barrier to bottom-transported particulate material from the Fraser River (Johannessen

479 et al., 2005b). Sediment characteristics north of Texada Island suggest that Fraser River material

480 does not contribute to particulate deposition, and that natural sedimentation and organic flux,

481 mainly from marine detritus, are much lower than in the southern half of the basin (Burd et al., in 482 press).

483

484 In contrast to the northern half of the basin, the southern half of the basin (which includes the 485 central and southern oceanographic regimes; Section 1.2) receives markedly higher

486 sedimentation (organic and inorganic) (see Macdonald and Crecelius, 1994 for literature review)

487 which is from the Fraser River (Burd et al., in press). This higher sedimentation is related to

488 heavier material deposited primarily at the mouth of the river (up to $10 \mathrm{~cm} / \mathrm{yr}-\mathrm{Hart}$ et al., 1998) 
and transported along the bottom northward along the bank straddling the Fraser River mouths,

490 as well as down the slopes to deeper areas (McClaren and Ren, 1995; Hodgins and Hodgins,

491 2000). As one progresses northward from the river mouth, sediments become progressively finer

492 (see Fig. 4), and show characteristics of declining proportions of Fraser River deposits (Burd et

493 al., in press).

494

495 However, the high sedimentation rates to the south of the Fraser River are also related to

496 particulate deposition from the Fraser River plume during freshet. The dispersion patterns of the

497 Fraser River plume, which can extend 2-10 m down from the sea surface during freshet

498 (Thomson, 1981), are aerially visible during the summer months and have been tracked in detail

499 with satellite imagery (Fig. 5). South of the Fraser River, sedimentation may also be related to

500 upwelled fine sands (glacial material) from the southern Gulf Islands (Johannessen et al., 2006).

501 This creates a patchy mosaic of mixed sand and silt substrates in the southernmost portion of the

502 southern half of the Strait (Fig. 4). The sediments of the deep southern portion of the basin that

503 are most subject to plume deposition are somewhat sandy, but finer in texture than those along

504 the slope and bank on the east side of the SOG which receive the coarser, bottom-transported

505 materials from the Fraser River. Therefore, it can safely be said that the southern and northern

506 halves of the SoG constitute very different sedimentary regimes (see also Johannessen et al.,

507 2003).

508

509 Boundary areas of high primary production occur in areas of turbulent mixing in the vicinity of

510 the north and south island chains which constrict the entrances to the SoG (Parsons et al., 1981).

511 However, the constrictions at both the north and south end of the SoG result in very little 
512 exchange of particulates and, therefore, of contaminants which are bound to particulates,

513 between the Strait and surrounding waters (Macdonald and Crecelius, 1994, Johannessen et al.,

514 2003). In contrast, however, water-soluble contaminants can spread broadly outside the confines

515 of the Strait (Macdonald and Crecelius, 1994).

516

517 Sedimentation in the fjords of the SoG is largely isolated from the effects of the Fraser River.

518 Within the fjords, sedimenting material may arise from freshwater sources, delta slope failures,

519 marine detritus and/or terrigenous erosion of the steep surrounding rock cliffs. The mainland

520 fjords are bounded by the coast mountain range, so that much of the runoff in stream sources is

521 of glacial origin (www.pac.dfo-mpo.gc.ca/SCI/osap/projects/bcinlets). Material sedimenting

522 within fjords is typically fine and is trapped within the fjords' basins by the shallow sills at the

523 mouth (Thomson, 1981).

525 Turbidity in BCs mainland fjords increases as the degree of freshwater and glacial runoff

526 increases. Turbidity currents originating with delta slope failures at the heads of inlets are likely

527 responsible for the bottom water turbidity in some inlets (Pickard and Giovando, 1960; Bornhold

528 et al., 1994). In Knight Inlet, extremely high turbidity and seasonal vertical flux of glacial silt

529 from the two rivers that discharge into the head of the Inlet result in suspended matter

530 concentrations $>100 \mathrm{mg} / \mathrm{L}$ and a delta slope sedimentation rate of $4 \mathrm{~kg} / \mathrm{m}^{2} / \mathrm{d}$ in summer. As

531 commonly occurs in the mainland fjords, vertical flux and turbidity in Knight Inlet decrease

532 progressively down the Inlet (Farrow et al., 1983). In contrast, Jervis Inlet has very low

533 freshwater input and, thus, has remarkably clear water throughout the Inlet and at all depths 
534 (www.pac.dfo-mpo.gc.ca/SCI/osap/projects/bcinlets/Jervis_Inlet_e.htm; observations from the

535 submersible PICES IV, Burd, unpublished data).

537 Sedimentation rates for the main basin of Howe Sound have been estimated at $0.4 \mathrm{~cm} / \mathrm{yr}$ (Hickin, 538 1989) and for the area just outside the Sound's sill at 0.4 to $0.78 \mathrm{~cm} / \mathrm{yr}$ (Johannessen et al., 539 2003). Howe Sound has a relatively high freshwater input (Section 1.2) which results in high

540 levels of glacial, suspended particulates near the estuaries. Sediment types and probable

541 transport patterns in Burrard Inlet are complex but have been described by McLaren et al. (1993)

542 and McLaren (1994). Constrictions within the Inlet and high currents create zones of coarse

543 sand grading to hard substrate beds (Thomson, 1981), and tend to maintain particulates in

544 suspension throughout the Inlet. Dredging is required to maintain the channel at First Narrows

545 (near the Lions Gate outfall), suggesting net deposition. Similarly, high net sedimentation rates

$546(1 \mathrm{~cm} / \mathrm{yr})$ in Port Moody Arm necessitate continued dredging of the deep-sea berths (Levings and

547 Samis, 2001).

549 In Saanich Inlet, the majority of the shoreline consists of steep, rocky cliff walls with

550 embayments consisting of typical mud/sand flats with some eelgrass beds. The BC Provincial

551 synthesis report for the Saanich Inlet Study initiated in 1994 concisely summarizes the benthic

552 habitats and sediment types for different sections of Saanich Inlet (BC Ministry of Environment

553 Lands and Parks, 1996). The information is limited primarily to habitats at depths $\leq 50 \mathrm{~m}$

554 adjacent to the shore; due to the hypoxic/anoxic nature of the deeper basin areas $>50 \mathrm{~m}$, biotic 555 production is limited considerably. 


\section{7}

558

559

560

561

562

563

564

565

566

567

568

569

570

571

572 In contrast to subtidal habitats, which tend to be more physically predictable, intertidal habitats

573 are influenced by greater variability in physical factors (e.g. waves, tidal currents, erosion, slope,

574 light, air exposure, temperature, salinity, sediment stability). Factors that also affect subtidal

575 habitats, such as tidal currents, can also affect intertidal areas; for example biodiversity tends to

576 be enhanced in intertidal areas with fast currents (Levings and Thom, 1994). The influence of

577 these factors, as well as biological factors, can lead to spatial heterogeneity of intertidal

578 assemblages in what appear to be similar habitats (Dayton, 1971; Denny et al., 1985; Maurer and 
579 Aprill, 2007). Section 1.3 describes the estimated proportions of the intertidal zone of the SoG

580 that are made up of the different habitat types described below.

582 Levings and Jamieson (2001) assessed the fish habitat significance of the marine riparian habitat 583 in the SoG. The marine riparian area is defined, by the authors, as the ecotone where aquatic

584 habitat at higher tides merges into terrestrial habitat (i.e. the supralittoral). Levings et al. (1983)

585 reviewed intertidal benthic communities in the SoG in relation to habitat type, specifically sand

586 beaches, rocky shores, mud flats and vegetated areas. The authors provide a list of invertebrate

587 studies conducted in each habitat type prior to 1982. Several studies on sand beaches, with many

588 focusing on Boundary Bay, report on a range of invertebrates from macrofauna to meiofauna

589 (Kellerhals and Murray, 1969; Harrison, 1981; Smith, 1981; Swinbanks and Murray, 1981). The

590 most extensive mudflats in the SoG, and those most heavily researched in terms of invertebrates,

591 are in the Fraser River estuary (see Levings et al., 1983) but research has also been carried out on

592 the mud flat invertebrate communities of the Squamish Estuary (Levings, 1980b) and Vancouver

593 Harbour (Levings and McDaniel, 1974). In the SoG, there is considerable variation in the slope

594 and geology of the rocky shores, with corresponding biological changes (Bousfield, 1957;

595 Levings et al., 1983). Faunal composition in this intertidal habitat type is thought to be

596 influenced predominantly by these geological factors, in addition to water characteristics, wave

597 energy and biological interactions (Levings et al., 1983). In their review of research on

598 invertebrate communities in vegetated intertidal areas, Levings et al. (1983) demonstrate the

599 importance of algae and eelgrass in structuring these communities.

600 
601 The importance of substrate type and vertical zonation on intertidal community composition is

602 emphasized in most studies in the SoG (c.f. Stephenson and Stephenson, 1961a, b; 1972). For

603 example, Burd et al. (1987) concluded that beach assemblages in Boundary Bay, BC are strongly

604 controlled by sediment grain size. Early synoptic helicopter surveys of rocky shorelines in the

605 strait are described in Ellis (1966), and the concept of vertical zonation and succession developed

606 by Stephenson and Stephenson (1972) in the Strait has also been applied locations outside the

607 SoG in BC (Ellis, 2002, 2003). Rock and gravel habitats are crucial for shellfish species,

608 especially the recreational and commercially harvested bivalves (Levings and Thom, 1994).

609 Larval settlement of Dungeness crabs (Cancer productus), as well as that of Manila clams

610 (Venerupis philippinarum), tends to be higher in areas of shell hash, gravel or eelgrass

611 (Thompson and Cooke, 1991; Dumbauld et al., 1993; Levings and Thom, 1994).

612

613 Other sources of information on intertidal restoration, conservation and mapping projects in the

614 SoG include the BC Community Mapping Network (http://www.shim.bc.ca/) and

615 the BC Coastal Eelgrass Stewardship Project (http://www. stewardshipcentre.bc.ca/

616 eelgrass/eelgrassfinalreport12_04.pdf). While invertebrate communities in eelgrass beds in the

617 SoG have not been studied extensively, there is some evidence that these communities are

618 biotically more diverse and structurally different than those in nearby bare sediments (Levings

619 and Coustalin, 1975; Sibert, 1979; Burd et al. 1987; Seacology et al., 2001). The roots and

620 rhizomes of eelgrass and the tubes of infaunal invertebrates reduce the mobility of a variety of

621 burrowing species, including polychaetes, bivalves, crustaceans, and some echinoderms

622 (Brenchley, 1982). Not only is burrowing time increased but hard bodied taxa, in particular, are

623 restricted by the biogenic structures (Brenchley, 1982). In addition, eelgrass beds are known to 
624 provide protection from predators (Heck et al., 1989) and to encourage the settlement of fine,

625 suspended particulate material, a potential factor in the noted differences in invertebrate

626 community composition (Fonseca and Fisher, 1986).

627

628 Considerable baseline environmental information on the intertidal zone of Saanich Inlet was

629 generated as a result of two proposed foreshore developments: a ferrochromium production

630 facility in the 1980s (see Rescan Environmental Services, 1988) and, a large-scale residential

631 development at the site of the defunct cement plant at Bamberton (Williams, G.L. \& Associates

632 Ltd., 1991; Madrone Consulting Ltd., 1993). Neither of the proposed developments came to

633 fruition, however. An extensive, and more recent, database is available from the sanitary surveys

634 of clam beaches in Saanich Inlet (see Walker, 1995) and from eelgrass restoration projects in

635 Todd Inlet (BC Coastal Eelgrass Stewardship project; http://www.stewardshipcentre.bc.ca/

636 eelgrass/eelgrassfinalreport12_04.pdf ). Similarly, the Saanich Inlet Seagrass Survey studied 67

637 locations (40.9 hectares total area) surveying intertidal and shallow subtidal areas; eelgrass was

638 limited to three areas with soft bottom substrates (http://www.env.gov.bc.ca

639 /wat/wq/saanich/siscr.html). There is also a wealth of uncollated information on the foreshore

640 biota of Saanich Inlet from the local shore-keepers surveys (see Section 2.1.2), as well as

641 unpublished data collected by W. Austin (Khoyatan Marine Laboratory, Sidney, BC).

642

643 At Boatswain Bank, just north of the Saanich Inlet sill, recent intertidal transect surveys were

644 done as part of the baseline assessment for a proposed landfall site for the GSX pipeline

645 (Seacology et al., 2001). This is an area of extensive intertidal eelgrass beds, as well as green

646 algae (e.g. Ulva/Enteromorpha). Such habitats are considered to be important nursery and 
647 feeding grounds for juvenile fish and were meant to be avoided by the pipeline drilling rig.

648 Although the pipeline project did not go forward, the report contains detailed data listing algae

649 and invertebrates that are commonly associated with sheltered, near shore habitats in southern

650 BC fjords. The authors describe this ecotype as a typical south-coast, shallow, sloping beach

651 with mixed cobble/sand/ gravel substrate (Seacology et al., 2001).

652 The intertidal wetlands of the Fraser River estuary cover an estimated 17,000 hectares

653 (http://www.env.gov.bc.ca/cdc/) and are also one of the most biologically productive systems in

654 Canada (Levings et al., 1983; Kennett and McPhee, 1988; Harrison et al., 1999). Estimated

655 productivity (based on biomass) for the 14,000 hectares of Sturgeon and Roberts Bank, including

656 the main mud flats on the outer shores of Lulu Island totals $1440.6 \mathrm{kcal} / \mathrm{m}^{2}$, broken down into

657 vascular plants (eelgrass) $\left(1320 \mathrm{kcal} / \mathrm{m}^{2}\right)$, microbenthic algae (diatoms) $\left(65 \mathrm{kcal} / \mathrm{m}^{2}\right)$, benthic

658 organisms (invertebrates) $\left(40 \mathrm{kcal} / \mathrm{m}^{2}\right)$, phytoplankton (in water) $\left(15 \mathrm{kcal} / \mathrm{m}^{2}\right)$ and zooplankton

659 plus epifaunal invertebrates $\left(0.6 \mathrm{kcal} / \mathrm{m}^{2}\right)$ (Levings, unpublished data). Macroalgae such as

660 Ulva/Enteromorpha are not included in these estimates (Levings, unpublished data) but are

661 occasionally present (Harrison et al., 1999). Plants clearly make up the greatest bulk of living

662 material on the mud flats, by far, and likely provide critical habitat and/or food resources for the

663 benthic invertebrate fauna. The diverse invertebrate fauna are described in Otte and Levings

664 (1975). Primary benthic production and nutrient dynamics of the delta, as well as the foreshore

665 area of Boundary Bay at the Canada/US Border (i.e. outside the influence from the Fraser River),

666 were recently reviewed by Harrison et al. (1999).

667 All the other major estuaries in the SoG are subject to various conservation and restoration

668 programs, for which information is available from a variety of sources. For example, research on 
669 the benthos of the Squamish River estuary was reviewed by Hoos and Vold (1975) and Levings

670 et al. (1983), with an inventory of research efforts in the estuary basin provided by Hickin

671 (1992). Research in the Nanaimo River estuary includes a study on the intertidal hyperbenthic

672 populations (Sibert, 1981) and the relationship between meiofaunal abundance and intertidal log

673 storage (Sibert et al., 1979). The Nanaimo and nearby Gulf Island marine shorezone areas were

674 also the focus of rocky shoreline zonation studies by Stephenson and Stephenson (1961a, b;

675 1972). Reports on the SoG estuaries can also be found on websites, such as that of BC Hydro

676 (http://www.bchydro.com/bcrp/reports/lower_mainland.html).

\section{2.1.2. Shore Zone Mapping Programs}

678 The Provincial Biological Shore Zone Mapping (and database) System (Frith et al., 1994) for

679 British Columbia was designed to integrate with the Physical Shore Zone mapping (Howes et al.,

680 1994; see Section 1.3) and is based on taxonomic groupings. The boundaries for units and

681 components in the physical system, based on geomorphological parameters, are used to define

682 boundaries for species assemblages (bands) in the biological system. A hierarchical coding

683 system for biota is included and is based on taxonomic groupings. Components are sub-divided

684 into across- shore areas of common species assemblages termed bands. Bands are defined by the

685 dominant cover species and the colour and texture of that band visible from aerial videography,

686 photography, or from ground surveys (Frith et al., 1994). Maps on a fine scale resolution can be

687 attained at http://ilmbwww.gov.bc.ca/. Publications describing the development of this system,

688 modeled characterization of intertidal communities and regional diversity are cited in Zacharias

689 et al. (1998a, b, 1999), and Zacharias and Roff (2001). 
691 The Canadian Department of Fisheries and Oceans began the Shorekeepers' program for

692 monitoring the intertidal zones of the British Columbia coast in 1996 in response to need for a

693 new data acquisition program. The program, aimed at involving coastal communities and

694 fostering stewardship of the coastal zone, was designed for the monitoring of intertidal habitat by

695 non-professionals. Full details including survey design, field sampling, data acquisition, etc., can

696 be found in Jamieson et al. (1999). Data from surveys conducted between 1996 and 2005 are

697 accessible online (http://www.shim.bc.ca/atlases/sk/ main.htm). Although the design and

698 limitations of survey methods for this program tend to produce a bias towards larger macrofauna,

699 the resulting data set is cumulative and relatively large, which allows comparison of the biomass-

700 dominant fauna to the physical characteristics used in the BC Shore Zone Mapping System. The

701 Shorekeepers' program (Fig. 6) provides a refinement to the habitat classification of the BC

702 system, including not only substrate type but also dominant algal coverage.

703

\subsubsection{Surveys and Studies Associated with Commercially Important Invertebrates}

705 The BC Shore Zone Mapping Program is also used to assess suitable habitat for invertebrate taxa

706 with commercial or recreational fishery value. For example, based on species-specific substrate

707 and habitat preferences, the relative suitability/rating for the success of Pacific oyster viability at

708 beach locations in SoG can be mapped (Fig. 7). Manila clam suitability shows a very similar

709 distribution (Fig. 7). The areas of "good" and "medium" viability correspond to sand and gravel

710 platforms and sometimes the presence of eelgrass (Fig. 7) (http://ilmbwww.gov.bc.ca/).

712 The BC Clam Atlas was developed as a means of mapping commercial intertidal clam beaches

713 (Manila, Littleneck and Butter) on the BC coast. The maps, area calculations and historical 
714 landings for the SoG area were published by Harbo et al. (1997), and the maps are presently

715 online (http://www-heb.pac.dfo-mpo.gc.ca/maps/maps-data_e.htm). Information on stocks of

716 these and other clams can also be accessed using the Canadian Department of Fisheries and

717 Oceans Stock Status Reports and the Fisheries Management Plans for each species. Geoducks

718 prefer to burrow in sand, silt and gravel from the intertidal to a depth of $110 \mathrm{~m}$ (Canadian

719 Department of Fisheries and Oceans, 2000). Landings in the SoG are minor (less than 1/3 of the

720 BC total) and most are collected subtidally by divers. Of the three typical intertidal species,

721 Manila clams are the species harvested primarily from the SoG (Canadian Department of

722 Fisheries and Oceans, 1999a, b; 2007). The Fisheries Management Plan for Intertidal Clams

723 suggests that, presently, stocks are healthy but that the commercial trend is toward reduced

724 landings as a result of reduction in overall effort, lower prices, and increasing alienation of beach 725 space for shellfish aquaculture tenures.

\subsection{Subtidal Zone}

728 Levings et al. (1983) reviewed the available sources of subtidal benthic biotic data for the SoG

729 up to that time. Examples of several large, unanalyzed data sources noted in that review include

730 Ellis (1967a, b, 1968a, b, c), who provided quantitative data (including abundance of "apparent"

731 species) resulting from comprehensive surveys of the subtidal fauna and sediments from a wide

732 variety of geographic locations with the SoG. These studies employed similar methodologies

733 (grab samples) to those used in more recent, similar studies (see Levings et al., 1983; Burd,

734 1992; Burd, 2006). Bernard (1978) reported the results of an extensive subtidal bottom survey of

735 invertebrate fauna from the SoG. The author described, but did not enumerate, the dominant

736 organisms captured primarily by trawling and divided the sampled 
737 areas according to depth range and substrate type. Although some grab sampling was carried out

738 at key locations, the fauna included in Bernard (1978) are primarily epibenthic.

740 This section is based primarily on background conditions where anthropogenic impacts are

741 expected to be absent or limited. Descriptions of subtidal biotic assemblages based on recent

742 studies are separated by depth range and substrate type in a manner similar to Bernard (1978) but

743 with two notable differences. First, four substrate types (mud/silt, sand, gravel and rock/cobbles)

744 are used in Bernard (1978) while here we employ the following five substrate types: mud,

745 silt/sand, sand, coarse sand/gravel/cobbles and rock (consolidated). Given that trawling was the

746 main sampling method used in Bernard (1978), it is assumed that the rock substrate in

747 rock/cobbles is not consolidated; therefore, the gravel and rock/cobbles substrates of Bernard

748 (1978) are considered equivalent to our coarse sand/gravel/cobbles substrate. Inherent in these,

749 and similar habitat classification systems, is that mixed habitats will have overlapping biotic

750 community types. Second, whereas Bernard (1978) described biota from 20-50 m, and 50-100 m

751 (primarily for logistical reasons related to towed sampling patterns), biota and available

752 information for the SoG are reviewed herein for 3 depth ranges (see below: 0-30 m, 30-100 m,

$753>100 \mathrm{~m}$ ) based on evident biotic shifts noted at these approximate depths from the literature

754 reviewed herein (see Burd, 2003a). An example of such a depth factor can be seen in Palsson et

755 al. (2003), who state that in the fully surveyed Washington State side of the BC/Washington

756 transboundary bottom trawl survey of $2001,60 \%$ of the invertebrate biomass was found in the 5-

75720 fathom (approximately 10-37m) depth range. Although this depth range was not surveyed on

758 the BC side of the SoG, invertebrate biomass declined dramatically with depth in the deeper

759 sampling strata. 
761 The depth ranges are defined as follows:

762 A. $0-30$ m corresponds, approximately, to the euphotic zone (depths within which light penetrates), although the depth of this zone varies considerably along the $\mathrm{BC}$ coast in relation to exposure and water clarity. $0 \mathrm{~m}$ depth is considered to be mean low tide, so that habitats within this depth range are subtidal;

B. 30-100 m encompasses the zone which, generally, has adequate water oxygenation due to influence of wind and tidal currents and which includes subtidal organisms and no primary producers. In any one location, the consistency of benthic communities in this which span 30-100 m; depth range will depend on depth-related shifts in habitat type, physical features and hydrographic processes. Many of the major taxa, however, have habitat depth ranges

777 Because the complete particle size distribution (including an assessment of flocculent material) 778 provides the most thorough information about depositional history, it is recognized that the

779 following five substrate types are simplistic (Burd 2003a). In addition, many habitats,

780 particularly near shore, are a heterogeneous mix of different substrate types over relatively small

781 areas. The 5 substrate types, and general features of these substrates regardless of depth, are 782 summarized below. 
1. Mud bottoms (>95\% silt/clay) typically occur in low energy areas and are sticky and tightly packed; mean sediment grain size is $<0.06 \mathrm{~mm}$.

2. Silt/Sand substrates are a mixture of these two sediment types. The mean sediment grain size for this substrate type ranges from 0.04 to $0.5 \mathrm{~mm}$.

3. Sand ( $>90 \%$ sand) substrates are typical of areas with moderate to high bottom currents and/or wave action and exposure, which prevent deposition of finer, marine deposits. Sediment grain size ranges from $0.5 \mathrm{~mm}$ to $2 \mathrm{~mm}$.

4. Coarse sand, gravel or fine cobble sediments have a grain size from $2 \mathrm{~mm}$ to 26 $\mathrm{cm}$. These substrates are less mobile than the previous substrate type, due to the size and weight of the particles, and are mobile only in high energy habitats.

5. Rocky substrates are composed of large cobble, boulders or bedrock and include reefs and outcroppings, rocky shorelines and fjord walls.

796 The above 5 substrate types are discussed in more detail below, citing research from both the

797 SoG and similar environments elsewhere. These more detailed descriptions are relevant to

798 understanding the diversity of subtidal habitats in the SoG. These depth- and substrate-specific

799 habitats are described, including biotic structure, for the SoG using information gathered from a

800 variety of data sources including unpublished remote sampling, submersible and ROV work,

801 collections of data in unpublished data reports. Hence, these generic descriptions of the SoG

802 subtidal habitats are synthesized and, in some cases, extrapolated from a variety of sources and

803 do not lend themselves to specific citations. However, specific type examples from the SoG are

804 provided for each depth- and substrate-specific habitat, including benthic invertebrate

805 community data, when available. 


\subsubsection{Mud (silt/clay) Habitats}

808

809 The finest substrate habitats in the SoG are found typically in low energy areas. Although bottom

810 turbidity is unlikely due to storm, wave or current exposure in these low energy environments, it

811 can be caused by physical disturbance such as bioturbation and anthropogenic mechanisms. The

812 fine, often flocculent bottom material may take some time to settle once it is suspended via

813 bioturbation (c.f. Orvain et al., 2003). This is likely the case at fish farms, for example, where

814 organic ooze under the nets is sometimes resuspended by falling debris (e.g. sloughed material)

815 from the overlying nets (Stucchi et al., 2005). However, a distinction should be made between

816 turbidity resulting from static resuspension, due to physical disturbance in mud substrates, and

817 turbidity due to mobile suspended solids resulting from up-stream slope failures in estuaries (c.f.

818 Prior et al., 1987). In the first case, and for most mud sediments, typical bottom disturbances

819 result in low net sediment transport. However, for up-slope failures or slumps, there likely will

820 be considerable transport and bottom turbidity can persist for some time (Prior et al., 1987;

821 Bornhold et al., 1994).

823 Sediment organic content can be highly variable in silt/clay sediments, depending not only on

824 organic deposition but also on inorganic deposition (see Burd et al., in press). For example, high

825 glacial silt deposition in more northerly mainland fjords tends to be low in organic content (c.f.

826 Farrow et al., 1983). The ratio of organic to inorganic deposition can be related to water depth

827 since, with increasing depth, inorganic (land-based) deposition tends to decrease while the

828 deposited material becomes increasingly dominated by marine detritus (c.f. Rhoads and Young, 
829 1970). In the southern SoG (i.e. south of Texada Island), deposition to mud substrates is

830 dominated by particulates from the Fraser River (Thomson, 1981; Harrison et al., 1983;

831 LeBlonde, 1983; Johannessen et al., 2003). This deposition produces organic carbon levels in

832 surface sediments averaging around $1 \%$ near shore in the most southerly portion of the main

833 basin and around 2\% in the deeper basin sediments, closer to Texada Island (Burd et al., in

834 press). This observed trend is due to declining riverine deposits and increasing marine

835 deposition (Johannessen et al., 2005b). In the northern SoG, the basin sediments show unsually

836 high \%TOC (3-6\%) but the overall flux of organic material, and total sediment, to the benthos is

837 low (Johannessen et al., 2003; Burd et al., in press). Stable isotope data and biological samples

838 also suggest that organic material in sediments in the northern SoG is not particularly labile

839 (Burd et al., in press; Macdonald et al., in press).

840

841 Not surprisingly, mud substrates are usually suboxic or anoxic, although \%TOC varies ( 1-7\%)

842 depending on the levels of inorganic input, and hydrogen sulphides or other metabolic

843 byproducts may build up depending on redox levels and labile organic input. In shallow mud

844 (silt/clay) substrates, sulfate reduction tends to be linked to a significant proportion ( $>50 \%)$ of

845 carbon oxidation, whereas in deeper mud sediments (continental shelf) the breakdown of organic

846 material is relatively evenly distributed between aerobic and anaerobic (sulfate reduction)

847 processes (Kristensen and Kostka, 2005). The density of infaunal burrows, however, can have a

848 profound dampening effect on anaerobic metabolism as a result of the increased oxygen supply

849 to subsurface sediment layers. The predominant type of burrowing is related to trophic mode

850 (Nickel and Atkinson, 1995), as well as sediment texture and geochemistry. Fine sediments tend 
851 to be dominated by surface deposit feeders or above-surface filter feeders (Kristensen and

852 Kostka, 2005), rather than sub-surface deposit feeders.

854 Extensive surface bioturbation without the binding influence of intact burrows can destabilize

855 fine surface sediments by producing a surface ("fluff") layer which is readily re-suspended (c.f.

856 Rhoads and Young, 1970; Orvain et al., 2003). Rhoads and Young (1970) even suggest that

857 surface fluff layers tend to prevent suspension feeding due to the clogging of feeding apparatus

858 and the inhibition of larval settlement. The authors use this suggestion to explain the distinct

859 dichotomy in dominant feeding types: deposit-feeders in soft, fine sediments versus suspension

860 feeders in sandier, or firmer, mud sediments. Following this line of reasoning, an assessment of

861 the feeding guilds in sediments could provide some insight into the sediment texture and

862 porosity, as well as near-bottom turbidity.

863

864 The fine-grained particles of mud substrates tend to contain considerable organic particulate

865 material in various forms, thereby providing a good substrate for bacterial and/or algal

866 production (Kristensen, 1988). Key general biotic features of mud bottoms include extensive

867 bacterial or algal mats or shallower near-surface invertebrate burrows that provide sediment

868 surface cohesion in shallow depths, or from invertebrate burrows. Microbial activity, which

869 breaks down organic material in marine sediments (Kristensen and Kostka, 2005), can be

870 stimulated by the presence of surface mucous layers from meiofauna (see Probert, 1984). The

871 stimulation of both microbial and meiofaunal activity creates a rich organic food layer for

872 macrofaunal deposit feeders (Hoskins et al., 2003, Hannides et al., 2005; for review see

873 Kristensen and Kostka, 2005). In addition, mucous layers from intertidal mudflat diatoms, 
874 bacteria and mucous-lined burrows can also help to bind the sediment surface (c.f. Decho, 2000;

875 de Brouwer et al., 2005). Mucous burrows are often impermeable to dissolved organic material

876 and redox chemicals in order to protect the animal from harsh chemical environments (c.f.

877 Hannides et al., 2005; Kristensen and Kostka, 2005). However, depending on their structure,

878 these burrows do provide a pathway for exchange of overlying water with deeper sediments, thus

879 preventing the buildup of potentially inhibitory metabolic byproducts (see Zorn et al., 2006).

880 However, the importance of both bacterial and diatomaceous mucous layers in sediments

881 declines in importance with increasing depth from the intertidal zone to the bottom of the

882 euphotic zone (Ziervogel and Forster, 2006).

883

884 Where oxic sediments are present in these habitats, macrofauna are primarily deposit feeding

885 shallow burrowers, such as polychaetes and bivalves, and predators such as various flatfish and

886 crabs from surrounding rocky areas. Megafauna typically include a variety of echinoderms such

887 as mud stars and burrowing holothurians.

888

889 2.2.1.1 Shallow $(\mathbf{0 - 3 0} \mathrm{m})$ mud

890 Mud substrates in the shallow subtidal tend to be protected from wave exposure and typically

891 have low tidal currents. Bottom turbidity in these habitats is likely due to physical disruption

892 from erosional events, delta slope failures or other unusual events. These habitats typically

893 occur in low flow estuaries and at the base of low current rocky outcrops. Shallow mud habitats

894 can be found in quiescent bays surrounded by rocky headlands, and in wave and current

895 protected estuaries with either low freshwater flow or where there is heavy glacial silt in runoff

896 (i.e. estuaries of mainland fjords; see Farrow et al., 1983). 
898 These are typically highly productive areas because they are within the euphotic zone, which 899 allows primary production as well as bacterial production on and within the sediments. They are

900 also common in coastal areas with physical developments that block or break up wave erosion

901 (e.g. marinas, breakwaters, etc.). Surface shell debris can be common, attesting to the

902 importance of bivalves in this food chain. Organic carbon flux to the sediments may be high

903 and, hence, sediment \% TOC may also be high depending on the level of inorganic input. (Boyd

904 et al., 1998). If the input is primarily salt-marsh plant debris, however, the organic material may

905 have low lability. Primary production in these habitats is primarily from benthic micro-algae and

906 blue-green algae (refs). These sediments typically have a high level of bacteria, which can

907 include sulphur-fixing species (refs).

908

909 Usually, these areas have oxygenated bottom water, with sufficient oxygen for shallow

910 burrowers that are mostly deposit feeders (bivalves and polychaetes), epifauna (scavenging

911 amphipods and bottom shrimp), surface grazers (gastropods) and predators (mud stars, brittle

912 stars, heart urchins, echiurans, drills, fish) (Burd, 1992). In some habitats, mud-dwelling sea

913 cucumbers such as Molpadia or Chirodota may be found if there is sufficient oxygen in surface

914 sediments (Burd, 1992). Meiofauna, particularly nematodes, are important in these shallow

915 subtidal mud habitats (see section 1.1).

916

917 Examples can be seen in areas such as Patricia Bay, Saanich Inlet, and around numerous

918 estuarine bays in the Strait. Unfortunately, there are few published examples of shallow subtidal

919 mud studies in the SoG. Burd (1992) and Boyd et al. (1998) described mud assemblages from 
920 shallow areas of the innermost part of Burrard Inlet (Port Moody Arm). These substrates had

921 low invertebrate abundance and biomass compared with deeper, coarser substrate areas further

922 out in the inlet, and were dominated by polychaetes, followed by bivalves and crustaceans.

923 Faunal composition was distinct between Port Moody Arm and areas further out in the inlet

924 (Burd, 1992) and in some areas with reducing sediments, dominated by the tolerant opportunistic

925 polychaete Capitella capitata complex (Boyd et al., 1998), Considerable sediment chemical

926 contamination and organic enrichment are evident in the Port Moody Arm area (see Burd, 1992;

927 Boyd et al., 1998).

928

$929 \quad$ 2.2.1.2 Mid-depth (30-100 m) mud

930 Mud substrates at 30-100 m depth are a common marginal habitat around the SoG, particularly

931 on the eastern side, including Burrard Inlet, north along the coast, and in isolated bays with low

932 bottom currents (Fig. 1). These fine-grained substrates are not found in areas exposed to sandy

933 deposition from the southern Gulf Islands, the Fraser River discharge and other relatively large

934 freshwater estuaries such as the Cowichan River (north of Saanich Inlet), and the Squamish

935 River (Howe Sound). This type of habitat is commonly found inside the sill, or near the mouth of

936 fjords, in areas with either limited, or absent, bottom currents and very low freshwater runoff.

937 These habitats may also occur surrounded by, or at the base of, rocky outcrops or cliffs. Bernard

938 (1978) lists the dominant invertebrate epibenthic megafauna (11 species) found in mud/silt

939 habitats from 20-100 m depth at multiple locations within the SoG.

940

941 Because of the depth range, these habitats tend to have limited tidal influence and no wave

942 influence. In addition, as the mud substrates are below the euphotic zone, the development of 
943 surface biofilms may be less extensive than in shallow subtidal mud habitats (c.f. Ziervogel and

944 Forster, 2006). If the redox boundary occurs at the sediment surface, however, sulfide-fixing

945 bacteria such as Beggiatoa spp. may produce mucous mats. For example, Beggiatoa spp. mats

946 can be found between 65-100m depth in areas of Saanich Inlet (Burd, unpublished data; see >100

947 m anoxic basins, below).

948

949 An example of this type of habitat is bottom areas shallower than sill depth in Saanich Inlet, such

950 as Patricia Bay (http://www.env.gov.bc.ca/wat/wq/saanich/siscr.html). Although there have been

951 no studies focused on the benthic soft-bottom fauna in the mid-depth range of Saanich Inlet

952 sediments, another example of this habitat type in the SoG, for which data are available, is outer

953 Burrard Inlet. Sedimentation rates are low in this region (Johannessen et al., in press), although

954 the complex hydrographic mixing results in high suspended particulates in the water column (as

955 noted during reconnaissance ROV surveys - CORI, 2002) and sediment TOC levels between 1.5

956 and 2\% (McPherson et al., 2006b). Although there are a variety of anthropogenic discharges and

957 physical disturbances in the inlet (see Section 3), long-term monitoring for the outer inlet

958 suggests that benthic infauna are not impoverished and are not dominated by opportunistic

959 polychaetes (c.f. PICES, 2001; McPherson et al., 2006b). Fauna within the inlet are dominated

960 by small burrowing bivalves, which constitute $\sim 55-85 \%$ of the total abundance over a range of

961 sediment enrichment conditions and which contribute the largest percentage of biomass of any

962 major taxonomic group (McPherson et al., 2006b). Polychaetes constitute 10-40\% of the total

963 abundance and species numbers are within the ranges expected for this depth range in the SoG

964 (Burd et al, in press). Ophiuroids are patchily abundant and both crustaceans and holothurians

965 are rare in this inlet. 
967 Data are also available for shoreline areas just outside the north side of Burrard Inlet which fit 968 this habitat type (McPherson et al., 2004a). Biotic samples taken from a similar depth to the 969 outermost Burrard Inlet show similar species richness to the Burrard Inlet samples but somewhat 970 lower abundance levels (McPherson et al., 2004 a, c). Fauna increase in abundance from outside

971 the inlet to the innermost part of the outer basin (west of $1^{\text {st }}$ Narrows) (Fig. 1), with bivalves

972 showing the clearest abundance gradient (McPherson et al. 2004 a,c). Like Burrard Inlet, the area

973 just outside the north side of the inlet experiences relatively low sedimentation rates compared to

974 the rest of the southern SoG, as well as moderate \% TOC in the sediments $(\sim 1.5 \%)$ Burd et al., in 975 press; (Johannessen et al., in press).

977 Biotic and synoptic sediment geochemical and contaminant sampling data have been collected

978 for parts of inner Burrard Inlet (past $1^{\text {st }}$ Narrows), including the two inner arms (see Fig. 1) (Burd 979 and Brinkhurst, 1990; Cross and Brinkhurst, 1991; Boyd et al. 1998; PICES, 2001; Je et al., 980 2003). In addition, samples from the outer inlet were collected by Ellis (1971). These studies 981 suggest that faunal abundance and species richness decline along a gradient from $1^{\text {st }}$ Narrows

982 inward towards Port Moody Arm (Fig.1), where the heaviest organic enrichment and

983 contamination is found. In Port Moody Arm, which has fine mud sediments with poor flushing,

984 faunal abundance tended to be temporally variable relative to the rest of Burrard Inlet (Burd

985 1992; Boyd et al., 1998) but faunal biomass was consistently lower.

987 The spectrum of studies utilizing the same locations in Burrard Inlet but using different mesh 988 sizes $(0.3,0.5 \mathrm{~mm}$ and $1 \mathrm{~mm})$ for screening biotic samples, provides a unique opportunity to 
examine the difference in interpretation which is potentially possible for community structure

990 based on methodology. Ignoring potential differences in quality control of sampling, increasing

991 screen mesh size led to a decreasing proportion of juvenile (non-adult) forms at one outer

992 harbour station ( $50 \%$ to $10 \%$ ) but no notable shift in species number. However, the proportion

993 of abundance made up of bivalves shifted from $35 \%$ to $55 \%$, with a commensurate decrease in

994 proportion of polychaetes. In addition, although usually ignored in benthic macro-infaunal

995 studies, the proportion of nematodes collected decreases with increasing mesh size. Hence, the

$9961 \mathrm{~mm}$ screen appears to eliminate most of the juvenile fauna, as well as a modest proportion of

997 the smaller adult polychaetes and most of the "meiofauna" (primarily nematodes and

998 harpacticoid copepods). The most dramatic change in metazoan size spectra, biota types and life

999 history strategies appears to be found at about the $0.5 \mathrm{~mm}$ screen size, and the evolutionary

1000 drivers for the meiofaunal/macrofaunal dichotomy are discussed by Warwick et al. (2006). The

1001 various studies agree that polychaete dominance increased from the outer inlet towards the more

1002 eutrophic Port Moody Arm (Boyd et al., 1998; Burd and Brinkhurst, 1990; Je et al., 2003), with

1003 some examples of opportunistic enrichment of Capitella capitata complex (Burd and Brinkhurst,

1004 1990; Je et al., 2003).

1005

$1006 \quad$ 2.2.1.3 Deep $(>100$ m) mud

1007 Deep water mud habitats are not subject to tidal or wave influences, usually have very low

1008 bottom currents and limited flushing of bottom water. The origin of organic material in these

1009 environments is primarily marine detritus or terrestrial erosion from cliffs in fjords. Bottom

1010 turbidity can occur as a result of turbidity flows from delta slope failures in fjords (Prior et al.,

1011 1987; Bornhold et al., 1994). In general, substrates get finer with increasing depth in coastal 
1012 areas (Striplin, 1996; Llansó et al., 1998) because the input of coarser land-based erosional,

1013 riverine and current-transported material tends to decline with increasing depth. Organic carbon

1014 flux to these deep sediments is typically, although not always (Burd et al., in press), lower than

1015 in similar sediments in shallower areas, unless there is a specific source of organic input nearby

1016 (e.g. fish farms).

1017

1018 Areas with oxygenated, mud sediments are extensive throughout both the deep basin of the SoG

1019 and many of the fjords, and probably make up most of the subtidal bottom area of the SoG

1020 (Levings et al., 1983). Bottom water oxygen levels vary, depending on basin topography, but low

1021 bottom currents and shallow, isolating sills in fjords can result in significantly reduced bottom

1022 oxygen levels. Hence, there is limited oxygen replenishment to the sediments. These habitats

1023 are typical of the main basins of fjords and the deep basin of SoG. These sediments are

1024 dominated by near-surface, or epifaunal, deposit feeders and predators. Bivalves and ophiuroids

1025 are less abundant in these deep habitats than in shallower areas, while polychaetes, holothurians

1026 and echinoids increase in dominance (see Burd et al., in press). Bernard (1978) provides a list of

1027 the dominant (largely epibenthic) megafauna collected in trawl samples at locations throughout

1028 the SoG at depth ranges of 100-200 m, 200-300 m, and 300-400 m. Bernard's (1978) species list

1029 is the most diverse in all depth ranges for this substrate type, and includes bivalves, polychaetes,

1030 echinoderms and crustaceans.

1031

1032 Because organic carbon flux is low, faunal abundance and species richness is generally lower

1033 than in the mid-depth marginal SoG mud habitats discussed earlier. Llansó et al. (1998) describe

1034 biotic conditions in deep clay habitats $>80 \mathrm{~m}$ in Puget Sound. They suggest that, on average, 
1035 species richness and abundance was lowest in deep (>80 m) clay sediments of any soft substrate

1036 types in the sound or on the Washington shelf. Llansó et al. (1998), Burd and Brinkhurst (1992)

1037 and Burd (2003b) agree that several of the large, important bioturbators (the echinoderms

1038 Molpadia intermedia and Brisaster latifrons) seem to be primarily found in deep-water

1039 sediments, which in the fjords and main basin of the SoG are typically mud (silt/clay).

1040

1041 Some data on the benthic infaunal biota, collected using visual and remote sampling methods,

1042 are available for the fjords (Burd and Brinkhurst, 1992; Ellis, 1971; Levings, 1980a, b). Burd and

1043 Brinkhurst (1992) report infaunal abundances in silt sediments at depths of $>100 \mathrm{~m}$ in of three of

1044 the SoG fjords: Bute, Toba and Jervis. Faunal abundance was low at all sampling stations in that

1045 study and was dominated by polychaetes; occasional high abundances of sipunculids were

1046 recorded but few echinoderms and virtually no crustaceans or bivalves were observed (Burd and

1047 Brinkhurst, 1992). Burd (1992) did a multivariate comparative assessment of biotic assemblages

1048 from a series of deep fjord samples along BCs mainland coast compared with other assemblages

1049 found throughout BC. One notable feature of BC's deep fjords is the relative uniformity of

1050 benthic assemblages in the deep mud benthos, compared to other coastal areas, in the absence of

1051 overwhelming physical drivers such as anoxia or hypoxia, heavy glacial deposition or freshwater

1052 runoff (c.f. Burd 1992).

1053

1054 Ellis (1971) described fauna from some grab samples taken in the deepest basin of Jervis Inlet on

1055 the mainland $\mathrm{BC}$ coast. They note that about $80 \%$ of biomass from that area was contributed by

1056 the echinoderm Brisaster latifrons and a surface tube-mat forming polychaete; approximately

$105710 \%$ of the total biomass was contributed by bivalves. 
1059 A deep mud-bottom habitat in Knight Inlet (located immediately north of the SoG), described in

1060 Farrow et al. (1983), is a good example of a fjord with high loads of river-borne glacial silt.

1061 These loads of glacial silt add to the inorganic loading near the head of the inlet, while also

1062 introducing sufficient energy and flocculent material into the system to produce high turbidity

1063 and bottom resuspension or turbidity flows. This turbulent type of habitat is unsuitable for many

1064 soft-bottom species which may suffer from smothering (e.g. Holte and Gulliksen, 1998;

1065 Wlodarska-Kowalczuk et al., 2005). In Knight Inlet, BC, Farrow et al. (1983) found a down-inlet

1066 gradient of increasing diversity of large suspension-feeding organisms, and a change in epifauna

1067 from mobile shrimp and crabs at the turbid, high inorganic input head of the inlet, to burrowing

1068 shrimp in the middle inlet, to ophiuroids in the least turbid and least inorganic input areas of the

1069 lower inlet. Similar trends have been observed elsewhere; for example Wlodarska-Kowalczuk et

1070 al. (2005) describe the spatial gradient in sediment biota away from heavy glacial silt

1071 sedimentation towards the head of a European fjord as showing similar trends in faunal

1072 abundance and species richness as those found in organic enrichment gradients. Changes in

1073 species diversity and types of sponges related to water turbulence and sedimentation in an Irish

1074 sea lough were also noted by Bell and Barnes (2000a, b).

1075

1076 During the SoG Ambient Monitoring Program (Wright et al., in press), deep-water mud habitats

1077 were sampled at two stations. One station was within the deepest part of the SoG basin (388 m),

1078 just south of Texada Island (Fig. 1), and had moderate organic flux to sediments while the

1079 second station was north of the mid-basin sill near Texada Island (187 $\mathrm{m})$ and was within the low

1080 organic flux regime in the northern SoG (see Burd et al., in press). In addition, the organic 
1081 carbon at the shallower, more northern station was relatively refractory compared with the

1082 deeper, southerly station, and had a high clay component, with virtually no terrigenous or shell

1083 debris. The difference in these substrate conditions produced a striking difference in biota, which

1084 was much more abundant and diverse at the deeper, southerly station. However, similarities

1085 between the two stations include polychaete dominance, the lack of bivalves and crustaceans,

1086 and the presence of large burrowing holothurians. In fact, this latter group was responsible for

1087 the relatively high faunal biomass at the deeper, southerly station (Burd et al., in press).

1088

1089 Saanich Inlet, below sill depth (70 m) (Fig. 1), is an example of a deep anoxic basin. It

1090 experiences progressive hypoxia and anoxia from winter through summer. In the fall, upwelling

1091 within the SoG spills dense, oxygenated water over the sill and, sinking to the bottom, this water

1092 pushes the anoxic layer up to mid-water depths before the anoxic waters disperse

1093 (http://www.pac.dfo-mpo.gc.ca/sci/OSAP/projects/bcinlets/saanich_inlet_e.htm). Saanich Inlet

1094 has high organic carbon content in deep sediments (Bornhold, 1978) but a moderate C/N ratio

1095 ( 6.8), suggesting that, historically, the origin of organic input has been largely marine. The high

1096 carbon content in Saanich Inlet deep sediments has been supported by more recent studies

1097 (Boatman and Murray, 1982; Tunnicliffe, 2000), however Tunnicliffe (2000) indicates that

1098 increasing terrestrial input over the past century has resulted in shifts in organic carbon content,

1099 and therefore, the $\mathrm{C} / \mathrm{N}$ ratio. Organic carbon may build up in sediments because overlying water

1100 hypoxia and anoxia greatly slow the decomposition and consumption of this material by bacteria

1101 and invertebrates, respectively (Emerson and Hedges, 2003). Although the cliff fauna of

1102 Saanich Inlet have been studied, (Tunnicliffe, 1981; Burd and Brinkhurst, 1984), information on

1103 the infaunal benthos of the deep mud basin is lacking. However, because of the occasionally 
1104 vertically mobile anoxic water layer in this inlet, along with observed mass mortalities of cliff

1105 fauna (Tunnicliffe, 1981; Burd and Brinkhurst, 1984), it has been assumed that soft-bottom areas

1106 influenced by long-term anoxia will be largely azoic.

1108 At the sediment interface, where dissolved oxygen is minimal and sediments are anoxic, white

1109 mucous mats of Beggiatoa spp. and similar sulphur-fixing bacteria may form (Burd and

1110 Brinkhurst, 1984). In this oxycline, the sediments are devoid of any sign of bioturbation or

1111 evidence of infaunal or epifaunal life (Gucluer and Gross, 1964; Burd, unpublished data; PICES

1112 IV observations 1980-1983), with the following exceptions. A bentho-pelagic amphipod species

1113 (Orchomene obtusus) can tolerate anoxic conditions for extended periods of detrital scavenging,

1114 after which they migrate back up to oxygenated water periodically (De Robertis et al., 2001).

1115 The galatheid crab, Munida quadrispina, has been observed to frequent silty bottom areas where

1116 the mucous mats are present and near-bottom water oxygen levels are very low (Burd and

1117 Brinkhurst, 1984) and has been observed, in situ and in the laboratory, to feed opportunistically

1118 on sediment detritus and the aforementioned amphipods. The crabs have exceptional metabolic

1119 regulation under low oxygen conditions in the laboratory (Burd, 1985), along with significantly

1120 hypertrophied gill tissue in the deep areas of Saanich Inlet (Burd, 1988), compared with

1121 surrounding areas outside the inlet. In the deep, severely hypoxic to anoxic sediment areas, these

1122 are the only visually evident fauna although facultative anaerobic meiofauna (typically

1123 nematodes) may be present in sediments.

1124

1125 Like Saanich Inlet, Howe Sound on the mainland coast of BC has a shallow sill at the entrance 1126 and experiences hypoxic conditions in the deep basin for part of the year. Historical bottom 
1127 trawl surveys in Howe Sound related to bottom hypoxia are described in Levings (1980a, b) and

1128 Levings et al. (1983). Survey data show that the relatively immobile invertebrates and a few

1129 slow-moving fish experienced mass mortalities during severe hypoxic periods; bottom fish

1130 catches declined, presumably due to migration to shallower, more oxic waters. The mobile

1131 epifauna appeared to return fairly rapidly following hypoxic periods, including the galatheid

1132 crabs also found in Saanich Inlet, and various shrimp species (Levings 1980a, b).

\section{$1134 \quad$ 2.2.2 Silt/Sand Habitats}

1136 The presence of sand implies transport of inorganic material, from nearby glacial deposits or

1137 moderate to high input from freshwater sources nearby. Although variable spatially and

1138 temporally, these sediments are net depositional. In coastal areas with a source of relatively

1139 coarse, inorganic material from large riverine inputs, the sediments tend to be mixed. This type

1140 of habitat is common in marginal coastal areas in the southern SoG, particularly along the eastern

1141 margin of the southern Strait where the Fraser River discharges. For a description of

1142 sedimentary dynamics along the Fraser River delta, see Hill et al. (in press). Most notable about

1143 these sediments is the input of coarse material that increases mobility beyond that found in mud

1144 substrates. The delta sediments along the bank and slope where the Fraser River discharges into

1145 the SoG provide a good example of this mobility, as the sediments appear to be continuously

1146 transported to the north and downslope (McLaren and Ren, 1995; Hodgins and Hodgins, 2000).

1147 The importance of sediment mobility in determining the distribution and stability of coastal

1148 benthic infauna has been documented in Australia (Post et al., 2006), New Zealand (Hewitt et al.,

1149 1997; for a general review see Newell et al., 1998), and in laboratory experiments (Roegner et 
1150 al., 1995; Dunn et al., 1999; Hunt and Mullineaux, 2002). Research in the northeast Pacific has

1151 focused on transport of sediment particle sized organisms such as foraminifera (Snyder et al.,

1152 1990).

1153

1154 In the sediments influenced by Fraser River deposits, the relatively high deposition of inorganic

1155 riverine material seems to limit the TOC levels to values $<1.5 \%$ (McPherson et al., 2006a; Burd

1156 et al., in press). However, these TOC values are not indicative of the productivity of these

1157 sediments, which is more closely related to the input of organic material (see Burd et al., in

1158 press). Because of the inorganic input to these sediments, however, and their tendency to be less

1159 sticky and cohesive than mud, they are usually better oxygenated that marine muds. Surface

1160 mixing layer depths related to bioturbation in substrates affected by Fraser River discharge are

1161 estimated at between 7-10 cm deep (Johannessen et al., in press). These substrates tend to be

1162 located in moderate or variable current regimes and, because the sediments are easily re-

1163 mobilized, bottom turbidity may occur. These substrates are typically oxic but, if organic carbon

1164 loading is high, can be suboxic.

1165

1166 A wide range of habitat types, based on fine-scale structural features, can be found in these

1167 substrates, along with a mixture of biotic features of both mud and sand communities. Analyses

1168 of biotic data with an extensive geographic distribution within the SoG (Burd et al., in press),

1169 indicates that this silt/sand habitat along the Fraser River delta appears to have a high abundance

1170 of invertebrate fauna compared with the rest of the SoG. Biota are diverse in terms of species

1171 richness, type (polychaetes, bivalves, echinoderms, crustaceans and more) and size spectrum of

1172 organisms, as well as feeding types (mixed deposit and/or suspension feeders, scavengers and 
1173 predators) (McPherson et al., 2006a). Using functional group categories for benthic fauna,

1174 Pearson and Rosenberg (1978) suggest that off-shore silt/sand habitats in temperate coastal areas

1175 tend to have the greatest diversity of functional groups in soft sediments.

1176

\section{$1177 \quad$ 2.2.2.1 Shallow $(\mathbf{0}-30 \mathrm{~m})$ silt/sand}

1178 Shallow silt/sand habitats in the SoG are usually semi- protected in regard to wave exposure and 1179 tidal currents. Sediment is either fluvial in origin or from an along-shore source. Oxygen levels

1180 in bottom water are reasonable and natural sediments tend to have some oxygenation. In the

1181 SoG, eelgrass occurs in oxic sediments in areas with "clean" water and at depths usually $<10 \mathrm{~m}$.

1182 Both red and green macroalgae are associated with eelgrass beds, as a result of the low sediment

1183 mobility (eelgrass roots/rhizomes stabilize the sediments). In the shallow silt/sand habitats in the

1184 SoG, mobile macrofauna (e.g. sea stars and crabs) are abundant and, usually outside of the

1185 eelgrass beds, deep-burrowing large bivalves as well as burrowing anemones, agglutinated tube-

1186 building worms and tubicolous amphipods occur.

1188 Bazan Bay on Vancouver Island, serves as an example of some of the more interesting features

1189 that may occur in these shallow silt/sand habitats. A mixed eelgrass, red and green filamentous

1190 algal community is evident to the $10 \mathrm{~m}$ depth (J. Harper, CORI, Sidney, BC, pers. comm.), along

1191 with patches of eelgrass that vary in density (see Bornhold and Harper, 2002). Eelgrass beds are

1192 typically considered to be important habitat and nursery areas for various species of fish and

1193 mobile, or epiphytic, macro-invertebrates (Goldstein et al., 1996; Heck et al., 2003;

1194 http://www.ecy.wa.gov/programs/sea/pugetsound/species/eelgrass.html) 
1196 In deeper waters, but still within this habitat type, foliose red algae and other macroalgae are

1197 seasonally abundant, suggesting attachment in the relatively stable silt/sand substrates. Benthic

1198 invertebrate data from close proximity to an abandoned outfall pipe in Bazan Bay was collected

1199 (Glaholt et al., 2002) as part of the reconnaissance information related to the proposed SoG

1200 Crossing pipeline project. The study was designed to show the expected changes in biota related

1201 to the introduction of an artifical reef (a pipeline), into a shallow, silty sand habitat in the SoG.

1202 The faunal assemblage in these substrates is dominated, to an indeterminate water depth, by a

1203 dense sediment-surface mat of tube-dwelling amphipods, sponges and hydroids, with lesser

1204 dominance by polychaetes, followed by bivalves (Glaholt et al., 2002). The presence of these

1205 mats suggests a lack of bottom disturbance from excessive sedimentation, organic input or

1206 physical disruption. The presence of sponges and hydroids in the mats suggests a strong

1207 suspension feeding component within the community. The amphipod tubes produce a micro-

1208 heterogeneity of structure which benefits other species, such as the hydrozoans and a multitude

1209 of other amphipods and crustaceans. Faunal distributions were highly variable spatially, with

1210 isolated patches of anoxic sediments and higher silt content where drift algae had piled up on the

1211 quiescent down-current side of the Bazan Bay pipeline (Glaholt et al., 2002). Other infaunal

1212 organisms which may be common in shallow silt/fine sand habitats include relatively deep

1213 burrowing, large bivalves, burrowing anemones, and larger mobile predators and scavengers

1214 (e.g. mud stars, crabs, shrimp and nudibranchs).

1216 Another example of a shallow mixed silt/sand habitat study is Boatswain Bank along the eastern

1217 coast of Vancouver Island just north of Saanich Inlet. A shallow subtidal study was done along

1218 an onshore/offshore transect at the proposed landfall for the SoG pipeline. The relevant habitat, 
1219 macroalgae and surface megafauna are described based on diver surveys in Seacology et al.

1220 (2001). Megafauna included sea-pens, tubeworms, gastropods, hermit crabs, sand stars, and

1221 various fish. Beach seining in the same study showed a number of rock, kelp and helmet crabs.

1222 Concurrently, a study of the infauna (Burd and Glaholt, 2000) showed a diversity of polychaete,

1223 bivalve, crustacean and echinoderm fauna with numerous bryozoan and cnidarian colonies

1224 attached to fauna and macroalgae. The diversity of this assemblage appeared to be comparable to

1225 the deeper, siltier samples in Satellite Channel (Burd et al. 2000a), except for a much lower

1226 abundance of shallow burrowing bivalves in the Boatswain Bank area. The area was also

1227 surveyed by video to map the habitat, extent of eel-grass beds and other macro-algae

1228 (Archipelago Marine Research Ltd., 2000).

\subsubsection{Mid-depth (30-100 m) silt/sand}

1231 Mid-depth silt/sand habitats in the SoG tend to have a broad range of organic carbon fluxes and

1232 bottom water oxygen levels. An example of the mid-depth silt/ sand habitat is found on the

1233 western side of the SoG, straddling the Fraser River discharges. Extensive biological and

1234 geochemical monitoring of these sediments has been conducted as part of the Iona outfall

1235 monitoring program for GVRD (Burd, 2000; Burd, 2003b; Bailey et al., 2003, McPherson et al., 1236 2003, 2004b, 2005a, 2006a, 2007a), providing extensive data on both background and impacted

1237 areas (see Section 3). This area spans the Fraser River delta and hence receives the maximum

1238 influence from plume particles and bottom transported material, particularly from the south arm

1239 of the Fraser River (Hill et al., in press). Bioturbation in the area is considerable, with a surface

1240 mixed layer of up to 5-10 $\mathrm{cm}$ (Johannessen et al., in press). The area has a rich and diverse

1241 macrofaunal community dominated by a broad size range of bivalves, although $40-60 \%$ of the 
1242 total faunal abundance is contributed by one small, burrowing species, Axinopsida serricata. A

1243 second bivalve, Macoma carlottensis, comprises $\sim 10 \%$ of the abundance. All bivalves comprise

$1244 \sim 50 \%$ of the organismal biomass in these sediments (McPherson et al. 2006a). The remaining

1245 biomass is mostly comprised of echinoderms, primarily the brittlestar Amphiodia

1246 urtica/periercta complex, and a few large holothurians (Molpadia intermedia). Although there is

1247 a diversity of polychaete taxa present, these organisms are clearly of minor importance in the

1248 productivity of these sediments. Infaunal crustaceans are rare, comprising less than $1 \%$ of faunal

1249 abundance and far less than 1\% of biomass (McPherson et al., 2007a).

1251 The bivalve dominance evident in the 30-100m silt/sand sediments spanning the Fraser River 1252 delta, discussed above, appears to be unusual within the SoG (Burd et al., in press). Burd et al. 1253 (op. cit.) suggest that the bivalve dominance is related to the high sedimentation rates along the 1254 delta (see Johannessen et al., in press), which are less easily tolerated by infaunal polychaetes 1255 (Reid and Baumann, 1985; Burd, 2002). Brittle stars may also have an advantage in this habitat 1256 type in regard to the speed and extent of their burrowing capability. Close to the south arm 1257 discharge of the Fraser River, the sedimentation rates are too high to be measured in the standard 1258 box cores used in other locations (Johannessen et al., in press). In this location, the dominant 1259 bivalve (Axinopsida serricata) and the ophiuroids periodically decline, with a concurrent 1260 increase in abundance of small polychaetes typically considered to be primary colonizers 1261 (McPherson et al., 2006a). Presumably, there is therefore a limit in the ability of the infaunal 1262 bivalves and brittle stars to cope with heavy sedimentation conditions (or events). 
1264 Although mid-depth (30-100 m) sampling stations in outer Burrard Inlet are described as having

1265 mud substrate (see earlier), several stations in this area have silt/sand substrates (i.e. stations

1266 close to the $1^{\text {st }}$ Narrows bridge and near the mouth on the south side of the inlet (Fig. 1)

1267 Conversely, some areas along the bank and slope between the south arm of the Fraser River and

1268 the opening to Burrard Inlet can be classified as primarily mud. Species richness values and

1269 faunal types are similar throughout the Fraser River delta and Burrard Inlet (McPherson et al.,

$12702006 \mathrm{a}, \mathrm{b})$, illustrating the overlap in faunal types between mud and sandy silt habitats. However,

1271 regardless of substrate type, species abundance and biomass values have been consistently lower

1272 in outer Burrard Inlet than along the Fraser River delta (McPherson et al., 2006 a, b), and total

1273 sediment flux and organic flux are higher along the river delta than in Burrard Inlet (Burd et al.,

1274 in press; Johannessen et al., in press). These patterns suggest that faunal productivity in the main

1275 basin of the SoG is more dependent on the Fraser River discharge than on substrate type or depth

1276 (Burd et al., in press).

1277

1278 2.2.2.3 Deep (>100 m) silt/sand

1279 Silt/sand habitats are rare below $100 \mathrm{~m}$ depth in the SoG, since most of the sand (coarser, land-

1280 based material) deposits closer to shore. In most of the deeper parts of the main basin of the

1281 SoG, and at the bottom of fjords, substrates are mud (see earlier text). In the southernmost part

1282 of the main basin of the SoG, however, intense mixing throughout the water column in Haro

1283 Strait (Masson and Cummings, 2004) (see Fig. 1) may carry sandy material eroded from the

1284 southern gulf islands to the deep basin of the SoG (see also Johannessen et al., 2006), explaining

1285 why these sediments have some sand content. In addition, some of the coarse, sandy sedimenting

1286 material from the Fraser River is transported northward and downslope off the delta, ultimately 
1287 ending up in the deep basin of the eastern margin of the southern SoG and resulting in mixed

1288 sand and silt substrates at depths greater than $100 \mathrm{~m}$ (McPherson et al., 2004a).

1290 The example used to provide a description of the biota in these habitats is the area at the foot of 1291 the slope $(120 \mathrm{~m})$ on the south-eastern margin of the SoG, along the Fraser River discharge area.

1292 The biotic community of this area overlaps with that for the mid-depth range to some extent, but 1293 there are marked differences in faunal dominance (McPherson et al., 2004a). For example, the 1294 mid-depth bivalves, such as Axinopsida serricata, which are dominant from 30-100 $\mathrm{m}$ in the 1295 Fraser River delta and outer Burrard Inlet, decline in abundance at depths $>100 \mathrm{~m}$ in these same 1296 areas (McPherson et al., 2004a, b, c). Brittle stars are also rare below $100 \mathrm{~m}$, whereas large

1297 holothuroids such as Molpadia increase in abundance and the crustacean fauna changes.

1298 Number of taxa and total abundance tend to decline somewhat with increasing depth but are still 1299 relatively high at $120 \mathrm{~m}$. At a location close to the south arm of the Fraser River discharge (Fig. 1300 1) the main features of the fauna tend to be similar at depths from $60-120 \mathrm{~m}$, because this entire 1301 habitat is overwhelmed by continuous high deposition of river-derived material. At $500 \mathrm{~m}$ north 1302 of the Iona outfall (McPherson et al., 2004b) (Fig. 1), and another location just outside the mouth 1303 of Burrard Inlet (McPherson et al., 2004a), faunal abundance and diversity decline dramatically 1304 with depth. Near the outfall, the faunal decline may be related to slumping of elevated (outfall1305 related) deposits along the steep slope areas. However, in both the aforementioned more 1306 northerly locations, faunal declines may be related to a combination of decreased sediment 1307 organic flux with depth and natural declines in bivalve abundance below $100 \mathrm{~m}$ (Burd et al., in 1308 press). 
1310 Several stations sampled in the deep, southern basin of the SoG as part of a collaborative

1311 ambient monitoring program between the Canadian Department of Fisheries and Oceans,,

1312 Natural Resources Canada and the Greater Vancouver Regional District (Wright et al., in press)

1313 showed infaunal biomass as high, or higher, than that observed in the mid-depth zone along the

1314 Fraser River delta (see earlier text this section; Burd et al., in press). Faunal abundance and

1315 species richness were also considerably higher than those found in either of the deep, mud

1316 habitats in fjords or other deep areas of the BC coast (Burd, 1992; Burd, 2006; Burd et al., in

1317 press). At one southern SoG station, sediments had unusually high organic and inorganic flux,

1318 biomass and species richness (see Burd et al., in press) and were dominated (e.g. 40\% of total

1319 abundance) by crustaceans, particularly a cumacean (Eudorellopsis integra) and an ostracod

1320 (Eudorella pacifica); both these crustacean species were rare in the proximate mid-depth zones

1321 for this substrate type (McPherson et al., 2007a). Approximately 25\% of the total faunal

1322 abundance at the same station consisted of bivalves, which is unusually high for the deep

1323 habitats, and $25 \%$ consisted of polychaetes. The remaining fauna consisted of gastropods,

1324 aplacophorans, and a few echinoderms. The second station was dominated by polychaetes with

1325 few bivalves but had a high biomass due largely to echiurans (Burd, et al., in press). A third

1326 station in the southern main basin of the Strait appeared to have a faunal composition that was

1327 intermediate between the other two stations, albeit with a lower overall biomass and abundance

1328 than the other two stations along with a lower organic flux to bottom sediments (Johannessen et

1329 al., in press). These differences illustrate the wide variety of faunal types which may occur at

1330 depth within the deep basin of the SoG, presumably related to differences in sedimentation

1331 conditions (Burd et al., in press). 


\section{3}

1334

1335

1336

1337

1338

1339

1340

1341

1342

1343 Sand substrates are porous and well oxygenated, often to sediment depths $>10 \mathrm{~cm}$; they are

1344 subject to both diffusion and lateral seepage of oxygen and dissolved organic material. Low

1345 porewater oxygen would be expected only in very unusual circumstances, such as may be found

1346 in a stagnant basin with high inorganic input. Organic flux may vary greatly but the deposition of

1347 typically fine, organic material is limited such that sediment TOC content is generally low

$1348(<1 \%)$. Sand habitats are the most extensively bioturbated of all the habitat types, as the

1349 sediments tend to be loosely packed, and, thus, are relatively easy to move through. Sand

1350 habitats may be subject to considerable transport in high energy areas, so that biotic community

1351 types and stability are directly related to the frequency and type of high energy, remobilizing

1352 events.

1353

1354 Biotic factors in sand substrates include a high potential for bioturbation; tube-building

1355 polychaetes and amphipods are frequently found in these substrates. Sand substrates tend to 
1356 have a higher proportion of suspension feeders than deposit feeders, and epifaunal predators and

1357 scavengers are common. While some species that are found in the mixed silt/sand habitats may

1358 also be present in sand habitats, the strictly deposit-feeding species are typically absent or rare

1359 (Rhoads and Young, 1970).

\section{$1361 \quad$ 2.2.3.1 Shallow $(\mathbf{0 - 3 0} \mathrm{m})$ sand}

1362 In the SoG, sand substrates in depths $<30 \mathrm{~m}$ range from being semi-protected to semi-exposed to

1363 wave and storm disrupted, and some bottom turbidity is possible. Sediment sources may be

1364 fluvial, along-shore or onshore/offshore. Predominantly sand substrates in low to moderate

1365 energy areas in the SoG typically include high numbers of deep burrowing bivalves, such as

1366 horse clams (Lauzier et al., 1998) butter clams, littleneck clams (Gillespie and Bourne, 1998).

1367 These species are common throughout BC and Alaska. Where clam populations are high, the

1368 surface sediments are commonly littered with shell debris resulting from predation. The surface

1369 of the sediments in shallow sand habitats may be dominated by sand dollars, sea pens or surface

1370 bivalves such as Tellina spp. (Burd, 1992). Mobile predators such as small to mid-size crabs, sea

1371 stars and drills, are common. Grazers such as small and large gastropods (such as Gastropteron

1372 sp.) may be present. Epibenthic amphipods can be highly concentrated, scavenging in areas of

1373 detrit. Polychaetes are common in sandy substrates, but tend to be dominated by mobile forms,

1374 which may be predators or suspension feeders. Palsson et al. (2003) note that Dungeness crab

1375 were most abundant in this depth range in the Washington State SoG (southernmost part) during

1376 the 2001 transboundary trawl survey, although they were not surveyed in this depth range in the

1377 SoG. However, there is an active crab fishery in the sandy sediments east of Vancouver Island

1378 within the southern Gulf Islands. Filamentous red and green macroalgae occur in undisturbed 
1379 sediments and foliose red algae may be found, drifting, in the deeper areas in this habitat. In

1380 more exposed areas (or where herviborous predators such as sea urchins are abundant),

1381 encrusting coralline algae may predominate. Eelgrass beds occur in clean water, relatively low

1382 energy (i.e. sheltered) areas in these sand habitats. While the epiphytic fauna in eelgrass beds in

1383 this habitat may be similar to that found in the shallow silt/sand habitat, the infaunal

1384 communities will be composed primarily of suspension feeders rather than deposit feeders. In the

1385 deeper areas of this habitat, in specific and spatially limited patches, deep burrowing geoduck

1386 populations may be present.

1388 An example of the shallow sandy habitat is found in Boundary Bay, which is a typical sand

1389 beach in the southern SoG (Fig. 1). Burd et al. (1987) identified 200 taxa as part of a study on

1390 the distribution and abundance of macrofauna in Boundary Bay. Most of the shallow, sand

1391 substrate stations were dominated numerically by nematodes plus several species of bivalves,

1392 amphipods and echinoderms. Polychaetes were less prominent than the aforementioned taxa.

1393 The authors note that their study illustrates the spatial heterogeneity of shallow subtidal benthic

1394 communities. Cluster analysis of the abundance data showed considerable dissimilarity between

1395 and within sand stations, particularly when compared with similar analyses for deep water

1396 benthic communities in BC (Brinkhurst, 1987). Using visual counts of specific large macrofauna

1397 along transects in Boundary Bay, Swinbanks and Murray (1981) concluded that in predominately

1398 sand substrates, tidal exposure was an important factor delineating communities. Burd et al.

1399 (1987) suggest that the spatially and seasonally patchy distribution of eelgrass in Boundary Bay

1400 (Swinbanks and Murray, 1981) is a potential factor related to the distribution patterns of species. 
1402 Another example of a relatively unimpacted shallow sandy habitat was studied on the western 1403 margin of the Strait, just north of Saanich Inlet (Boatswain Bank). This location was discussed 1404 earlier (under shallow silt/sand habitats; section 2.2.2.1), and included both habitat types along 1405 an on-shore/offshore gradient, with sandy substrates in the shallower subtidal region.. Epifaunal 1406 biota and macroalgae (Seacology et al., 2001) and infauna (Burd and Glaholt, 2000) were 1407 surveyed along several transects perpendicular to shore at the proposed SoG crossing pipeline 1408 landfall site. Eelgrass beds and other macroalgae were mapped more extensively in the area by 1409 video survey (Archipelago Marine Research Ltd., 2000). The sandy stations were all found at 1410 less than $10 \mathrm{~m}$ depth, below a typical cobble intertidal beach, and were dominated by infaunal 1411 bivalves and crustaceans, along with polychaetes and a few echinoderms within patchy eelgrass 1412 beds. The authors noted that juvenile fauna were numerous, which would be consistent with the 1413 concept that eel-grass beds are important nursery grounds for many types of fauna (Archipelago

1414 Marine Research Ltd., 2000).

1415

$1416 \quad 2.2 .3 .1$ Mid-depth (30-100 m) sand

1417 Mid-depth sand habitats in the SoG are subject to a variety of wave exposures, are often affected 1418 by currents or swells and may be influenced by large storm events. Bottom turbidity is usually 1419 low in these sand substrates, however, because these sediments are heavy and settle quickly. The 1420 biota found include burrowing bivalves that may be smaller, on average, than those found in the 1421 shallower sand habitats. Burrowing polychaetes and mat-forming tubicolous polychaetes occur 1422 in mid-depth sand habitats, as do ophiuroids, although these are found in lower abundance than 1423 in finer grained habitats (Burd et al., 2000a; McPherson et al., 2007a). Crustacean fauna are an 1424 important component in these habitats and depths, including Dungeness crabs (Palsson et al., 
1425 2003). Sea pens and sea whips are found in higher current areas (Burd, unpublished data) and

1426 some attached forms of invertebrates (e.g. hydroids) occur on larger fauna and debris (V.

1427 Macdonald, pers. comm. Biologica Environmental Services Ltd, Victoria, BC).

1429 The mid-depth sandy habitat type example from the SoG is the Ecological Reserve 67, located in

1430 Satellite Channel. Although an Ecological Reserve, this area was neither regulated nor subject to

1431 enforcement until several years ago. However, the only major impact on the area has been

1432 bottom trawling and, despite the known biotic changes that can occur in areas of concentrated

1433 bottom trawling (Engel and Kvitek, 1998; and see Conservation Biology issue 12: Vol. 6, 1998),

1434 a reconnaissance survey in 2000 for the proposed GSX pipeline suggested that the benthic biota

1435 are typically diverse and abundant compared with other areas of the SoG (Burd et al., 2000a;

1436 Burd et al., in press). Fauna in the reserve are dominated by bivalves and a mixture of mobile

1437 and non-mobile polychaetes (epibenthic and burrowing, free-living and tube-dwelling); the latter

1438 group may have comparable or lower abundances than the bivalves. The fauna also includes

1439 abundant crustaceans but relatively few gastropods. Echinoderms are rare which may be because

1440 large, mobile organisms with patchy distribution are not readily sampled using the methodology

1441 (grabs) of the studies cited here or, alternatively, the low abundance may reflect the adverse

1442 effects of bottom trawling. Older studies of the same area suggest that echinoderms were more

1443 common in the late 1960s (Ellis, 1970; 1971), before bottom trawling was frequent in this area.

1444 Ophiuroids also are relatively rare, which may be related either to the non-selective deposit-

1445 feeding habits of these animals and the lower organic content of sediments or, again, to the

1446 damage caused to these near-surface fauna by bottom trawling. Mats of tube-dwelling

1447 polychaetes Galathowenia oculata and Owenia fusiformis were abundant in the Satellite Channel 
1448 area in the late 1960s (Ellis, 1970, 1971), but were not abundant in 2000 (Burd et al., 2000a).

1449 Bottom trawling is likely to cause disruption of tube mat structures on the sediment surface.

1450 Largely because mid-depth sand habitats typically have moderate sediment oxygen levels and

1451 low turbidity, hydroids are found attached to shelled organisms on or just below the surface

1452 (Burd et al. 2000a), and may be an important component of the filter feeding biota of these

1453 habitats.

1454

1455 During the 2001 PICES Burrard Inlet workshop, fauna were sampled from a mid-depth sand

1456 habitat reference station outside the sill of Howe Sound (PICES, 2001; Je et al., 2003). Results

1457 using similar sampling methods showed species richness at this station was similar to that of

1458 samples from the ER67 Satellite Channel stations (Burd et al., 2000a; Je et al., 2003). Faunal

1459 abundance, however, was much higher in the Satellite Channel samples, as there were fewer

1460 bivalves present in the Howe Sound location. Polychaetes, rather than bivalves, were dominant at

1461 the Howe Sound location. A range of epifaunal types (8 taxa) are listed in Bernard (1978) to

1462 occur at depths of 20-100 $\mathrm{m}$ in sandy areas sampled in the SoG.

1463

$1464 \quad$ 2.2.3.1 Deep $(>100 \mathrm{~m})$ sand

1465 Deep sand habitats only occur, typically, in moderate to high current (erosional) areas. In low

1466 current areas, the deposition of fine marine detritus would cover the sands eventually. The epi-

1467 benthic list of Bernard (1978) includes 4 taxa for the 100-200 m depth range but only one

1468 polychaete (Pectinaria californiensis) is listed for the $200-300 \mathrm{~m}$ depth range and one

1469 scaphopod (Dentalium rectius) for the 300-400 m depth range Although no other data or studies

1470 are available from such habitat types in the SoG, these sand habitats may occur in deep water in 
1471 isolated areas near the southern Gulf Islands or in the northern half of the SoG (Fig. 3).

1472 Information on the biotic communities in these habitats outside the SoG, specifically in Hecate

1473 Strait and la Perouse Bank, is available in Burd and Brinkhurst (1987) and Brinkhurst (1987),

1474 respectively.

1475

$1476 \quad$ 2.2.4 Cobble, Gravel and Coarse Sand Habitats

1477

1478 Cobble, gravel and coarse sand habitats are usually found in moderate to high energy locations.

1479 This substrate can also occur, however, where there are coarse glacial deposits in lower energy

1480 locations with no source of finer glacial or freshwater-derived inorganic particulates (finer

1481 sands). These substrates can be both mobile and immobile. For example, constant deposition of

1482 substrate material from a major land-based source would probably lead to unstable deposits

1483 subtidally, particularly on slopes. In stable habitats, however, these substrate materials tend to be

1484 heavy and can only be moved by high energy waves or storm events, particularly in shallow

1485 subtidal areas. Similarly, the coarse materials are a difficult substrate for the burrowing activities

1486 of bivalves and other fauna and, as a result, bioturbation may be limited. Because the substrate

1487 materials in these habitats are so coarse, sediments tend to be well-flushed and oxygenated. The

1488 benthic fauna are dominated by suspension feeders and mobile predators, particularly in high

1489 current areas. Cobble substrates in particular are likely to have fauna similar to rocky substrates

$1490 \quad$ (Section 2.2.5).

1491

1492 Bernard (1978) includes a few dominant epifauna from these habitats at various depths, but the

1493 epifauna list is short relative to that for soft substrates due perhaps to the difficulties in sampling 
1494 this habitat type. These habitats can be viewed as "intermediate", as they are neither soft enough

1495 for effective grab samples to be taken nor flat and smooth enough for visual transect surveys.

1496 Much of the fauna is interstitial (ie. living between sediment particles) and there is no efficient

1497 way to sample them. Similarly, while trawls may collect some epibenthic forms, both the nets

1498 and the captured biota are prone to damage by cobble and gravel substrates. Bottom sampling is

1499 further hampered by the fact that these habitats are usually very high current areas. Hence, there

1500 is very little information about these habitats in the SoG, and none of the information available is

1501 quantitative.

1502

$1503 \quad$ 2.2.4.1 Shallow $(0-30 \mathrm{~m})$ cobble, gravel and coarse sand

1504 In shallow depths in the SoG, these coarse substrates are found most often on high energy or 1505 exposed to semi-protected areas, extending from the intertidal to the shallow subtidal. An

1506 example of such a habitat is given in Seacology et al. (2001) and Burd and Glaholt (2000), but it

1507 is noted in both studies that the cobble or gravel does not extend very far below the intertidal,

1508 and tends to occur in patches along with coarse sand. These habitats are usually non-depositional

1509 but may be influenced by seasonal onshore/offshore movement of material due to storm events

1510 and strong currents. In addition, periodic storms may lead to patches of storm or tidal debris

1511 (organic and inorganic) which are usually transitory. If these shallow habitats are not too high

1512 energy, seasonal macroalgae such as the brown algae Laminaria, Costaria and Desmarestia may

1513 be dense along with patches of bull kelp (Seacology et al., 2001) along with epifaunal grazers. A

1514 variety of mobile epifauna are found in these habitats, including amphipods, sea stars,

1515 nudibranchs, gastropods, echinoids and large mobile polychaetes, shrimp and crabs, and is also

1516 noted to be a nursery habitat for juvenile Pacific cod. Sessile invertebrates attached to the larger 
1517 substrate particles include bryozoans, hydrozoans, small sponges and anemones. If the sand

1518 content is high, deep burrowing bivalves may occur. However, in larger particle mixes (gravel,

1519 small cobble), near-surface bivalves may be common, and shell debris extensive. Coarse,

1520 unconsolidated habitats, if stable, can have extensive macroalgal growth seasonally, with all the

1521 associated grazing, epiphytic and epifaunal biota associated with it. Typically, this may include

1522 extensive bryozoan (in shallow, near-subtidal) and hydrozoan growth, shrimp, crabs, amphipods

1523 and other crustaceans, nudibranchs, gastropods, sea-stars and sea-urchins, with anemones, small

1524 sponges and tunicates attached to larger, stable debris. One common bivalve which can be seen

1525 "walking" through coarse sands is Tellina sp., which can be found intertidally to subtidally in

1526 Hecate Strait and throughout southern Alaska, BC and Washington State. Other, larger

1527 echinoderms may be present in coarser debris, such as the sea-cucumber Parastichopus sp.

\section{$1529 \quad$ 2.2.4.2 Mid-depth $(30-100 \mathrm{~m})$ cobble, gravel and coarse sand}

1530 Cobble, gravel, and coarse sand habitats below $30 \mathrm{~m}$ water depth are rare in the SoG, with the

1531 exception of very high energy environments such as tidal channels, on fjord sills, and high

1532 current areas. Because of the size of the substrate particles, these habitats are relatively

1533 physically stable, although they may be mobile in rare, large storm events. Suspended particles

1534 may be extensive, given the high energy nature of these habitats. Generally, the faunal

1535 community in these habitats includes mobile epifauna (e.g. sea stars, nudibranchs, gastropods,

1536 amphipods), as well as "surface film" grazers and attached forms (e.g. hydroids, small sponges,

1537 anemones) on the larger sediment particles (see Farrow et al., 1983). 
1539 An example of mid-depth coarse habitats is the sill of Knight Inlet, which is located immediately 1540 north of the SoG. The Knight Inlet sill is also a tidal channel, with coarse sand, gravel and large

1541 boulders which can be moved by the strong tidal currents (see Farrow et al., 1983). Tunnicliffe

1542 and Syvitski (1983) describe how large gorgonian corals attached to boulders provide "windage"

1543 which contributes to the transport of boulders in this area. The authors found that these rare

1544 habitats may contain typical rock cliff epifauna occurring in patches but, unlike cliff fauna, the

1545 forms are usually encrusting which may be related to the potential physical damage caused by

1546 the moving boulders and high currents. The distribution of the large planktivorous corals was

1547 patchy but the organisms were most concentrated on the sill crest, where the zooplankton were

1548 visually dense (Tunnicliffe and Syvitski, 1983). The level of heterogeneity within this type of

1549 habitat will determine the abundance of small mobile fauna that like to hide, such as shrimp and

1550 small crabs.

1552 Although the extensive outfall monitoring program in outer Burrard Inlet focused on soft

1553 substrate, video assessment of the nearfield substrate revealed the presence of cobble, gravel and 1554 coarse sand substrate (CORI, 2002). Flocculant levels were high in the water column, reducing

1555 visibility. However, large concentrations of the anemone Metridium senile suggested

1556 opportunistic utilization of the suspended organic material (CORI, 2002). Visual surveys by the

1557 Victoria Capital Regional District describe the 40-60 m depth range off southern Victoria near

1558 Clover Point (just outside the SoG, in Juan de Fuca Strait) as cobble-gravel, with extensive horse 1559 mussel and scallop growth (Capital Regional District, 2000). Bernard (1978) listed 2 bivalve 1560 species, (Glycymeris subobsoleta and Mysella tumida) sampled by trawl from gravel substrates 1561 and 6 different species found in rock/cobble substrates. 


\subsubsection{Deep (>100 m) cobble, gravel and coarse sand}

1565 These coarse grained habitats seem to be rare in the deeper parts of the SoG (Fig. 3). It is likely 1566 that these habitats are limited to the few deep, strong tidal channels in the SoG at the north and 1567 south end (Section 1.2) and to areas where debris resulting from cliff erosion has settled at the 1568 foot of steep slopes. These areas have been observed, occasionally, using a submersible (Burd, 1569 unpublished data) and, although most fish farms in BC are located outside the SoG, information 1570 on these habitats under fish farms in the fjords of the SoG may also be archived in ROV video 1571 footage maintained by the provincial Ministry of Environment.

1573 There is very limited information about these coarse habitats and associated biota in depths $>100$

$1574 \mathrm{~m}$ within the SoG. However, it is expected that the faunal communities would be of similar 1575 composition to those described earlier for the mid-depth coarse habitat. The only caveat is that at 1576 these depths, it is likely that organic flux to the bottom is reduced, so that there may not be as 1577 much labile organic suspended material available for bottom organisms. Bernard (1978) 1578 describes invertebrate epifauna from trawls conducted at 100-200 m depths in gravel habitat type 1579 and lists the same two species found in the 20-100 gravel substrates, the bivalve Glycymeris 1580 subosoleta and the crustacean Munida quadrispina. The author lists no species for sampling 1581 conducted in gravel substrates $>200 \mathrm{~m}$. Invertebrate species were more abundant in the 1582 rock/cobbles substrate than in the gravel substrate, but only the cloud sponge Aphrocallistes 1583 vastus, was reported from the rock/cobbles substrate type at $>200 \mathrm{~m}$ depths. As noted earlier, 
1584 archived information on videos from deep ROV work related to fish farms may be one of the 1585 best sources of epifaunal data available.

\subsubsection{Rock (consolidated) Habitat}

In exposed coastal areas, these substrates are subject to very high wind and wave exposure

1591 and/or tidal currents, preventing any deposition. However, in isolated basins such as fjords, the

1592 steep sides prevent accumulation from sedimentation regardless of current conditions. Some

1593 island archipelagos, with no freshwater or nearby glacial deposits, can retain rocky substrates in

1594 lower energy habitats. Although high levels of suspended organic particles occur, depending of 1595 the current regime and organic input, organic flux to the sediments if virtually nil.

1597 Rocky habitats are abundant in the SoG and Levings et al. (1983) note that rocky and sandy

1598 shores combined make up $88 \%$ of the total length of the shoreline (shoreline consists of the 1599 intertidal and subtidal habitats $\leq 20 \mathrm{~m}$ ), while the area of rocky substrate accounts for $\sim 25 \%$ of

1600 the total area (see Section 1.3.1). Many of the SoG's mainland fjords have extensive, near1601 vertical rocky cliffs, limiting the fauna to those that can attach to vertical rock and that can 1602 tolerate sediment deposition. These rock wall communities are dominated by sessile filter 1603 feeding invertebrates or mobile scavengers and predators. Tidal currents in these habitats are 1604 usually low due to the near-vertical walls which don't "channel" or intensify tidal surges. 
1608 The diversity and coverage of rocky shoreline communities is dependant on exposure to waves,

1609 freshwater, salinity, light and currents and is, therefore, seasonally variable. The presence of

1610 crevices or heterogeneous structure for hiding and attachment also affects both the plants and

1611 invertebrates found in these shallow rock habitats. The bottom water in these habitats is usually

1612 highly oxygenated. If there is a rich supply of suspended particulate material, these areas can be

$1613 \sim 100 \%$ covered by sessile invertebrates and plant growth. Seasonal macroalgal cover of

1614 filamentous and bladed red, green and brown algae is extensive in the upper photic zone, with

1615 foliose reds commoner in slightly deeper areas (i.e. $>10 \mathrm{~m}$ ).

1616

1617 The fauna found in these habitats, both sessile and mobile forms, tends to be relatively consistent 1618 throughout the $\mathrm{BC}$ coast. The diverse fauna in these habitats includes bivalves, calcareous tube

1619 worms, ascidians, bryozoans, hydrozoans, small sponges, as well as echinoderms and

1620 crustaceans. Because these rocky habitats have been so well described by scuba surveys at these

1621 shallow depths, the flora and fauna are not described in detail herein (e.g.

1622 http://ilmbwww.gov.bc.ca/lup/coastal/north_island/cortes/docs/2-description.pdf; Levings et al.,

16231983 and references therein). An example of a shallow rock habitat just outside the SoG is Race

1624 Rocks, near Sooke, BC. Race Rocks, a tidally-exposed rocky outcrop in a "clean" environment

1625 which has been well studied using SCUBA. The area has a remarkably rich and diverse flora and

1626 fauna (see Wright and Pringle, 2001 for references) and is a federal marine protected area. The

1627 invertebrate fauna tolerates strong currents and high wave exposure and includes abundant

1628 barnacles, goose-neck barnacles, and mussels, as well as a variety of anemone species, surface-

1629 grazing gastropods, mobile predators such as sea-stars, nudibranchs, crabs and gastropods. 
1631 Shallow rock habitats may be structurally heterogeneous as a result of algal growth and also

1632 from faunal communities such as mussel beds. Up to 300 species have been identified inhabiting

1633 the interstices of established mussel beds (Seed and Suchanek, 1972; Suchanek, 1979) and

1634 species richness has been shown to increase with increasing age and thickness of the mussel bed

1635 (Asmus, 1987; Jamieson et al., 1999; Ragnarsson and Raffaelli, 1999; Smith et al., 2006).

1636

1637 In the deeper, high current areas of shallow rock habitats, bull kelp can form dense forests which

1638 modify currents and light penetration and provide important refugia for fish, as well as food for

1639 sea urchins and other grazers. Sea urchins are known to be a key species which controls and

1640 modifies algal community associations in near-shore rocky habitats on the west coast of North

1641 America (Paine and Vadas, 1969; Duggins, 1981). Abalone may play a similar role but tend to

1642 be less widely distributed in BC coastal waters than are sea urchins due to excessive fishing

1643 pressure over the years (http://www.dfo-mpo.gc.ca/species-especes/species/species

1644 northernAbalone_e.asp).

1645

$1646 \quad$ 2.2.5.2 Mid-depth $(30-100 \mathrm{~m})$ rock (consolidated)

1648 Mid-depth rock habitats in the SoG typically have moderate to steep slopes; accumulation of

1649 deposited material is unlikely to occur on steep slopes but pockets of deposition may occur on

1650 lesser slopes. These habitats are exposed to limited, or no, wave exposure, while levels of tidal

1651 currents vary. Bottom water renewal, and therefore bottom water oxygenation, in these habitats 
1652 in the SoG is variable and depends on the physical topography and, in fjords, also depends on the 1653 depth of the sill.

1654

1655 Because these habitats can only be studied using ROVs or submersibles, they are, therefore, less 1656 well studied than soft substrate habitats at comparable depths. The majority of this research in 1657 the SoG was conducted in the early 1980s, when the research submersible PICES IV was 1658 available through the Canadian Department of Fisheries and Oceans. Much of this research is 1659 published (e.g. Tunnicliffe, 1981; Levings et al., 1983; Tunnicliffe and Wilson, 1988) and 1660 additional, unpublished information is archived in video or still photographic form (Tunnicliffe, 1661 unpublished; Burd, unpublished). The following general descriptions of the faunal communities 1662 in the mid-depth rock habitats of the SoG are based on both sources of data.

1664 The spatial cover by invertebrates in the mid-depth rock habitats does not vary as much 1665 seasonally as it does in shallow subtidal areas. However, there may still be some encrusting 1666 coralline algae present at the shallow end of this depth range, depending on light penetration (e.g. 1667 Farrow et al., 1983; Spalding et al., 2003). Rather, the spatial cover by invertebrates declines 1668 with increasing depth and decreasing oxygen levels in the water. Examples of the mid-depth 1669 rock habitat are the rock cliff walls of fjords in the SoG. These mid-depth habitats contain a 1670 number of species, such as eel-pouts, that are more common in the deep sea. Similarly, sea fans

1671 (gorgonians, soft corals) are common on the walls of some of the SoG inlets (Tunnicliffe, 1981;

1672 Tunnicliffe and Wilson, 1988) but are also found when sampling in the deep water off the

1673 continental shelf. Huge glass sponges, normally associated with polar or deep seas, are also 1674 common in mid-depth rock habitat in the SoG fjords (Tunnicliffe, 1981; Burd, PICES IV- 
1675 unpublished data). Tunnicliffe (1981) describes tube worms, sponges, brachiopods, cup corals,

1676 extensive gorgonian sea fans, anemones and colonial tunicates as some of the dominant sessile

1677 organisms on the vertical rock walls. Some of the larger sponge and erect coral growths are

1678 expected to be very old, as these habitats are typically less susceptible to physical damage than

1679 are level bottom habitats.

1680 Tunnicliffe and Wilson (1988) describe the distributions of 3 species of brachiopods from

1681 Knight, Jervis and Saanich inlets; brachiopods are a ubiquitous group reaching extremely high

1682 densities (average density of $190 / \mathrm{m}^{2}$, maximum density of $945 / \mathrm{m}^{2}$ ) at depths $>30 \mathrm{~m}$ on the cliff

1683 walls of the fjords. Depth ranges were noted for each species of brachiopod. All brachiopod

1684 species seem to be relatively tolerant of low oxygen and a species in Saanich Inlet was found to

1685 be highly tolerant of periodic low oxygen levels down to $0.1 \mathrm{ml} / \mathrm{L}$. Another brachiopod species

1686 from Saanich Inlet was found in abundance in high energy and/or high suspended sediment

1687 conditions. Thus, brachiopods are an important structural component of mid-depth cliff faunas

1688 and may be good indicators of sedimentary conditions. In contrast to brachiopods, bivalves are

1689 almost absent on the vertical cliff walls, suggesting that they do not settle on vertical surfaces. In

1690 addition, as a group they do not seem to be particularly tolerant of low oxygen (see also Burd,

1691 2006).

1692

1693 Several mobile crustaceans are common on, or near, the rocky cliff walls of the fjords at mid-

1694 depth. These areas encompass the prevailing prawn fishery habitats, as the larger pandalid

1695 species tend to be abundant in the rocky crevices and on larger, upright epibenthos. Predatory

1696 crabs are less common in this depth range than in the shallow rocky cliff areas, (Burd,

1697 unpublished), however, a small anomuran crab (Munida quadrispina), with feeding and habitat 
1698 requirements similar to prawns co-exists with the prawns on the cliffs (Burd and Brinkhurst

1699 1984). Examination of prawn catches and habits of prawn fishermen in a series of coastal fjords

1700 in the SoG in 1983/84 (Burd, unpublished) made it clear that when M. quadrispina were

1701 dominant, this necessitated a change in the location for setting traps.

1702

1703 Saanich Inlet and Howe Sound, as noted earlier, can experience severe annual stagnation and this 1704 can lead to mass mortalities of sedentary cliff fauna (Tunnicliffe, 1981) as well as mobile forms

1705 such as prawns and Munida quadrispina (Burd and Brinkhurst, 1984; Jamieson, 1988).

1706 Tunnicliffe (1981) described a high biodiversity in the mid-water cliff assemblage of Saanich

1707 Inlet, however, despite annual low oxygen, M. quadrispina is usually far more abundant in

1708 extreme habitats, such as the very low oxygen areas $(\sim 0.1 \mathrm{ml} / \mathrm{L})$ in Saanich Inlet (Burd and

1709 Brinkhurst, 1984) than in areas with higher oxygen levels. The higher abundance (and lack of

1710 normal territorial and hiding behaviour) of the crabs has been speculated to be related to a lack of

1711 predators in these extreme habitats (Burd and Brinkhurst 1984), whereas the tolerance of very

1712 low oxygen areas is due to unusual respiratory and gill adaptations (Burd, 1985, 1988). In

1713 addition, the pelagic amphipod Orchomene obtusens is found in extremely high numbers on, or

1714 near, the rocky cliffs in hypoxic to anoxic conditions in Saanich Inlet (De Robertis et al., 2001),

1715 where it is extremely efficient at consuming any detrital animal tissue used as bait in traps (Burd, 1716 unpublished data).

1718 Farrow et al. (1983) describe the fauna of the cliff walls in Knight Inlet along vertical cliff

1719 transects which include the mid-depth zone. The along-inlet differences in faunal structure were 1720 compared with a suspended particulate gradient which typifies the faunal changes that are likely 
1721 to occur in areas of high, moderate, and low bottom turbidity from glacial runoff. In the high

1722 turbidity areas, the authors describe the dominant suspension feeders as sabellid worms and

1723 brachiopods (see also Tunnicliffe and Wilson, 1988) which take small particles (<8 $\mu \mathrm{m})$.

1724 Crinoids and gorgonian corals are more prevalent in the moderate tubidity areas and take larger

1725 particles, while barnacles and glass sponges predominant where turbidity is low. In general, the

1726 turbidity, oxygen and organic carbon content of suspended particulates within these habitats play

1727 a significant role in determining which species will dominate. For example, brachiopods are

1728 tolerant of relatively low oxygen conditions and can also tolerate relatively high turbidity.

1729 Passive feeders, such as sponges, require some current movement for adequate feeding, but may

1730 be tolerant of low oxygen (e.g. Tunnicliffe, 1981), and are usually found in deeper regions in

1731 more quiescent waters (Tunnicliffe, 1981; Farrow et al., 1983) with limited sediment deposition

1732 (Farrow et al., 1983 and see below).

1733

1734 A bottom hexactinellid sponge reef has been recently discovered at an unprecedented shallow

1735 depth of about $60 \mathrm{~m}$ near the sill of Howe Sound (see Cook et al., in press). Most of these reefs

1736 in the Strait are deeper than 120 m, making this location unusual. This reef has not been visually

1737 surveyed yet. A description of other, deeper reefs in the Strait is given in the next section.

1738

1739 2.2.5.3 Deep (>100 m) rock (consolidated)

1740

1741 While deep subtidal rock habitats in the main basin of the Strait of the Georgia are mostly

1742 confined to elevated rocky outcrops on the bottom of the basin (evident in detailed multibeam

1743 and side-scan sonar transects e.g. Conway et al., 2007), these habitats are often dominant in 
1744 many of the steep-sided fjords. Many of the SoG fjords are much deeper (up to $800 \mathrm{~m}$ ) than the

1745 adjoining continental shelf ( $<400 \mathrm{~m}$ deep), with extensive rock cliffs. The same limitations for

1746 studying the mid-depth rock habitats, discussed earlier, apply to these much deeper habitats.

1747

1748 In deep rock habitats that are "flushed", bottom currents are generally low to moderate. Bottom

1749 water oxygen is likely to be moderate. Spatial cover of sessile invertebrates on these "flushed"

1750 rock substrates is moderate to low, declining with increasing depth and decreasing oxygen levels

1751 and is also related to current levels. The faunal composition does not necessarily change

1752 significantly from that described for mid-depth rock habitats except that, as suspended organic

1753 material and oxygen levels decline with increasing depth, spatial coverage may decrease and

1754 some organisms or trophic forms may decline while other, more tolerant forms increase. For

1755 example, as noted earlier, prawns decline with increasing depth and anemones such as Metridium

1756 senile are not found below 80-100 m (Tunnicliffe, 1981; Burd, unpublished data). The faunal

1757 community may include calcareous tube worms, brachiopods, ascideans, hydrozoans, small

1758 sponges, boot and cloud sponges, gorgonian and small corals, large plumose anemones and

1759 tunicates.

1760

1761 It should be noted that deep rock habitats in the SoG are also found on the walls of isolated

1762 fjords in stagnant basins. The water column in the deep rock habitats in the fjords may flush

1763 seasonally or only occasionally. Generally, the rock may be too steep for sediment accumulation

1764 but small pockets of organic material may accumulate in crevices and became suboxic or anoxic

1765 with filamentous bacterial mats. In these low current areas, the rock is usually minimally

1766 colonized with numerous areas of bare rock. As mentioned for mid-depth rocky areas, the fauna 
1767 in these deep stagnant areas may include small anemones, encrusting sponges and brachiopods,

1768 as well as specialized mobile predators (e.g. amphipods, M. quadrispina) (Burd and Brinkhurst, 1769 1984).

1770 An interesting example of the deep, rocky habitat is the relatively recently discovered deep rocky

1771 outcrops or reefs in the SoG that are covered in hexactinellid sponges (predominantly

1772 Heterochone calyx and Aphrocallistes vastus) or in a few cases, scleractinian coral reefs

1773 (Lophelia pertusa) (Conway et al., 2007). There are nine confirmed glass sponge reef complexes

1774 in what Thomson (1998) describes as the central Georgia Basin (Fig. 1). Each of these sites has

1775 been surveyed using multibeam acoustics and ground truthed using remote video techniques by

1776 the Geological Survey of Canada. There are a further 3 sponge reefs which have been located by

1777 multibeam and seismic surveys but which have not yet been visually examined using video

1778 (Conway et al., 2007). Of the nine reefs which have been visually surveyed, only three are in

1779 good health, with consistent areas of live reef-building sponges (Cook et al., in press). The three

1780 healthy reefs are located on rock pinnacles well above the surrounding seafloor, where bottom

1781 trawling is not feasible. The other six appear to have suffered extensive mechanical damage

1782 resulting in large areas of fragmented sponge skeleton, with 3 reefs showing some evidence of

1783 re-growth. (Cook et al., in press). ). Conway et al. (2007) concluded that there has been

1784 considerable damage to the reefs in the SoG from trawling and possibly from ocean dumping and

1785 increased siltation in the southern areas. There is a marked difference in terms of abundance and

1786 diversity of rockfish on the healthy and damaged reefs, illustrating that these are likely important

1787 refugia for deep reef fish. An ecological description of these reefs is in Cook et al. (in press),

1788 including the current state of their health and faunal associations. 
1790 It is well documented that hexactinellid sponge communities, such as those found in deep rock

1791 habitats in the SoG, modify the environment around them. Bathyal environments in particular are

1792 enriched by enhanced supplies of organic matter associated with sponges and their spicule mats

1793 (Bett and Rice, 1992). In the Antarctic, Barthel, (1992) documented species-rich associations of

1794 sponges in areas of sponge spicule mats. These reefs trap fine sediments and provide habitat for

1795 annelid worms, bryozoans, bivalves, gastropods, rockfish, crabs, shrimp, prawns, sea stars, sea

1796 urchins and ophiuroids. In other areas of the world, hexactinellid sponges provide habitats for

1797 new and rare species, including numerous species of shrimps in the Bahamas (Berggren, 1993),

1798 Hawaii (Baba, 1983), New Zealand and South Africa (Bruce and Baba, 1973), and in the East

1799 China Sea (Hayashi and Ogawa, 1987). Their locally limited distribution and potential biological

1800 importance as refugia in the SoG warrant protection (Conway, 1999; Conway et al., 2001;

1801 Krautter et al., 2001).

1802

1803 Underwater cables provide hard substrate in deep water, albeit of anthropogenic origin. Levings

1804 and McDaniel (1974) describe encrusting macro-invertebrates collected off a deep-water

1805 telephone cable across the main basin of the SoG. This habitat appears to be a "refugia"

1806 containing fauna that are found on the steep rocky cliffs of the surrounding basin shoreline. The

1807 authors note that most of the deeper, hard-substrate species such as sponges, brachiopods and

1808 gorgonian corals were not present on the cables on the eastern side of the SoG (Point Grey),

1809 probably due to heavy sedimentation from the Fraser River. Even in these high sedimentation

1810 areas, however, several anemones, such as the ubiquitous and relatively tolerant Metridium

1811 senile, were found on the cables. 


\section{3. Anthropogenic Influences}

1815 Section 2 reviewed invertebrate communities likely to occur in a variety of undisturbed habitats

1816 (different depths and substrates) within the SoG. In this section, changes to habitats and

1817 invertebrate fauna found in areas of anthropogenic influence are examined and placed within the

1818 context of background biotic conditions in the SoG. Following a brief summary of

1819 anthropogenic sources and recognized influences of the type of major sources in the SoG,

1820 additional detail is provided on each source including case studies where appropriate. It should

1821 be noted that while input from some anthropogenic sources may affect intertidal or shallow

1822 subtidal areas, most of the major discharges into the SoG are deeper than the shallow subtidal

1823 (i.e. $>30 \mathrm{~m}$ ) and, consequently, habitats monitored for anthropogenic change also tend to be $>30$

1824 m depth (mid- to deep subtidal).

1825

1826 The primary sources of anthropogenic influence in the SoG are municipal waste water outfalls

1827 (marine and along the Fraser River), ocean dumping sites (dredged material primarily from

1828 Burrard Inlet and terminal areas along the eastern margin of the southern Strait), pulp and paper

1829 mills, as well as runoff and discharges from agriculture and other industries along the Fraser

1830 River and Burrard Inlet. Localized sources of anthropogenic influence to marine habitats within

1831 the SoG include a small number of fish farms in several mainland fjords, log-booms, marinas,

1832 loading docks for industry, and stream runoff. While a large number of beach and near-shore

1833 shellfish aquaculture sites are located in the SoG, research into the potential impacts of these

1834 farms on benthic habitats and invertebrate community structure started only recently (e.g.

1835 Carswell et al., 2006) and, hence, the potential impact of these farms is largely unknown. 
1836 Although the biotic effects of these localized small inputs can be varied and difficult to

1837 encapsulate, available studies on these inputs are summarized briefly in this review (and see

1838 Levings et al., 1983).

1839 Although the majority of the anthropogenic influences in the SoG include an organic enrichment

1840 component, virtually all of these influences also include some level of sediment contaminants

1841 which can make it difficult to determine causality. A huge literature on sediment and pore-water

1842 toxicity, much of it laboratory-based, illustrates the on-going struggle with these issues in the

1843 scientific community (Wang and Chapman, 1999; Burgess, 2000; Long et al., 2001). Burrard

1844 Inlet, the major harbour for Vancouver, provides an example of a body of water in the SoG that

1845 is subject to numerous sources of anthropogenic input. The proceedings of an international,

1846 cooperative research workshop in Burrard Inlet (Stehr and Horiguchi, 2001) include a summary

1847 of the discharges and contaminant sources in the inlet (Levings and Samis, 2001). This inlet

1848 receives the discharge from a major primary-treatment municipal wastewater outfall, about 32

1849 combined sewer overflows (CSOs) (GVRD, 2004), and 36 permitted industrial or municipal

1850 discharges (Levings et al., 2004). Several of the more isolated sections (or arms) of Burrard Inlet

1851 are considered to be severely chemically polluted by hydrocarbons (Yunker et al., 1999) and

1852 organically enriched (Burd and Brinkhurst, 1990). The multitude of discharges, along with

1853 complex hydrographic conditions, has made the design of monitoring programs for specific

1854 discharges in the Inlet challenging (c.f. McPherson et al., 2007b). Similarly, Howe Sound has

1855 been subject, historically, to notable industrial inputs including a chlor-alkali plant (mercury

1856 discharge) and a copper mine with contaminated tailings and acid drainage issues which are still

1857 evident many years after cessation of operations (Hagan et al., 2004). Contaminant inputs and 
1858 transport from these sources were reviewed by Macdonald and Crecelius (1994), West et al.

1859 (1994) and see Johannessen et al. (in press).

1860 Despite the confounding influences described above, however, certain patterns of benthic faunal 1861 response seem to be common to all organic enrichment inputs in British Columbia regardless of 1862 contaminant input (Cross, 1990; Burd, 1997; Brooks, 2001; Burd 2003a,b,c; Cross et al. 2005;

1863 Golder Associates Ltd., 2005; Burd, 2006; McPherson et al., 2007a, b; EEM monitoring data 1864 www.ec.gc.ca/eem/english/PulpPaper/default.cfm; ).

1865 Biotic responses in marine sediments to conditions resulting from extreme organic loading have 1866 been described by Pearson and Rosenberg (1978). Based on this model, when sulphides are high 1867 and/or sediments are anoxic to depth, most fauna disappear. When these sediment conditions 1868 occur, white fibrous mats of sulphur-fixing bacteria (e.g. Beggiatoa spp.) may become extensive 1869 on the seafloor. In addition to high sulphides, however, the bacteria need oxygen from the 1870 overlying water for metabolism and, therefore, these mats occur only at the oxidation-reduction

1871 (redox) boundary (Møller et al., 1985), making them a good indicator of underlying anoxic 1872 sediments or, in rocky areas, of an anoxic near-bottom boundary layer. In fact, the presence and 1873 extent of Beggiatoa mats is used as a monitoring indicator of benthic condition for fish farms in 1874 BC (MWLAP, 2002). The few organisms that can survive, or sometimes even thrive, in these 1875 conditions include certain mobile epibenthic forms such as demersal amphipods and squat 1876 lobsters (Burd and Brinkhurst, 1984), as well as burrowing organisms that can maintain access to 1877 the oxygenated overlying water, some of which may have a high tolerance to sulphide (Brooks, 1878 2001). Despite these organisms, however, infaunal production is typically low in extreme 1879 environments due to loss of most of the macrofauna and energetic constraints on microfauna 
1880 utilizing energy resources without available oxygen (Emerson and Hedges, 2003). In rocky

1881 habitats, most fauna will disappear, with the possible exception of some tolerant cup corals

1882 (Tunnicliffe, 1981). Examples of benthic environments in the SoG where anthropogenic inputs

1883 causing these conditions may arise or have been recorded include municipal wastewater outfall

1884 receiving environments (Capital Regional District 2003; 2004; 2005 and

1885 www.crd.bc.ca/wastewater/marine/reports.htm; McPherson et al., 2007a, b); log boom areas

1886 (Conlan and Ellis, 1979; Sibert et al., 1979; Sibert and Harpham, 1979; McGreer et al., 1984),

1887 the close vicinity of some fish farms (Brooks, 2001; Burd, 2006; Wright et al., 2007a-e), and

1888 areas subject to pulp and paper mill effluent (www.ec.gc.ca/eem/english/PulpPaper/default.cfm).

1889 These extreme conditions can also occur naturally in stagnant fjord basins (e.g. Saanich Inlet,

1890 Section 1.2).

$1892 \quad$ 3.1 Marine Outfalls

1893 Benthic sediment and biological monitoring for the marine receiving environments of the Metro

1894 Vancouver (formerly the Greater Vancouver Regional District GVRD) outfalls that discharge 1895 into the SoG (Iona and Lions Gate) also encompasses the marine discharge zones of the other

1896 three outfalls along the Fraser River (Annacis, Lulu Island and Langley - GVRD 2004). These

1897 monitoring programs have essentially provided the bulk of present-day information about

1898 benthic infauna and habitats along the southeastern margin of the SoG (see McPherson et al.

1899 2007a, b). The Iona outfall monitoring grid is along the $80 \mathrm{~m}$ depth contour (Figure 1) straddling

1900 the mouths of the Fraser River. The Lion's Gate monitoring grid encompasses all of the outer

1901 Burrard Inlet to 1st Narrows (Figure 1).

1902 
1903 Harrison et al. (1999), reviewing the heavy metal and organic contamination along the foreshore

1904 of the Fraser River, found that most of the contamination in this area came from heavy

1905 deposition of Fraser River sediments which had run the gauntlet of contamination sources.

1906 However, at the north end of the delta, there was a fairly large historical (1962-1988) wastewater

1907 discharge in the near shore. Harrison et al. (1999) showed that in the area of historical

1908 wasterwater discharge (which also receives about $15 \%$ of the industrial and municipal wastes

1909 from the Fraser River), there is evidence of long term recovery in terms of organic loading, as

1910 well as primary and secondary production of the benthos. Two moderately abundant invertebrate

1911 indicators, the amphipod Corophium salmonis and the bivalve Macoma balthica, were selected

1912 for measurements of biomass/production and growth, and were used to demonstrate the recovery

1913 from basically azoic conditions (i.e. no life) to background conditions typical for the area. The

1914 historical wastewater discharge noted above was replaced in 1988 with the Iona deep-sea outfall,

1915 with diffusers which discharge along the slope fronting the Fraser River discharges.

1916

1917 The deposition model of Hodgins and Hodgins (2000) for the Iona outfall effluent solids

1918 suggests that maximum deposition of outfall particulates occurs between 60-90 $\mathrm{m}$ depth along a

1919 primarily north and secondarily south gradient away from the outfall. This model provided the

1920 basis for a revised monitoring program for the outfall from 2000 onward (2WE Consulting,

1921 1999). The maximum deposition zone corresponds to clear patterns in sediment chemistry and

1922 geochemistry, including moderate organic enrichment (Burd, 2003b). The long-term monitoring

1923 data for Iona (see McPherson et al., 2007a) clearly show subtle changes in biotic conditions

1924 within a $3 \mathrm{~km}$ zone north of the outfall, which corresponds to the maximum deposition zone for

1925 outfall particulates (Hodgins and Hodgins, 2000). Within this same area, clearly related to the 
1926 outfall, there is low to moderate biotic impoverishment (GVRD, 2004) and a modest

1927 enhancement of polychaete species know to be opportunistic in areas of organic enrichment.

1928 These changes can be explained by increased organic loading alone, with no evidence of biotic

1929 effects related to contaminants (Burd, 2003b). Certain contaminant inputs from the outfall are

1930 discussed in more detail in Johannessen et al. (in press) and Macdonald et al. (in press).

1931 Surrounding the impoverished zone is a region with less deposition of particulates that has no

1932 notable biotic impoverishment and shows enrichment of some taxa. Echinoderms and

1933 crustaceans, the taxa which are most impoverished in the maximum deposition zone, tend to

1934 have enhanced abundance in this enrichment zone (Burd, 2003b; McPherson et al., 2007a).

1936 To the south of the outfall, where no outfall particulates deposition can be detected, a range of

1937 background biotic conditions provides context for the changes found within the two "effect"

1938 zones. Interestingly, however, biotic impoverishment within this background area can be similar

1939 to, or greater than, that found in the maximum deposition zone. This impoverishment does not

1940 co-occur with organic enrichment, or any contaminant loading, but seems, rather, to be

1941 characteristic of on-going and patchy physical disturbance of the sediment surface (Burd, 2003b,

1942 McPherson et al., 2004b).

1943

1944 McPherson et al. (2007a) includes a time-scale comparison of biotic and geochemical conditions

1945 which clearly show that both have remained relatively stable throughout the Iona outfall

1946 monitoring region since 2000, including consistently low total organic carbon levels in sediments

1947 throughout the monitoring grid, along with modest geochemical buildup of sulphides in the

1948 maximum deposition zone The reason for the uniformly low organic carbon levels is mostly the 
1949 high loading of inorganic material from the south arm of the Fraser River, which tends to 1950 continually bury the organic input, keeping the entire system in a relatively steady state.

1951 However, rapid oxidation of carbon at this location (Wright et al., in press) from benthic

1952 organisms may also contribute to the stable sediment conditions. In the maximum deposition

1953 zone, infaunal biomass does not show any clear or consistent depression, but the community is

1954 conspicuously devoid of echinoderms and infaunal amphipods (Burd, 2003b; McPherson et al., 1955 2007a).

1956

1957 In support of the monitoring program for the receiving environment of the Lions Gate

1958 Wastewater Treatment Plant Outfall located at $1^{\text {st }}$ Narrows (Fig. 1), the Greater Vancouver

1959 Regional District has conducted annual biological monitoring in outer Burrard Inlet since 2002.

1960 Prior to that, historical data from the Inlet had been collected by Environment Canada (c.f. Boyd

1961 et al., 1998, and references therein) and the Department of Fisheries and Oceans (Burd and

1962 Brinkhurst, 1990; Cross and Brinkhurst, 1991; Burd, 1992; Je et al., 2003). Although the earlier

1963 work is not directly comparable to the GVRD monitoring due to differences in sampling

1964 protocols, a comparative assessment of the historical biotic conditions and geochemical sediment 1965 conditions of the outer Inlet was conducted by Burd (2004).

1966

1967 Both the deposition model of Hodgins et al. (2000) for the Lions Gate effluent solids and 1968 analysis of cores taken in 2004 (Burd, 2004) suggest that some material from the outfall is 1969 carried along the north shore of outer Burrard Inlet before settling offshore near the mouth of the 1970 inlet (Fig. 1). The model predicts that the remaining material will go into the inlet, past $1^{\text {st }}$ 
1971 Narrows (Inner Burrard Inlet), under specific tidal conditions, although sediment sampling has 1972 not confirmed this.

1974 Unlike the receiving environment of the Iona Deep-Sea Outfall, where sediment chemistry and 1975 biota clearly show identifiable changes which can be directly related to the deposition of 1976 particulates from the outfall, no biotic changes which can be related to the discharge from the

1977 Lions Gate Outfall have been detected (McPherson et al., 2007b). This is partially because the 1978 outer Burrard Inlet is very well mixed and flushed (Thomson, 1981), and partially because there 1979 are numerous sources of anthropogenic discharge into the water body which can cause 1980 conflicting signals in sediment chemistry. Beyond First Narrows, the inner Inlet is particularly 1981 prone to the conflicting signals due to the greater intensity and frequency of various urban and 1982 industrial discharges than are found in the outer Inlet (GVRD, 2004). Sediment organic 1983 enrichment accompanied by sporadic elevated levels of typical sewage indicators or tracers (i.e. 1984 acid volatile sulphide, total organic carbon, sediment fecal coliforms, silver, 4-nonylphenol, 1985 coprostanol) do occur along the north shore of the outer inlet (McPherson et al., 2007b), with 1986 these effects decreasing with increasing distance offshore. Biotic changes in these areas have 1987 been noted, but are minor (McPherson et al., 2007b).

1989 One location in the Burrard Inlet monitoring program, beyond First Narrows (in the inner inlet), 1990 has consistently shown more extreme organic enrichment and biotic impoverishment than any 1991 location in the outer inlet. Despite this, sewage indicators (e.g., silver, 4-nonylphenol and 1992 coprostanol) are not elevated, suggesting that sediment conditions are unlikely caused by the 1993 Lions Gate Outfall. Instead, combined sewer overflows are a potential source of the organic 
1994 enrichment which could be related to the biotic changes in the inner harbour (GVRD, 2004),

1995 although multiple discharges in the area make it difficult to determine the source or sources.

1997 A detailed analysis of sediment and outfall effluent metals data for 2002 and 2003 by Paine

1998 (2003 q.v. GVRD, 2004) suggested that elevated levels of some metals in outer Burrard Inlet are

1999 not likely related to the Lions Gate outfall, and are present at levels and in a form which should

2000 be biologically unavailable. Other metals are present below levels expected to cause any

2001 biological toxicity, based on Canadian Environmental Quality Guidelines (CCME, 1999).

2002

2003 Although technically not in the SoG, Victoria's Macaulay Point and Clover Point outfalls have

2004 been extensively studied and the long-term data on the benthos provide important context for

2005 similar habitats in the SoG. Also, despite the fact that the depth and current regime trap the

2006 plumes, suggesting that material from these outfalls is not likely to enter the SoG, there are times

2007 when the plumes have been known to surface so that any dissolved organics or contaminants in

2008 the upper water layer could enter through Haro Strait and eventually find their way to sediments

2009 in the SoG (Thomson, 1981) (also see Section 1.2). For that reason, information about the

2010 benthos near these two outfall areas is covered briefly below.

2011

2012 Victoria's Macaulay Point is an area of sandy substrate and high current that receives only

2013 screened (i.e. primary treatment) wastewater that is discharged at an approximate mean depth of

2014 60-65 m. The Clover Point outfall in Victoria discharges at a similar depth but into a rocky,

2015 cobble environment that is dominated by a horse mussel (Tressus tapyx) community (Capital

2016 Regional District, 2000). Environmental monitoring of the benthic receiving environment at 
2017 both of these major Victoria outfalls has been conducted since the early 1970s (Balch et al.,

2018 1973; 1975), with a revision of methods and quality control initiated in 2000

2019 (http://www.crd.bc.ca/es/environmental_programs/wastewater_marine/macaulay/reports.htm).

2020 Numerous reports have been prepared by consultants on the results of this monitoring, along

2021 with annual monitoring reports (Capital Regional District, 2003, 2004, 2005; Paine, Ledge and

2022 Associates, 2004), along with a recent review of the Liquid Waste Management Plan and

2023 seafloor triggers by Stubblefield et al. (2006). Burd (2003c) reviewed the 1994 to 2001 data on

2024 benthic infauna and sediment geochemistry from the Macaulay Point outfall area and reported

2025 that the monitoring data show some faunal effects, but severe biotic degradation is not occurring

2026 in the vicinity of this outfall. Although, based on the available data, it is impossible to determine

2027 what toxic contamination effects may be important to the fauna of the receiving environment, the

2028 patterns of faunal change relative to the outfall strongly suggest that sediment geochemical

2029 changes and particle size are the predominant factors affecting faunal composition (Burd,

2030 2003c). The sampling stations are situated radially around the outfall along a spatial gradient to

2031 800m distant, with diminishing biotic and geochemical impacts to this distance in the E and SE

2032 (Burd, 2003c).

2033

2034 The biotic monitoring at the Clover Point outfall consists entirely of growth and condition factors

2035 for the dominant species, horse mussels. The hard substrates in this environment do not lend

2036 themselves to sediment sampling. Historically, the mussels within $800 \mathrm{~m}$ of the outfall tend to

2037 show a declining gradient of enhanced growth compared with reference locations

2038 (www.crd.bc.ca/wastewater/marine/ reports.htm). 


\subsection{Ocean Disposal Sites}

2041 There are 11 designated ocean disposal sites regulated by Environment Canada in the SoG.

2042 Locations and annual dumping volumes for these sites are available at the Environment Canada

2043 website (http://www.pyr.ec.gc.ca/disposal_at_sea/sitemap_e.htm). The site also contains links to

2044 monitoring reports for all the sites over time. A brief overview of ocean dumping in BC is given

2045 in Ellis (1982), but there is almost no biological monitoring data from dumpsites in the SoG,

2046 except for the Point Grey dumpsite. Side-scan mosaicing has been proposed as an efficient

2047 method of monitoring new debris accumulation and dispersal at ocean disposal sites (Mosher et 2048 al., 1997).

2049 The Point Grey disposal site, outside Burrard Inlet on the southeast side of the Strait, is the 2050 largest multi-user site in BC. This site has been in continuous use since the 1930s, and has been 2051 regulated by Environment Canada since 1975. Wilson and McKinnon (2003) reviewed the 2052 history, sediment and benthos monitoring data gathered for the Point Grey site from 1975 through 2053 2001. The site is between 230 and $250 \mathrm{~m}$ deep, with $80 \%$ of the sedimenting material from 2054 dumping and most of the remainder from the Fraser River discharge. In the late 1970s there was 2055 clear evidence of material from Burrard Inlet dumped outside of, en route to, the disposal site 2056 and evidence of this trail was still present in the early 1990s (see Mosher et al., 1997 and 2057 www.gsc.nrcan.gc.ca/marine/gbgi/proj_ptgrey_e.php). In addition, detailed investigation of 2058 polycyclic aromatic hydrocarbon (PAH) signatures based on area-wide data suggested that 2059 recently dumped contaminants from Burrard Inlet were evident at the north end of the Iona 2060 outfall monitoring transect (80 m depth) in 2000 (Yunker, 2000; Yunker et al., 2000), well 2061 outside the ocean disposal boundaries. 
2062 Benthic infaunal surveys were conducted periodically at the Point Grey disposal site (most

2063 recently in 1994) but sampling effort and taxonomic work varied considerably (Wilson and

2064 McKinnon, 2003). The accumulated material is presently significantly coarser than the

2065 surrounding area, probably due to winnowing and transport on the way to the bottom. Despite

2066 the limitations to interpretation imposed by taxonomic effort and quality control, and

2067 modification of substrates within the dumpsite, Wilson and McKinnon (2003) concluded that the

2068 Environment Canada monitoring data on benthic invertebrate biota did not show notable

2069 differences from biota found outside the dumpsite; for a guideline, the authors used the range in

2070 values expected within reference conditions for the Benthic Response Index (BRI) from the

2071 Southern California Coastal Water Research Project (SCCWRP). Unfortunately the BRI is

2072 based on local species-specific data, whereas the Point Grey biotic data were for different species

2073 identified only to the family level or higher, thus making extrapolation to the BRI problematic.

2074 Probably more convincing is the fact that on-going visual surveys (see below) show that the

2075 disposal site has historically been dominated by a range of polychaete taxa and had numerous

2076 burrowing and near-surface, echinoderms and amphipods, both of which groups are known to be

2077 sensitive to contamination and organic enrichment, as well as unusually high sedimentation

2078 (Burd, 2003b).

2079 At the Point Grey disposal site, ROVs equipped with video and still cameras are used

2080 periodically to record images of the disposal site and the surrounding ocean floor (Wilson and

2081 McKinnon, 2003). Predetermined track lines plotted across the disposal site are followed by the

2082 ROV and continuous images of the ocean bottom are recorded. These visual images aid in the

2083 qualitative evaluation of the disposal site environment. ROV surveys show that the dumping of

2084 debris (e.g. logs, wire and construction materials) has created a more heterogeneous habitat than 
2085 would normally be present at this depth, resulting in an artificially increased biodiversity of hard 2086 and soft substrate fauna.

\section{3. 3 Pulp and Paper Mills}

2089 Macdonald et al. (1991) concluded that the pulp and paper mills in the SoG and surrounding

2090 fjords were contributing significantly to organic carbon input into the sediments of the Strait.

2091 Since then, the draft Pulp and Paper Effluent Regulations (PPER) were promulgated by

2092 Environment Canada in 1992, put into effect in 1996 and revised in 2004 (Regulations

2093 Amending the Pulp and Paper Effluent Regulations, (RAPPER), in order to reduce and control

2094 emissions (http://www.ec.gc.ca/nopp/pandp/en/p2004Letter. cfm). There are 6 operating pulp

2095 and paper mills which discharge effluent into marine subtidal habitats in the SoG and which are

2096 regulated by Environment Canada under the PPER. The mills in the Strait are shown in Fig. 1

2097 (Crofton, Harmac, Elk Falls, Powell River and two in Howe Sound). Monitoring takes place

2098 from $30 \mathrm{~m}$ to $135 \mathrm{~m}$ depth and all but one of the mills discharge primarily into soft substrates

2099 ranging from 98\% sand to 98\% silt/clay (http://www.ec.gc.ca/EEM/English/PulpPaper

2100 Igeneral.cfm). The Elk Falls mill discharges onto hard substrates and the Environmental Effects

2101 Monitoring (EEM) program for that mill focuses on invertebrate communities found in intertidal

2102 Fucus beds (www.ec.gc.ca/eem/English/PulpPaper/ data/showinfo.cfm?Mill_id=PP1122).

2104 The current Environmental Effects Monitoring (EEM) program for the pulp and paper mills has

2105 now completed 3 cycles: 1996, 2000 and 2004. Data collection for cycle 4 is complete and

2106 reports have been submitted to Environment Canada but are not yet publicly available. The EEM

2107 program and technical guidance for monitoring are available at http://www.ec.gc.ca/EEM/ 
2108 English/PulpPaper/general.cfm, including the national database of benthic infauna and habitat

2109 conditions.

2110

2111 Results from Environment Canada's national synthesis reports available on the website show that

2112 although effluent quality from pulp and paper mills has vastly improved since initiation of the

2113 PPER (following the EEM cycle 1), effects on benthic invertebrates and fish are still observed.

2114 Some pulp and paper mill reports suggest that current effects on marine benthos are still related

2115 to historical deposition and that current inputs are much less of a problem. Aside from organic

2116 enrichment, the accumulation of wood fibre mats, organochlorines and dioxins/furans have been

2117 historical problems. Although the organic contaminants mentioned are now controlled (or

2118 banned) substances, their historical presence in these sediments suggests that they are still

2119 cycling through the food chain in the vicinity of pulp and paper mills.

2121 The aforementioned synthesis reports further suggest that while eutrophication of the water

2122 column is the dominant factor affecting freshwater benthos exposed to pulp and paper mill

2123 effluent input, the typical response of biota in marine/estuarine benthic habitats is a decrease in

2124 abundance and richness of taxa that is more indicative of toxic, or smothering, effects

2125 (http://www.ec.gc.ca/EEM/English/PulpPaper/general.cfm). Near mill discharges, elevated C/N

2126 ratios $(>15)$ are common while sediment sulphides are not particularly elevated in comparison,

2127 for example, with fish farm sediments (Burd, 2006). However, a re-examination of the EEM

2128 cycle 3 data from the SoG shows no trends in species richness or abundance related to distance

2129 from the discharge, sediment redox, sulphides, TOC or $\mathrm{C} / \mathrm{N}$ ratio (Burd, unpublished data). 
2130 However, there is some indication that taxa number and abundance decline with increasing

2131 depth, as found overall in the SOG data (Burd et al. in press; see Section 2).

2132

2133 Although the pulp and paper mills in the SoG appear to have no gross impact on subtidal

2134 infaunal benthos, this should not be interpreted to mean that the mills are not affecting the

2135 benthos; for example, quality control has never been standardized for the taxonomy of the pulp

2136 and paper mills marine EEM (technical guidance document

2137 http://www.ec.gc.ca/EEM/English/PulpPaper/general.cfm).

2139 Environment Canada's EEM program for pulp and paper mills includes one mill site in the SOG

2140 which is predominantly hard substrate and is thus not amenable to the regular infaunal sampling

2141 methods recommended in the technical guidance. Data from the Elk Falls mill includes mixed

2142 studies of Fucus recolonization baskets in some cycles and standard beach quadrat surveys in

2143 others. The recolonization studies show a limited (rapid colonizing) species list of amphipods,

2144 isopods, and nemerteans that is missing the typical hard substrate species such as the molluscs

2145 and polychaetes, and larger predators (http://www.ec.gc.ca/eem/English/PulpPaper/data/

2146 showinfo.cfm?Mill_id=PP1122). The quadrat studies provide a species list much more typical

2147 of Fucus habitats as described in the Shorekeepers lists (http://www.shim.bc.ca/atlases/sk/

2148 main.htm). At present, these studies have not shown any gradient responses in biota to distance

2149 from the discharge. Based on research in the SoG, Bard (1998) describes biotic sensitivities and

2150 a proposed biotic index related to intertidal rocky beach fauna in areas affected by pulp mill

2151 effluent in BC. 
2152 High organic loading from pulp mills and log boom areas is relatively refractory due to the slow

2153 rate of bacterial and invertebrate breakdown of organics. Therefore, the packing of dense debris

2154 typically causes severe sediment deoxygenation without dramatically elevated sulphides in

2155 sediments (http://www.ec.gc.ca/eem/english/PulpPaper/default. cfm; Samis et al., 1999). These

2156 areas may show a generalized depression of fauna (see Burd et al, in press), but be patchy,

2157 depending on deposition characteristics. The benthos may take a long time to recover in

2158 sediments with heavy wood-fibre mats due to the reduced and slow biotic activity, and

2159 sometimes low penetrability by burrowers.

2160 3. 4 Log Booms

2161 Areas of near-shore log booms are common along the SoG coastline. Log storage activities

2162 primarily impact low intertidal and shallow subtidal habitats within estuaries. Impacts include

2163 the physical shading of habitat by booms, leading to decreased primary productivity by algae and

2164 eelgrass (NEMP, 2002). At low tide, the physical grounding and abrasion by log booms result in

2165 compaction of sediments, scouring and physical disruption of habitats, particularly eelgrass beds

2166 (NEMP, 2002). Adjacent intertidal areas can be similarly impacted by escaped logs and

2167 propeller wash from tow boats can scour and increase the levels of suspended sediment in the

2168 water column (NEMP, 2002).

2170 The working of logs against each other within the bundle results in deposition and accumulation

2171 of bark and wood debris on bottom sediments. These deposits are relatively refractory and the

2172 slow rate of bacterial and invertebrate breakdown can cause long-term stress to the benthic

2173 environment as a result of sediment deoxygenation, although sulphide levels are not dramatically 
2174 elevated (http://www.ec.gc.ca/eem/ english/PulpPaper/default.cfm). General biotic effects may

2175 be similar to those described for pulp and paper receiving environments (Section 3.3), although

2176 the deposition of wood debris tends to be coarser and may be much heavier under log booms.

2177 McGreer et al. (1984) examined the recovery of an intertidal community in an area of the

2178 Nanaimo River estuary from which log booms had been removed. At 13 months after removal,

2179 common macro-invertebrate species were those typical of organic enrichment but the overall

2180 abundance was lower than that of the control area. The reduction in abundance was attributed to

2181 a shallow, but persistent, redox boundary at the log removal site. The effects of wood waste on

2182 near-shore sand beds (4-11 m) and associated fauna were studied by Conlan (1977) and Conlan

2183 and Ellis (1979), who found that deposition of $>1 \mathrm{~cm}$ of wood debris caused notable faunal

2184 impoverishments, particularly in the suspension feeding fauna. Additional studies have suggested

2185 that wood debris may also inhibit the abundance of some infaunal bivalves (Burd et al., in press;

2186 Kathman et al., 1984; http://www.mareco.org/report/intro.htm). Kathman et al. (1984) examined

2187 the recolonization of settling trays in 15-20 m depth in outer Burrard Inlet, using different

2188 concentrations or wood waste from the Port Mellon pulp mill location in Howe Sound. After 11

2189 weeks, they found that the $20 \%$ wood waste trays had a higher species diversity and lower

2190 dominance than found in the $0 \%, 50 \%$ and $100 \%$ wood waste trays, whereas abundance was

2191 equally high in the $20 \%$ and $100 \%$ trays. However, the $100 \%$ trays were dominated by

2192 nematodes, typical organic enrichment polychaetes and the wood-burrowing bivalve Bankia

2193 setacea. Other bivalves and polychaetes were abundant in the $0 \%$ and $20 \%$ trays, but rare in the $219450 \%$ and $100 \%$ trays.

2195 
2196 A larger-scale examination of benthic responses to log-boom operations for the north coast of

2197 British Columbia, as well as Esquimalt Harbour (Victoria) is underway as part of a Ph.D. project

2198 (http://www.erf.org/cgi-bin/conference_abstract.pl?conference=erf2003\% id+755).

3.5. Mine Tailings and Acid Mine Drainage

2201 Between 1902 and 1974, the Britannia copper/zinc mine discharged 40 million tonnes of tailings

2202 into Howe Sound. Tailings were concentrated on the slope within $3 \mathrm{~km}$ of Britannia Beach but

2203 also covered most of the floor of the Sound's inner basin. During mine operations, subtidal

2204 sediments in areas deeper than $30 \mathrm{~m}$ had levels of copper and zinc that were considerably

2205 elevated above background (Levings and McDaniel, 1973, 1976; McDaniel, 1973), as well as

2206 above the current Probable Effects Levels for marine sediments (CCME, 1999). They also found

2207 that burial by the Squamish River sediment load and inputs from local creeks had diluted, or

2208 covered, the deposited tailings and reduced the metal concentration in surface sediments. Below

2209 sill depth (73 m), waters in Howe Sound tend to be seasonally anoxic, limiting not only the

2210 mobility of metals from the sediments but also the biodiversity and abundance of benthic fauna,

2211 regardless of tailings (Levings et al., 1983). Several studies in the 1970s focused on the effects

2212 of deposition of metals and tailings from the active Britannia Mine operation on the

2213 macrobenthos (Levings and McDaniel, 1973; McDaniel, 1973; Levings and McDaniel, 1976),

2214 but based on more recent studies near Brittania (Ellis and Hoover, 1990) and on long-term

2215 recovery of sediments affected by tailings from mines located outside the SoG in British

2216 Columbia (Burd et al., 2000b; Burd, 2002), it is assumed that the deep benthos has recovered

2217 some 30 years after cessation of tailings deposition. However, it is also clear that considerable

2218 acid mine drainage is still leaching out into the near shore area around the historical Britannia 
2219 mine. Recent studies confirm impacts on near shore fish and fish habitat (for an overview, see

2220 Hagan et al., 2004). In addition, Grout and Levings (2001) examined the effects of acid mine

2221 drainage on intertidal mussels in the area and showed that caged and ambient mussels were

2222 adversely affected by elevated tissue copper levels to a distance of about $2 \mathrm{~km} \mathrm{~N}$ and $\mathrm{S}$ of the

2223 discharge creek. In December 2001, the acid mine drainage was diverted to an outfall at $30 \mathrm{~m}$

2224 depth into Howe Sound. Zis et al. (2004) looked at the intertidal community recovery at

2225 Britannia Beach after diversion, and found that some, but not total recovery was evident in

2226 invertebrate species number and abundance, as well as transplanted mussels. The authors

2227 concluded that some continued seepage from the old mine was still inhibiting normal growth and

2228 survival in the intertidal area. G3 Consulting (2003) provided a report on the shallow subtidal

2229 (<30 m depth) biota, sediment metals and organics from the foreshore around the Brittania mine.

2230 Levings et al. (2004) describe the toxicity of the acid mine drainage to estuarine organisms from

2231 the discharge creek, noting that invertebrate food resources for juvenile salmonids in the

2232 intertidal near the drainage creek were adversely affected by the acid mine drainage.

\section{$2233 \quad 3.6$ Aquaculture}

2234 In BC, the majority of the finfish aquaculture industry in the inside waters is located north of the

2235 SoG; there are only a few salmonid farms at the south end of Johnson Strait (the north end of the

2236 SoG) and in some of the contiguous mainland fjords. Where organic deposition is excessive, and

2237 fauna have declined, reactive organic detritus may be present in a labile state as a flocculent

2238 layer on the sediment surface (Kristensen, 1988). Fish farms provide an example of an organic

2239 source with minor copper (antifoulants) and zinc (feed) contaminants (c.f. Brooks 2001). Studies

2240 of benthic faunal patterns and recovery at the few marine mine tailings deposition sites, 
2241 however, suggest that particulate levels of these metals typically found under fish farms do not

2242 seem to have a notable effect on infaunal benthos in the deeper subtidal, despite the fact that

2243 bivalves, in particular, can accumulate metals (Burd et al., 2000b; Burd, 2002). Rather, zinc and

2244 copper levels are typically used as deposition tracers around fish farms (Yeats, 2002).

2245 The organic deposition in the vicinity of fish farms tends to be highly labile, as compared to

2246 wood fibre waste or other organic materials. Hence, the organic material tends to be broken

2247 down relatively quickly (e.g. in comparison to wood fibre debris) and recovery proceeds at a

2248 measurable pace. The effects of this highly labile deposition include sediment de-oxygenation

2249 and hydrogen sulphide accumulation which lead to the enrichment of some taxa such as the

2250 opportunistic polychaete Capitella capitata complex that are tolerant of these conditions and the

2251 impoverishment of sensitive taxa. At fish farms where organic enrichment loads are high and

2252 sediment geochemistry includes low oxygen levels and high sulfide accumulation (i.e. 6000

$2253 \mu \mathrm{m}$ ), tolerant and opportunistic polychaete species tend to dominate on soft substrates and on

2254 hard substrates where sedimentation occurs, whereas most other fauna disappear under these

2255 extreme conditions (Brooks, 2001; Burd, 2006; Hargrave et al., 2008). However, some epifaunal

2256 crustaceans typically found in detritus mats nearshore may thrive in the debris mats under the net

2257 cages (Burd, 2006).

2258 Under more moderate sulphide buildup conditions (1700-3000 $\mu \mathrm{M})$, a variety of organism types

2259 may be present, but Burd (2006) show that some biotic impoverishments are highly likely, along

2260 with a potential proliferation of opportunistic polychaetes. In particular, echinoderms and

2261 infaunal crustaceans appear to be highly sensitive to organic enrichment conditions in sediments

2262 (Burd, 2006; McPherson et al., 2007a). On hard substrates, some cnidarians (such as Metridium 
2263 senile) may be opportunistic under moderate organic enrichment conditions, but echinoderms

2264 will still be absent, as will larger sponges (Emmett et al., 2005; 2006; 2007), due primarily to

2265 excessive deposition, and/or near-bottom low oxygen conditions. Where organic loading is

2266 elevated, but within the assimilative capacity of the sediments, a biotically-enriched community

2267 may be present (Burd, 2006; Brooks, 2001). Recent reviews of biotic effects related to fish farms

2268 in BC are given in Brooks (2001),Burd (2003a; 2006) and Hargrave et al. (2008). Some

2269 important information on general sediment sulphide tolerance of common BC species is

2270 available in Brooks (2001).

2271 A large number of beach and near-shore shellfish aquaculture sites are located in Baynes Sound

2272 on the east coast of Vancouver Island. Carswell et al. (2006) describe an aerial survey method

2273 that has been used to show that $>20 \%$ of the intertidal zone of the sound is occupied by shellfish

2274 tenures. A review of the available literature and monitoring data related to potential impacts from

2275 shellfish culture for the intertidal areas of Baynes Sound is given in Jamieson et al. (2001). To

2276 date, studies show that the benthic impact of deep-water suspended culture of Pacific oysters

2277 appears to vary depending on the specifics of the site, including hydrography, bathymetry and

2278 natural deposition rates and sediment characteristics (Barnes, 2006). Regardless, data revealed

2279 that the benthic invertebrate communities in close proximity to the shellfish farms showed no

2280 reduction in either faunal abundance or diversity (Barnes, 2006). In Baynes Sound, an area of

2281 the SoG heavily tenured by shellfish leases, Bendell-Young (2006) studied three geographically

2282 similar clam farm beach sites, along a farming intensity gradient (fallow, 3 years active, 5 years

2283 active). In contrast to the fallow site, the 3 and 5 year active sites had intertidal regions with

2284 heavier silt and organic matter, lower species richness and increased domination by bivalves.

2285 However, a geographically more diverse study, including a site on the west coast of Vancouver 
Island, found that clam density on netted farm sites was significantly greater than on reference

2287 sites only in the low intertidal and that this significant increase in total clam density mirrored the

2288 increase in 1 species of bivalve, Venerupis philippinarum, in this stratum at farm sites (Whiteley

2289 and Bendell-Young, 2007). The study also demonstrated that bivalve species composition was

2290 not significantly different between farms and reference sites, suggesting that predator nets did

2291 not effectively change the structure of the infaunal communities at these sites. Farm sites were

2292 more similar to each other as a group than reference sites, however, and the authors suggest that

2293 this may lead to a loss of the regional distinctness that was evident among the reference sites

2294 (Whiteley and Bendell-Young, 2007).

\subsection{Bottom Trawling}

In near-shore coastal areas such as the SoG, bottom trawling is likely to result in physical

2297 disturbance. Bottom trawling can have devastating effects on bottom infaunal and epifaunal

2298 communities in other coastal areas (Watling and Norse, 1998). For example, otter trawling on

2299 soft bottoms has been found to significantly reduce the abundance of most invertebrate taxa

2300 (Engel and Kvitek, 1998; and other papers in Conservation Biology issue 12: Vol. 6). Effects on

2301 the benthos range from crushing, burying and dislocation of fauna, to habitat destruction and

2302 resuspension of fine particulates into a turbid boundary layer. Such practices can also damage

2303 nursery grounds or bottom fish stock. Various studies report a reduction in organism abundance

2304 and species richness $\geq 50 \%$, and substantial reductions in biomass (for review, see Watling and

2305 Norse, 1998). The effects of bottom trawling do not resemble any of the contaminant impacts

2306 described in the literature (Burd 2003b; Cook et al., in press), and arguments have been made

2307 that certain refugia such as the sponge reefs in the Strait should be protected from bottom 
2308 trawling (Conway et al., 2007). Unfortunately, there is virtually no concurrent spatial or temporal

2309 information on the combined, or synergistic, biotic effects of contaminant discharges and bottom

2310 trawling in the SoG.

\section{$2311 \quad 3.8$ General Contaminants Loadings (non-point source)}

2312 There are numerous sources of contaminants entering the SoG, particularly originating from, or

2313 as a result of, the highly urbanized centers near the BC/Washington border. Aside from

2314 localized surveys of sediment contaminant loadings related to specific discharges (see references

2315 in above sections 3.1 to 3.7 related to monitoring programs for site-specific discharges), there

2316 have been a few broader-scale studies of certain contaminants of concern or tracers of discharge

2317 types, focusing on their distributions and budgets (c.f. Macdonald et al., 1991,1992 - Pulp mills;

2318 Gordon,1997 - silver; Shang et al., 1999 - nonylphenols; Yunker et al., 1999 - PAHs;

2319 Johannessen et al. 2005a - Mercury; Johannessen et al. in press - PCBs/PBDEs). In addition,

2320 the potential for development of bottom water and sediment hypoxia from organic loading have

2321 been discussed using organic carbon budgets (Johannessen et al., 2003), and evaluation of

2322 sediment organic/oxygen conditions based on redox chemicals in cores (Macdonald et al., in

2323 press).

2324 Sediment guidelines and all the studies that have contributed to their development (CCME, 1999;

2325 BCWQO;http://www.env.gov.bc.ca/wat/wq/BCguidelines/approv_wq_guide/approved.html)

2326 provide some guidance related to possible responses of benthic invertebrate fauna to

2327 contaminants of concern. However, field validation of these hypothetical tolerances and

2328 responses is lacking for SoG fauna. 


\section{Conclusions}

2330 Although there is considerable descriptive information pertaining to invertebrate benthos (largely

2331 unpublished) of the SoG, quantitative evaluations are much less abundant and patchy spatially

2332 and temporally. Burd et al. (in press) provide a comparative assessment of infaunal biomass,

2333 species richness, and abundance measures which can be reasonably predicted by measurements

2334 of organic quality and flux to sediments in the SoG. Results are also dependent on the source and

2335 relative quantity of inorganic flux, with areas influenced by the Fraser River discharge providing

2336 apparently more productive substrate for macro-invertebrates than marine depositions. With a

2337 broader scale understanding of sediment organic and inorganic sources and fluxes in the SoG, it

2338 may be possible to begin to model and ground-truth subtidal benthic productivity of the SoG.

2339 This would also require a clearer understanding of how the smaller invertebrate groups

2340 (meiofauna) and microfauna respond to sediment organic and inorganic fluxes. The next logical

2341 step would be to interpret sediment productivity in the context of budgets/models of sediment

2342 contaminants, organic inputs and redox conditions for the SoG. In addition to understanding how

2343 benthic organisms may be affected by contaminant and organic loading on a regional scale, the

2344 potential for bio-accumulation and trophic transfer of contaminants of concern needs to be

2345 studied for the bottom-dwelling portion of the subtidal food chain. Predicting the effects of on-

2346 going climate changes will also require an understanding of how the sessile components of the

2347 benthic ecosystem are likely to change in response to major sedimentation shifts or events. 
2351 As in all reviews, acknowledgements must go primarily to all those researchers that have "gone

2352 before". However, this review would not have been possible without the motivation and

2353 financial support of Metro Vancouver (formerly Greater Vancouver Regional District), through

2354 Dr. Albert van Roodselaar. This work was completed as part of a collaborative research program

2355 between Metro Vancouver, Canadian Department of Fisheries and Oceans and Natural

2356 Resources Canada.

2357

2358

2359

2360 


\subsection{References}

2363 2WE Consulting, 1999. Iona Deep-sea Outfall 1998 Environmental Monitoring Program, Postdischarge Review, Report for Greater Vancouver Regional District by 2WE Associates Consulting Ltd., Victoria, B.C., 97 pp.

Albright, L.J., 1983. Influence of river-ocean plumes upon bacterioplankton production of the Strait of Georgia, British Columbia. Marine Ecology Progress Series 12, 107-113.

Anderson, J.J., Devol, A.H., 1973. Deep water renewal in Saanich Inlet, an intermittently anoxic basin. Estuarine, Coastal and Shelf Science 1, 1-10.

Archipelago Marine Research Ltd., 2000. Subtidal video (SIMS) survey of the Manley Creek landfall site at Boatswain Bank, British Columbia. Report to the Georgia Strait Pipeline Crossing Ltd.

Asmus, H. 1987. Secondary production of an intertidal mussel bed community related to its storage and turnover compartments. Mar. Ecol. Prog. Ser. 39, 251-256.

BC Ministry of Environment Lands and Parks, 1996. Saanich Inlet Study. Synthesis Report Summary, $35 \mathrm{pp}$.

2377 Baba, K., 1983. Spongicoloides hawaiiensis, a new genes of shrimp (Decapoda:Stenopodidea) from the Hawaiian Islands. Journal of Crustacean Biology 3, 477-481.

Bailey, H.C., McPherson, C.A., Hodgins, D.O., Fanning, L., Paine, M.D., Burd, B.J., Macdonald, V., Brooks, G.C., Chen, F., Brand, D., Raverty, S., 2003. Iona Deep-Sea Outfall, 2001 Environmental Monitoring Program. Final Report, Prepared for the Greater Vancouver Regional District by EVS Environmental Consultants Ltd., North Vancouver BC, 344 pp. + appendices. 
2384 Balch, N., Brown, D., Pym, R., Marles, E., Ellis, D.V., Littlepage, J., 1975. Monitoring marine outfalls by using ultraviolet absorbance. Journal of the Pollution Control Federation, 47, 195-202.

Balch, N., Ellis, D.V., Littlepage, J., 1973. Macaulay Point outfall monitoring programme, May 1970 - October 1972, Volume 1 and 2 final report to Capital Regional District, Victoria, BC by Department of Biology, University of Victoria.

Bard, S.M., 1998. A biological index to predict pulp mill pollution levels. Water Environment Research 70, 108-122.

Barnes, P.A.G., 1987. Aspects of the Ecology of the Gutless Protobranch Bivalve, Solemya reidi. University of Victoria, M.Sc. thesis, $435 \mathrm{pp}$.

2394 Barnes, P.A.G., 2006. Shellfish Culture and Particulate Matter Production and Cycling: A Literature Review, B.C. Aquaculture Research and Development Committee. Project AE02.03-02.01, $101 \mathrm{pp}$.

Barthel, D., 1992. Do hexactinellids structure Antarctic sponge associations? Ophelia 36, 111118.

Bell, J.J., Barnes, D.K., 2000a. The distribution and prevalence of sponges in relation to environmental gradients within a temperate sea lough: vertical cliff surfaces. Diversity

2402 Bell, J.J., Barnes, D.K., 2000b. The distribution and prevalence of sponges in relation to environmental gradients within a temperate sea lough: inclined cliff surfaces. Diversity and Distributions 6, 305-323. 
2405 Bendell-Young, L.I., 2006. Contrasting the community structure and select geochemical characteristics of three intertidal regions to shellfish farming. Environmental Conservation 33, 21-27.

Berggren, M., 1993. Spongiocaris hexactinellicola, a new species of stenopodidean shrimp (Decapoda: Stenopodidae) associated with hexactinellid sponges from Tartar Bank, Bahamas. Journal of Crustacean Biology 13, 784-792.

Bernard, F.R., 1978. British Columbia Faunistic Survey: Subtidal and Deep-water Megafauna of

Bett, B.J., Rice, A.L., 1992. The influence of hexactinellid sponge (Pheronema carpenteri) the Strait of Georgia. Canadian Fisheries and Marine Services Manuscript Report 1488, $41 \mathrm{pp}$. spicules on the patchy distribution of macrobenthos in the Porcupine Seabight (bathyal NE Atlantic). Ophelia 36, 217-226.

Boatman, D.C., Murray, J.W., 1982. Modeling exchangeable $\mathrm{NH}_{4}{ }^{+}$adsorption in marine sediments: Process and controls of adsorption. Limnology and Oceanography 27, 99-110.

Bornhold, B.D., 1978. Carbon/nitrogen (C/N) ratios in surficial marine sediments of British Columbia, in: Current Research, Part C, Geological Survey of Canada, Scientific and Technical Notes, Paper 78-1C, 108-112.

Bornhold, B.D., Harper, J.R., 2002. Pilot Nearshore Habitat Mapping Using Acoustic and Visual Techniques, Report Prepared for the North Pacific Research Board Anchorage, Alaska, (Project R0201), 128 pp.

Bornhold, B.D., Ren, P., Prior, D.B., 1994. High-frequency turbitidy currents in British Columbia fjords. Geo-Marine Letters 14, 238-243. 
2427 Bousfield, E.L., 1957. Ecological investigations of shore invertebrates of the Pacific coast of 2428 Canada. National Museum of Canada Bulletin 147, 105-155.

2429 Boyd, J., Baumann, J., Hutton, K., Bertold, S., Moore, B., 1998. Sediment Quality in Burrard 2430 Inlet Using Various Chemical and Biological Benchmarks, Burrard Inlet Environmental

2434 Brinkhurst, R.O., 1987. Distribution and Abundance of Macrobenthic Fauna from the Action Program, Burnaby, British Columbia, 87 pp. + appendices.

Brenchley, G.A., 1982. Mechanisms of spatial competition in marine soft-bottom communities. Jounal of Experimental Marine Biology and Ecology 60, 17-33. Continental Shelf off Southwestern Vancouver Island, British Columbia. Canadian Technical Report on Hydrography and Ocean Sciences 89, 45 pp.

Brinkhurst, R.O., Casillas, E., Word, J.Q., 1994. Marine benthos of British Columbia/Washington State boundary waters, in: Wilson, R.C.H., Beamish, R.J., Aitkens, F., Bell, J., (Eds.), Review of the Marine Environment and Biota of Strait of Georgia, Puget Sound and Juan de Fuca Strait. Canadian Technical Report of Fisheries and Aquatic Sciences 1948, 187-202.

Brooks, K.M., 2001. An evaluation of the relationship between salmon farm biomass, organic inputs to sediments, physiochemical changes associated with those inputs and the infaunal response-with emphasis on total sediment sulfides, total volatile solids, and oxidation reduction potential as surrogate endpoints for biological monitoring, Technical Advisory Group, Ministry of Environment, Lands, and Parks, Port Townsend, Washington, 172 pp. + appendices. 
2448 Bruce, A.J., Baba, K., 1973. Spongiocaris, a new genus of stenopodidean shrimp from New Zealand and South Africa waters, with a description of two new species (Decapoda: Nutantia, Stenopodidea). Crustaceana (Leiden) 25, 153-170.

Burd, B.J., 1985. Respiration of a low oxygen tolerant galatheid crab, Munida quadrispina (Benedict, 1902). Canadian Journal of Zoology 63, 2538-2542.

Burd, B.J., 1988. Comparative gill characteristics of Munida quadrispina (Decapods, Galatheidae) from different habitat oxygen conditions. Canadian Journal of Zoology 66, 2320-2323.

Burd, B.J., 1992. Qualitative and quantitative studies of benthic marine infaunal communities in British Columbia coastal waters, University of Victoria, Ph.D thesis., 375 pp.

Burd, B.J., 1997. Part D: Waste Discharges Discussion Paper. Salmon Aquaculture Review, Technical Advisory Team Discussion Papers, B.C. Environmental Assessment Office, Victoria, B.C., 3:D1-D118.

Burd, B.J., 2000. Ecological Effects and Indicators Analysis for the IONA Receiving Environment, in: Greater Vancouver Regional District, (Ed.), Development of a Receiving Environment Monitoring Approach to Liquid Waste Management: Progress

Burd, B.J., 2003a. Review and Prioritization of Benthic Invertebrate Indicator Species, Species Assemblages, and Chemical Characteristics that Could be Used in Assessing Efffects of Workshop 2, Burnaby, B.C., 48 pp.

Burd, B.J., 2002. Evaluation of mine tailings effects on a benthic marine infaunal community over 29 years. Marine Environmental Research, 53 481-519. Marine Finfish Farms on Fish Habitat, Report to the Department of Fisheries and Oceans, Pacific Region, 59 pp. 
Burd, B.J., 2003b. Ecological Significance of IONA 2000-2002 Monitoring Results for Benthic Infaunal Communities, in: Greater Vancouver Regional District, 2004. Greater Vancouver Regional District.Cautions, Warnings \& Triggers: A Process for Protection of the Receiving Environment, Appendices: Technical Reports and Monitoring Programs.

Burd, B.J., 2003c. Ecological Effects Related to the Outfall Particulates Discharge Determined from the Macaulay Point Monitoring Program 1994-2001, Report to Capital Regional District, Victoria, British Columbia.

Burd, B.J., 2004. Comparative Assessment of Biological and Related Sediment Factors for Outer Burrard Inlet: Historical and Current Monitoring Data: Ambient Monitoring Data; Iona Monitoring Data, Prepared for the Greater Vancouver Regional District, 83 pp.

Burd, B. J., 2006. Analysis of Historic Benthic Biological Data to Determine Validity of the Ecological Threshold Concept for Soft Substrate Impacts Related to Coastal BC Fish Farm Discharges. Report to BC Ministry of Environment, December 6, 2006, 62 pp.

Burd, B.J., Brinkhurst, R.O., 1984. Distribution of the galatheid crab, Munida quadrispina (Benedict 1902) in relation to oxygen concentrations in British Columbia fjords. Journal of Experimental Marine Biology and Ecology 81, 1-20.

Burd, B.J., Brinkhurst, R.O., 1987. Macrobenthic infauna from Hecate Strait, B.C. Canadian Technical Report of Hydrography and Ocean Sciences 88, 123pp.

Burd, B.J., Brinkhurst, R.O., 1990. Vancouver Harbour and Burrard Inlet Benthic Infaunal Sampling Program, October 1987. Canadian Technical Report of Hydrography and Ocean Sciences 122, 49 pp.

Burd, B.J., Brinkhurst, R.O., 1992. Benthic Infaunal Surveys of British Columbia Fjords, 1988 to 1990. Canadian Data Report of Hydrography and Ocean Sciences 114, 37 pp. 
2494 Burd, B.J., Glaholt, R., 2000. Survey of benthic infauna at the Manley Creek landfall site at Boatswain Bank, British Columbia. Ecostat Research Ltd. and Tera Environmental Consultatns (Alta) Ltd. Report to the GSX Pipeline Crossing Project.

2497

Burd, B.J., Glaholt, R., Macdonald, V., 2000a. Reconnaissance Level Baseline Survey of Benthic Infaunal communities at Ecological Reserve 67 and Adjacent Satellite Channel, June 4, 2000. Georgia Strait Crossing Pipeline Ltd., 14 pp. + appendices.

Burd, B.J., Macdonald, R.W., Boyd, J., 2000b. Punctuated recovery of sediments and benthic infauna: a 19-year study of tailings deposition in a British Columbia fjord. Marine Environmental Research 49, 145-175.

Burd, B.J., Macdonald, R.W., Johannessen, S.C., Hill, P.R., van Roodselaar, A., In Press. A. Responses of subtidal benthos of the Strait of Georgia to ambient sediment conditions and natural and anthropogenic depositions. Marine Environmental Research,

Burd, B.J., Moore, D., Brinkhurst, R.O., 1987. Distribution and Abundance of Macrobenthic Fauna from Boundary and Mud Bays near the British Columbia/U.S. Border. Canadian Technical Report of Hydrography and Ocean Sciences 84, 1-34.

Burgess, R.M., 2000. Characterising and identifying toxicants in marine water: a review of marine toxicity identification evaluations (TIEs). International Journal of Environment and Pollution 13, 2-33.

Canadian Department of Fisheries and Oceans, 1999a. Manila Clam, DFO Science Stock Status Report, C6-03.

Canadian Department of Fisheries and Oceans, 1999b. Native Littleneck Clam, DFO Science Stock Status Report, C6-02. 
2516 Canadian Department of Fisheries and Oceans, 2000. Geoduck Clam, DFO Science Stock Status $2517 \quad$ Report, C6-05.

2518 Canadian Department of Fisheries and Oceans, 2007. Pacific Region, Intergrated Fisheries

2519 Management Plans, Intertidal Clams, January 1, 2007 to December 31, 2009, Fisheries

$2520 \quad$ and Oceans Canada, Nanaimo, BC. 71 pp.

2521 Capital Regional District, 2000. Core Area Liquid Waste Management Plan, CRD, Victoria, 2522 British Columbia, 104 pp. + appendices.

2523 Capital Regional District, 2003. Macaulay and Clover Point Wastewater and Marine

2524 Environment Program 2002 Annual Report, Capital Regional District, Environmental

2525 Services Department, Victoria, B.C., 63 pp. + appendices.

2526 Capital Regional District, 2004. Macaulay and Clover Point Wastewater and Marine

2527 Environment Program 2003 Annual Report, Capital Regional District, Environmental

2528 Services Department, Victoria, B.C., 93 pp. + appendices.

2529 Capital Regional District, 2005. Macaulay and Clover Point Wastewater and Marine

2530 Environment Program 2004 Annual Report, Capital Regional District, Environmental

2531 Services Department, Victoria, B.C., 127 pp. + appendices.

2532 Carefoot, T., 1977. Pacific Seashores: A guide to intertidal ecology. University of Washington

2533 Press, Seattle, WA., 208 pp.

2534 Carswell, B., Cheesman, S., Anderson, J., 2006. The use of spatial analysis for environmental 2535 assessment of shellfish aquaculture in Baynes Sound, Vanocuver Island, British 2536 Columbia, Canada. Aquaculture 253, 408-414. 
CCME, (Canadian Council of Ministers for the Environment) 1999. Protocol for the Derivation of Canadian Sediment Quality Guidelines for the Protection of Aquatic Life, Canadian Council of Ministers of the Environment, Ottawa, Ontario. 35 pp. + summary tables.

Conlan, K.E., 1977. The effects of wood deposition on from a coastal log handling operation on the benthos of a shallow sand bed in Saanich Inlet, British Columbia, University of Victoria, M.Sc. thesis, 203 pp.

Conlan, K.E., Ellis, D.V., 1979. Effects of wood waste on sand-bed benthos. Marine Pollution Bulletin, 10 262-267.

Conway, K.W., 1999. Hexactinellid Sponge Reefs on the British Columbia Shelf: Geological and Biological Structure with a Perspective on Their Role in the Shelf Ecosystem. Canadian Stock Assessment Secretariat Research Document 99/192, 21 pp.

Conway, K.W., Barrie, J.V., Hill, P.R., Austin, W.C., Pickard, K., 2007. Mapping sensitive benthic habitats in the Strait of Georgia, coastal British Columbia: Deep-water Sponge and Coral Reefs, in: Current Research, Geological Survey of Canada, 2007-A2, 6 pp.

Conway, K.W., Krautter, M., Barrie, J.V., Neuweiler, M., 2001. Hexactinellid sponge reefs on the Canadian continental shelf: A unique "living Fossil". Geoscience Canada 28, 71-78.

Cook, S., Conway, K.W., Burd, B. In press. Status of the glass sponge reefs in the Georgia Basin, Marine Environmental Research.

CORI (Coastal Ocean and Resources Inc), 2002. Lions Gate ROV far-field imaging survey. Report prepared for the Greater Vancouver Regional District, Burnaby, B.C., 30 pp. + appendices. 
2558 Coull, B.C., Bell, S.S., 1979. Perspectives in marine meiofauna ecology, in: Livingston, R.J., 2559 (Ed.), Ecological Processes in Coastal Marine Systems, New York: Plenum Press, pp. $2560 \quad 189-216$.

2561 Crean, P.B., Murty, T.S. and Stronach, J.A., 1988. Mathematical modelling of tides and estuarine 2562 circulation: the coastal seas of southern British Columbia and Washington State. 2563 Heidelberg: Springer Verlag, $471 \mathrm{pp}$.

2564 Cross, S.F., 1990. Benthic impacts of salmon farming in British Columbia, report prepared for 2565 the Ministry of the Environment, Water Management Branch, Government of British $2566 \quad$ Columbia, 78 pp.

2567 Cross, S.F., Brinkhurst, R.O., 1991. Spatial distribution of macrobenthos infauna in Burrard 2568 2569 Inlet: November, 1989. Canadian Data Report of Hydrography and Ocean Sciences 92, $40 \mathrm{pp}$.

2570

2571 Cross, S.F., Mehlenbacher, N., Lipovsky, S., Williams, A., 2005. Biological Monitoring of Salmon Aquaculture Benthic Impacts - Methods Review and Options Analysis, Report to the British Columbia Aquaculture Research and Development Committee, 123 pp. +

2578 Dayton, P.K., 1971. Competition, disturbance, and community organization: the provision and 2579 subsequent utilization of space in a rocky intertidal community. Ecological Monographs 2580 appendices.

Davenne, E., Masson, D. 2001. Water properties in the Straits of Georgia and Juan de Fuca, Fisheries and Oceans Canada, www-sci.pac.dfompo.gc.ca/osap/projects/straitofgeorgia/JdFG_e.pdf. 41, 351-389. 
2581 de Brouwer, J.F.C., Wolfstein, K., Ruddy, G.K., Jones, T.E.R., Stal, L.J., 2005. Biogenic 2582 stabilization of intertidal sediments: The importance of extracellular polymeric 2583 substances produced by benthic diatoms. Microbial Ecology 49, 501-512.

2584 De Robertis, A., Eiane, K., Rau, G.H., 2001. Eat and run: anoxic feeding and subsequent aerobic 2585 recovery by Orchomene obtusus in Saanich Inlet, British Columbia, Canada. Marine Ecology Progress Series 219, 221-227.

Decho, A.W., 2000. Microbial biofilms in intertidal systems: An overview. Continental Shelf Research 20, 1257-1273.

Denny, M.W., Daniel, T.L. and Koehl, M.A.R., 1985. Mechanical limits to size in wave swept organisms. Ecological Monographs 55, 69-102.

Duggins, D.O., 1981. Sea urchins and kelp: The effects of short term changes in urchin diet. Limnology and Oceanography 26, 391-394.

Dumbauld, B.R., Armstrong, D.A., McDonald, T.L., 1993. Use of oyster shell to enhance intertial habitat and mitigate loss of Dungeness crab (Cancer magister) caused by dredging. Canadian Journal of Fisheries and Aquatic Sciences 50, 381-390.

Dunn, R., Mullineaux, L. S., Mills, S.W., 1999. Resuspension of postlarval soft-shell clams Mya arenaria through disturbance by the mud snail Ilyanassa obsolete. Marine Ecology

2601 Ellis, D.V., 1967a. Quantitative Benthic Investigations. I. Satellite Channel biomass summaries Progress Series 180, 223-232.

Ellis, D.V., 1966. Aerial photography from helicopter as a technique for intertidal surveys. and major taxon rank orders, February 1965-May 1967. Fisheries Research Board of Canada Technical Report 25, 49 pp. 
2604 Ellis, D.V., 1967b. Quantitative benthic investigations. II. Satellite Channel species data, February 1965-May 1967. Fisheries Research Board of Canada Technical Report 35, 170 pp.

2607 Ellis, D.V., 1968a. Quantitative Benthic Investigations. III. Locality and environmental data for selected stations (mainly from Satellite Channel, Straits of Georgia and adjacent inlets), February 1965-December 1967. Fisheries Research Board of Canada Technical Report 59, 61 pp. + figures and appendices.

Ellis, D.V., 1968b. Quantiative benthic investigations. IV. Biomass summaries and major taxon rank orders for selected stations (mainly Straits of Georgia and adjacent inlets), May 1965-December 1967. Fisheries Research Board of Canada Technical Report 60, 91 pp.

Ellis, D.V., 1968c. Quantitative Benthic Investigations. V. Species data from selected stations (Straits of Georgia and adjacent inlets), May 1965-May 1966. Fisheries Research Board of Canada Technical Report 73, 307 pp.

Ellis, D.V., 1970. Ecologically significant species in coastal marine sediments in southern British Columbia. Syensis 2, 171-182.

Ellis, D.V., 1971. A review of marine infaunal community studies in the Strait of Georgia and adjacent inlets. Syesis, 4, 3-9.

Ellis, D.V., 1982. Ocean disposal in British Columbia. Oceans 14, 1101-1106.

Ellis, D.V., 2002. Underwater biodiversity surveys and biological colonization of the waste dump shoreline, (In) Poling, G.W., Ellis, D.V., Murray, J.W., Parsons, T.R. and Pelletier, C.A. Underwater Tailing Placement at Island Copper Mine. Society for Mining, Metallurgy and Exploration, USA, pp 137-146. 
2626

2627

2628

2629

2630

2631

2632

2633

2634

2635

2636

2637

2638

2639

2640

2641

2642

2643

2644

2645

2646

2647

2648

2649

Ellis, D.V., 2003. Rocky shore intertidal zonation as a means of monitoring and assessing shoreline biodiversity recovery. Marine Pollution Bulletin, 46, 305-307.

Ellis, D.V., Hoover, P.M., 1990. Benthos on tailings beds from an abandoned coastal mine. Marine Pollution Bulletin 21, 477-480.

Emerson, S., Hedges, J.I., 2003. Sediment diagenesis and benthic flux, in: Elderfield, H., (Ed.), The Oceans and Marine Geochemistry, Oxford: Elsevier-Pergamon, pp. 293-230.

Emmett, B., Bornhold, B.C., Burd, B., 2005. Evaluation of Video and Non-video, Hard Substrate Seabed Monitoring Techniques, Prepared for the B.C. Aquaculture Research and Development Committee, B.C. Innovation Council, 78 pp.

Emmett, B., Thuringer, P., Cook, S. 2006. The development of ROV video survey and data classification protocols for monitoring hard seabed substrates, Canadian Science Advisory Secretariat Working Paper I2006-04, Fisheries and Oceans Canada.

Emmett, B., Thuringer, P., Cook, S., Burd, B., 2007. Evaluation of hard seabed monitoring techniques: Development of video survey and data classification protocols: Phase 2, report prepared for the Aqua E-Fund, Project AE 03.04-02.02 by Archipelago Marine Research, 70 pp. + appendices.

Engel, J., Kvitek, R., 1998. Effects of otter trawling on a benthic community in Monterey Bay national marine sanctuary. Conservation Biology 12, 1204-1214.

England, L.A., Thomson, R.E., Foreman, M.G.G., 1996. Estimates of seasonal flushing times for the Southern Strait of Georgia. Canadian Techncial Report of Hydrography and Ocean Sciences 147, 24 pp.

Farrow, G.E., Syvitski, J.P.M., Tunnicliffe, V.J., 1983. Suspended particulate loading on the macrobenthos in a high turbid fjord: Knight Inlet, British Columbia. Canadian Journal of Fisheries and Aquatic Sciences 40(Supplement 1), 273-288. 
2650 Fonseca, M.S., Fisher, J.S., 1986. A comparison of canopy friction and sediment movements between four species of seagrass with reference to their ecology and restoration. Marine Ecology Progress Series 29, 15-22.

2653 Foreman, M.G.G., Sutherland, G., Cummings, P.F., 2004. M2 tidal dissipation around Vancouver Island: An inverse approach. Continental Shelf Research 24, 2167-2185.

Foreman, M.G.G., Walters, R.A., Henry, R.F., Keller, C.P., Dolling, A.G., 1995. A tidal model for eastern Juan de Fuca Strait and the southern Strait of Georgia. Journal of Geophysical

Freeland, H.J., Farmer, D.M., 1980. Circulation and energetics of a deep, strongly stratified inlet.

2660 Frith, H.R., Searing, G., Wainwright, P., 1994. Methodology for a BC Shoreline biotic mapping system, Land Use Coordination Office, Government of British Columbia, Victoria, B.C.

2662 G3 Consulting, 2003. Britannia Beach subtidal sampling programs: Final report, prepared for 2663 Environment Canada, $62 \mathrm{pp}$.

2664 Gargett, A.E., Stucchi, D., Whitney, F., 2003. Physical processes associated with high primary production in Saanich Inlet, British Columbia. Estuarine, Coastal and Shelf Science 56,

2667 Gerlach, S.A., Hahn, A.E., Schrage, M., 1985. Size spectra of benthic biomass and metabolism. Marine Ecology Progress Series 26, 161-173.

2669 Gillespie, G.E., Bourne, N.F., 1998. Exploratory intertidal clam surveys in British Columbia1997. Canadian Manuscript Report of Fisheries and Aquatic Sciences 2465, 43 pp.

2671 Glaholt, R., Burd, B., Haight, R., 2002. Preliminary report on the environmental effects of a marine pipeline on nearby soft bottom benthic infaunal communities, Bazan Bay, British 
Columbia, prepared for Georgia Strait Crossing Pipeline Limited by Tera Environmental Services, Ecostat Research Ltd., and Vacilador Productions Ltd., 21 pp. + appendices.

2675 Gordon, K., 1997. Sedimentary tracers of sewage inputs to the southern Strait of Georgia.

2676 University of British Columbia, M.Sc. thesis, 217 pp.

2677 Golder Associates Ltd., 2005. Potential environmental effects from the Macaulay and Clover Point Outfalls and review of the Wastewater and Marine Environment Program. Report prepared for the Capital Regional District, Victoria, BC, Canada. December 2005

Goldstein, B.A., Perkins-Visser, E., Wolcott, T.G., Wolcott, D.L., 1996. Nursery role of

Griffin, D.A., LeBlonde, P.H., 1990. Estuary/ocean exchange controlled by spring-neap tidal seagrass beds: enhanced growth of juvenile blue crabs (Callinectes sapidus Rathbun). J. mixing. Estuarine Costal and Shelf Science 30, 275-297.

Grout, J.A., Levings, C.D., 2001. Effects of acid mine drainage from an abandoned copper mine, Britannica Mines, Howe Sound, British Columbia, Canada on transplanted blue mussels (Mytilus edulis). Marine Environmental Research 51, 265-288.

2690 GVRD, 2004. Greater Vancouver Regional District cautions, warnings, and triggers: A process for protection of the receiving environment, Prepared for the Ministry of Environment Land and Air Protection, Greater Vancouver Regional District, Burnaby, B.C., 170 pp. + appendices. 
2694 Hagan, M., McCandless, R., More, B., Colodey, A., 2004. Nearshore contaminated sediment 2695 investigations at Britannia Beach, British Columbia, Environment Canada Pacific and

Hannides, A.K., Dunn, S.M., Aller, R.C., 2005. Diffusion of organic and inorganic solutes through macrofaunal mucus secretions and tube linings in sediments. Journal of Marine Research 63, 957-981.

Harbo, R.M., Marcus, K., Boxwell, T., 1997. Intertidal clam resources (Manila, Littleneck and Butter Clam). Volume II: The southern inside waters of Vancouver Island and the British Columbia mainland, 16 pp. + maps.

Hargrave, B.T. Holmer, M., Newcombe, C.P., 2008. Towards a classification of organic enrichment in marine sediments based on biogeochemical indicators. Marine Pollution Bulletin, 56, 810-824.

Harper, J.R., 1995. Physical processes overview for the west coast of Vancouver Island, report to the Land Use Coordination Office, Victoria, Government of British Columbia.

Harper, J.R., Christian, J., Cross, W.E., Frith, R., Searing, G., Thompson, D., 1993a. A classification of the marine regions of Canada, Environment Canada, Vancouver, B.C.

Harper, J.R., Peters, S., Booth, J., Dickins, D.F., Morris, M. 1993b. Coastal information resource inventory, prepared for the Resources Inventory Committee, Province of British 
Columbia., Victoria, B.C., 81 pp. Available electronically at: http://www.ilmb.gov.bc.ca/risc/o_docs/coastal/cir/assets/coastal.pdf

2719

2720

2721

2722

2723

2724

2725

2726

2727

2728

2729

2730

2731

2732

2733

2734

2735

2736

2737

Harrison, P.J., 1981. The biological determinants of the structure of harpacticoid copepod communities on an estuarine intertidal flat (Fraser River Delta, B.C.), University of British Columbia, Ph.D. thesis, 455 pp.

Harrison, P.J., Fulton, J.D., Taylor, F.J.R., Parsons, T.R., 1983. Review of the biological oceanography of the Strait of Georgia: pelagic environment. Canadian Journal of Fisheries and Aquatic Sciences 40, 1064-1094.

Harrison, P.J., Yin, K., 1998. Ecosystem delineation in the Georgia Basin based on nutrients, chlorophyll, phytoplankton species and primary production, in: Levings, C.D., Aitkens, F., (Eds.), Approaches to Marine Ecosystem Delineation in the Strait of Georgia: Proceedings of a D.F.O. workshop, Sidney, B.C., 4-5 November, 1997, Canadian Technical Report of Fisheries and Aquatic Sciences 2247, 124-134.

Harrison, P.J., Yin, K., Ross, L., Arvai, J., Gordon, K., Bendell-Young, L.I., Thomas, C., 1999. The delta foreshore ecosystem: past present status of geochemistry, benthic community production and shorebird utilization after sewage diversion, in: Gray, C., Tuominen, T., (Eds.), Health of the Fraser River Aquatic Ecosystem, Environment Canada, Vancouver, B.C., pp. 189-210.

Hart, B.S., Hamilton, T.S., Barrie, J.V., 1998. Sedimentation rates and patterns on a deep-water delta (Fraser Delta, Canada) integration of high-resolution seismic stratigraphy, core lithofacies, and ${ }^{137}$ Cs fallout stratigraphy. Journal of Sedimentary Research 68, 556-568. 
2738 Hayashi, K.I., Ogawa, Y., 1987. Spongicola levigata sp. nov., a new shrimp associated with a 2739 hexactinellid sponge from the East China Sea (Decapoda, Stenopodidae). Zoological $2740 \quad$ Science (Tokyo) 4, 367-373.

2741 Heck, K.J., Able, K., Fahay, M., Roman, C., 1989. Fishes and decapod crustaceans of Cape Cod 2742 eelgrass meadows: Species composition, seasonal abundance patterns and comparison with unvegetated substrates. Estuaries 12, 59-65.

Heck, K.L., Hays, G., Orth, R.J., 2003. Critical evaluation of the nursery role hypothesis for seagrass meadows. Mar. Ecol. Prog. Ser. 253: 123-136.

Hewitt, J.E., Pridmore, D., Thrush, S.F. and Cummings, V.J., 1997. Assessing the Short-Term Stability of Spatial Patterns of Macrobenthos in a Dynamic Estuarine System. Limnology and Oceanography 42, 282-288.

Hickin, E.J., 1989. Contemporary Squamish River sediment flux to Howe Sound. Canadian Journal of Earth Sciences,26, 1953-1963.

Hickin, E.J., 1992. An inventory of research conducted in Squamish Basin: Proceedings of the Howe Sound environmental workshop (September 30-October 3, 1991, Bowen Island, B.C.). Canadian Technical Report of Fisheries and Aquatic Sciences 1879, 43-47.

Hill, P.R., Conway K., Lintern, G.D., Meulé, S., Picard, K., Barrie, J.V. In press. Sedimentary processes and sediment dispersal in the southern Strait of Georgia, BC, Canada. Marine Environmental Research.

Hodgins, D.O., Hodgins, S.L.M., 2000. A Re-evaluation of Iona effluent solids deposition based on sediment grain size characteristics, in: Greater Vancouver Regional District, (Ed.), Development of a Receiving Environment Monitoring Approach to Liquid Waste Management. Progress Workshop 2 December 6, 2000, Support Material Part 2 of 3 Iona 
WWTP Receiving Environment, Draft Technical Report, GVRD, Burnaby, B.C., pp. 1.1 -1.24 .

2763 Hodgins, D.O., Chapman, P.M., Bailey, H.C., 2000. Lions Gate wastewater treatment plant

Howes, D.E., Zacharias, M.A., Harper, J.R., 1996. The Marine ecoregions of British Columbia,

Hoskins, D.L., Stancyk, S.E., Decho, A.W., 2003. Utilization of algal and baterial extracellular polymeric secretions (EPS) by the deposit-feeding brittlestar Amphiopholis gracillima (Echinodermata). Marine Ecology Progress Series 247, 93-101.

Howes, D.E., Harper, J.R., Owens, E., 1994. British Columbia physical shore-zone, British Columbia Resource Inventory Committee, Victoria, B.C., 84 pp.

Howes, D.E., Wainwright, P., Haggarty, J., Harper, J.R., Owens, E., Reimer, D., Summers, K., Cooper, J., Berg, L., Baird, R., 1993. Coastal resource and oil spill atlas for the southern Strait of Georgia, B.C. Ministry of the Environment, Lands and Parks, Environmental Emergencies Coordination Office, Victoria, B.C., 317 pp. The Land Use Coordination Office, Government of British Columbia, Victoria, B.C. Huggett, W.S., Thomson, R.E., Woodward, M.J., Douglas, A.N., 1980. Data record of current observations, Vol. VII Johnstone Strait, 1976, 1977, 1978, Institute of Ocean Sciences, Sidney, B.C., 288 pp. 
2784 Hunt, H.L., Mullineaux, L.S., 2002. The Roles of Predation and Postlarval Transport in

2785

2786

2787

2788

2789

2790

2791

2792

2793

2794

2795

2796

2797

2798

2799

2800

2801

2802

2803

2804

Recruitment of the Soft Shell Clam (Mya arenaria). Limnology and Oceanography 47, $151-164$.

Jamieson, G.S., 1988. Vertical distribution and mass mortality of prawns, Pandalus platyceros, in Saanich Inlet. Fishery Bulletin 86, 601-608.

Jamieson, G.S., Chew, L., Gillespie, L., Robinson, g., Bendell-Young, L., Heath, W., Bravender, B., Tompkins, A., Nishimura, D., Doucett, P., 2001. Phase 0 review of the environmental impacts of intertidal shellfish aquaculture in Baynes Sound. Canadian Science Advisory Secretariat Research Document 2001/125. URL: http://www.dfompo.gc.ca/csas/Csas/publications/ResDocs-DocRech/2001/2001_125_e.htm

Jamieson, G.S., Levings, C.D., Mason, B.C. and Smiley, B.D., 1999. Shorekeepers' guide for monitoring Intertidal habitats in Canada's Pacific waters, Fisheries and Oceans Canada, Sidney, BC, Modules 1, 2, and 3.

Je, J.-G., Belan, T., Levings, C., Koo, B.J., 2003. Changes in benthic communities along a presumed pollution gradient in Vancouver Harbour. Marine Environmental Research 57, 121-135.

Johannessen, S.C., Macdonald, R.W., Eek, K.M., 2005a. Historical trends in mercury sedimentation and mixing in the Strait of Georgia, Canada. Environmental Science \& Technology 39, 4361-4368.

Johannessen, S.C., Macdonald, R.W., Paton, D.W., 2003. A sediment and organic carbon budget for the greater Strait of Georgia. Estuarine, Coastal and Shelf Science 56, 845-860. 
2805

2806

2807

2808

2809

2810

2811

2812

2813

2814

2815

2816

2817

2818

2819

2820

2821

2822

2823

2824

2825

Johannessen, S.C., Macdonald, R.W., Wright, C.A., Burd, B., Shaw, D.P., van Roodselaar, A., In Press. Joined by geochemistry, divided by history: PCBs and PBDEs in the Strait of Georgia sediments. Marine Environmental Research.

Johannessen, S.C., Masson, D., Macdonald, R.W., 2006. Distribution and cycling of suspended particles inferred from transmissivity in the Strait of Georgia, Haro Strait and Juan de Fuca Strait. Atmosphere-Oceans 44, 17-27.

Johannessen, S.C., O'Brien, M.C., Denman, K.L., Macdonald, R.W., 2005b. Seasonal and spatial variations in the source and transport of sinking particles in the Strait of Georgia, British Columbia, Canada. Marine Geology 216, 59-77.

Kathman, R.D., Cross, S.F., Waldichuk, M., 1984. Effects of wood waste on the recruitment of marine benthic communities. Canadian Technical Report of Fisheries and Aquatic Sciences $1284,50 \mathrm{pp}$.

Kellerhals, P., Murray, J.W., 1969. Tidal flats at Boundary Bay, Fraser River Delta, British Columbia. Bulletin of Canadian Petroleum Geology 17, 67-91.

Kennett, K., McPhee, M.W., 1988. The Fraser River Estuary: An overview of changing conditions, Fraser River Estuary Management Program, New Westminister, B.C., 31 pp.

Kozloff, E. N., 1987. Marine invertebrates of the Pacific northwest. University of Washington Press, Seattle, WA., 511 pp.

Krautter, M., Conway, K.W., Barrie, J.V., Neuweiler, M., 2001. Discovery of a living dinosaur: Globally unique modern hexactinellid sponge reefs off British Columbia, Canada. Facies 44, 265-282. 
2826

2827

2828

2829

2830

2831

2832

2833

2834

2835

2836

2837

2838

2839

2840

2841

2842

2843

2844

2845

2846

2847

2848

Kristensen, E., 1988. Benthic fauna and biogeochemical processes in marine sediments: microbial activities and fluxes, in: Blackburn, T.H., Sorensen, J., (Eds.), Nitrogen Cycling in Coastal Marine Environments, John Wiley \& Sons, Chichester, pp. 275-299.

Kristensen, E., Kostka, J.E., 2005. Macrofaunal burrows and irrigation in marine sediment: microbiological and biogeochemical interactions, in: Kristensen, E., Haese, R., Kostka, J.E., (Eds.), Interactions between Macro- and Microorganisms in Marine Sediments. American Geophysical Union, Washington, D.C., pp. 125-158.

Lamb, A., Edgell, P., 1986. Coastal Fishes of the pacific northwest, Madiera Park, B.C., Harbour Publishing, 224 pp.

Lauzier, R.B., Hand, C.M., Campbell, A., Heizer, S., 1998. A review of the biology and fisheries of the horse clams (Tresus capax and Tresus nuttalli). Canadian Stock Assessment Secretariat Research Document 1998/88, 33 pp.

LeBlonde, P.H., 1983. The Strait of Georgia: functional anatomy of a coastal sea. Canadian Journal of Fisheries and Aquatic Sciences 40, 1033-1063.

Levings, C.D., 1980a. Benthic biology of a dissolved oxygen deficiency event in Howe Sound, B.C., in: Freeland, H.J., Farmer, D.M., Levings, C.D., (Eds.), Fjord Oceanography, New York, Plenum Publishing, pp. 515-522.

Levings, C.D., 1980b. Demersal and benthic communities in Howe Sound basin and their responses to dissolved oxygen deficiency. Canadian Technical Report of Fisheries and Aquatic Sciences, , 951, 27 pp.

Levings, C.D., Barry, K.L., Grout, J.A., Piercey, G.E., Marsden, A.D., Coombs, A.P., Mossop, B., 2004. Effects of acid mine drainage on the estuarine food web, Britannica Beach, Howe Sound, British Columbia, Canada. Hydrobiologia 525, 185-202. 
Levings, C.D., Coustalin, J.B., 1975. Zonation of intertidal biomass and related benthic data from Sturgeon and Roberts Bank, Fraser River Estuary, British Columbia. Fisheries and Marine Technical Services 468, 138 pp.

Levings, C.D., Foreman, R.E., Tunnicliffe, V.J., 1983. Review of the benthos of the Strait of Georgia and contiguous fjords. Canadian Journal of Fisheries and Aquatic Sciences 40, 1120-1141.

Levings, C.D., Jamieson, G.S., 2001. Marine and estuarine riparian habitats and their role in coastal ecosystems, Pacific Region. Canadian Science Advisory Secretariat Research Document 2001/109, 42 pp.

Levings, C.D., McDaniel, N., 1973. Biological observations from the submersible PICES IV near Britannia Beach, Howe Sound, BC, Fisheries Research Board Technical Report, 409, 23 pp.

Levings, C.D., McDaniel, N.G., 1974. A unique collection of baseline biological data: Benthic invertebrates from an under-water cable across the Strait of Georgia. Fisheries Research Board of Canada, Technical Report 441, 19 pp.

Levings, C.D., McDaniel, N.G., 1976. Industrial disruption of invertebrate communities on beaches in Howe Sound, B.C. Fisheries Marine Services Technical Report 663, 100 pp.

Levings, C.D., Samis, S., 2001. Section II site description and oceanography, in: Stehr, C.M., Horiguchi, T., (Eds.), Environmental Assessment of Vancouver Harbour Data Report for the PICES Practical Workshop, PICES Scientific Report No. 16, PICES Secretariat, Sidney, B.C., pp. 15-21.

Levings, C.D., Thom, R.M., 1994. Habitat changes in Georgia Basin: Implications for resource management and restoration, in: Wilson, R.C.H., Beamish,R.J., Aikens, F., Bell, J., 
(Eds.), Review of the Marine Environment and Biota of Strait of Georgia, Puget Sound and Juan de Fuca Strait: Proceedings of the BC/Washington Symposium of the Marine Environment, January 13 and 14, 1994. Canadian Technical Report of Fisheries and Aquatic Sciences 1948, 330-351.

Li, M., Gargett, A., Denman, K., 1999. Seasonal and interannual variability of estuarine circulation in a box model of the Strait of Georgia and Juan de Fuca Strait. AtmosphereOcean 37, 1-19.

Llansó, R.J., Aasen, S., Welch, K., 1998. Marine sediment monitoring program: II. Distribution and structure of benthic communities in Puget Sound 1989-1993, Washington State Department of Ecology: Environmental investigations and laboratory services program, Olympia, Washington, 114 pp. + appendices.

Long, E.R., Hong, C.B., Severn, C.G., 2001. Relationships between acute sediment toxicity in laboratory tests and abundance and diversity of benthic infauna in marine sediments: a review. Environmental Toxicology and Chemistry 20, 46-60.

Macdonald, R.W., Crecelius, E.A., 1994. Marine sediments in the Strait of Georgia, Juan de Fuca Strait and Puget Sound: What can they tell us about contamination? in: Wilson, R.C.H., Beamish, R.J., Aitkens, F., Bell, J., (Eds.), Review of the Marine Environment and Biota of Strait of Georgia, Puget Sound and Juan de Fuca Strait. Canadian Technical Report of Fisheries and Aquatic Sciences 1948, 101-137.

Macdonald, R.W., Cretney, W.J., Crewe, N., Paton, D., 1992. A history of octachlorodibenzo-pdioxin, 2,3,7,8-tetrachlorodibenzofuran and 3,3', 4-4'-tetrachlorobiphenyl contamination in Howe Sound, British Columbia. Environmental Science \& Technology 26, 1544-1550. 
2894 Macdonald, R.W., Johannessen, S.C., Gobeil, C., Wright, C.A., Burd, B.J., van Roodselaar, A., 2895 In press. Sediment redox tracers in the Strait of Georgia sediments - can they inform us 2896 of the loadings of organic carbon from municipal wastewater? Marine Environmental 2897 Research.

2898 Macdonald, R.W., Macdonald, D.M., O'Brien, M.C., Gobeil, C., 1991. Accumulation of heavy 2899 metals $(\mathrm{Pb}, \mathrm{Zn}, \mathrm{Cu}, \mathrm{Cd})$, carbon and nitrogen in sediments from the Strait of Georgia, 2900 B.C., Canada. Marine Chemistry 34, 109-135.

2901 Mackas, D.L., Louttit, G.C., 1988. Aggregation of the copepod Neocalanus plumchrus at the 2902 margin of the Fraser River plume in the Strait of Georgia. Bulletin of Marine Science 43, $2903 \quad 810-824$.

2904 Madrone Consulting Ltd., 1993. Bamberton: Biological inventory and evaluation, 1992-1993, 2905 prepared for South Island Development Corporation, Victoria, B.C.

2906 Marinone, S.G., Pond, S., 1996. A three-dimensional model of deep water renewal and its 2907 inluence on residual curretns in the central Strait of Georgia, Canada. Estuarine, Coastal $2908 \quad$ and Shelf Science 43, 183-204.

2909 Masson, D., 2002. Deep water renewal in the Strait of Georgia. Estuarine, Costal and Shelf $2910 \quad$ Science 54, 115-126.

2911 Masson, D., Cummings, P.F., 2000. Fortnightly modulation of estuarine circulation in Juan de 2912 Fuca Strait. Journal of Marine Research 58, 439-463.

2913 Masson, D., Cummings, P.F., 2004. Observations and modeling of seasonal variability in the 2914 Straits of Georgia and Juan de Fuca. Journal of Marine Research 62, 491-516.

2915 Maurer, D., Aprill, G., 2007. Intertidal benthic invertebrates and sediment stability at the mouth 2916 of Delaware Bay. International Review of Hydrobiology 64, 379-403. 
2917 McDaniel, N.G., 1973. A Survey of Benthic Macroinvertebrate Fauna and Solid Pollutants in

$2918 \quad$ Howe Sound. Fisheries Research Board of Canada Technical Report 385, 64 pp.

2919 McGreer, E.R., Moore, D.M., Sibert, J.R., 1984. Study of the recovery of intertidal benthos after 2920 removal of log booms, Nanaimo River Estuary, British Columbia. Canadian Technical 2921 Report of Fisheries and Aquatic Sciences 1246, vii + 63 pp.

2922 McLaren, P., 1994. Sediment transport in Vancouver Harbour: Implications to the fate of 2923 contaminated sediments and/or dredged material disposal, A Report for the Burrard Inlet Environmental Action Program, Vancouver, B.C., 25 pp. + appendices.

McLaren, P., Crentey, W.J., Powys, R.I., 1993. Sediment pathways in a British Columbia fjord and their relationship with particle associated contaminants. Journal of Coastal Research 9, 1026-1043.

McLaren, P., Ren, P., 1995. Sediment transport and its environmental implications in the lower Fraser River and Fraser Delta, A Report for Environment Canada, DOE FRAP 1993.03, Vancouver, B.C., 38 pp.

McPherson, C.A., Bailey, H.C., Chapman, M.K., Lee, M.K., Burd, B.J., Fanning, M.L., Paine, M.D., Hamilton, M.C., Chen, F., 2003. Iona Deep-sea Outfall, 2002 Environmental monitoring program: Sediment effects survey, prepared for the Greater Vancouver 
Sediment effects survey, prepared for the Greater Vancouver Regional District by EVS Consultants Ltd., Burnaby, BC, 262 pp. + appendices.

2942 McPherson, C.A., Chapman, M.K., Lee, M.K., Fanning, M.L., Olson, J., Chen, F., 2004c. Lions Gate Outfall, 2003 Environmental monitoring program: Sediment effects survey,

McPherson, C.A., Chapman, M.K., McKinnon, S., Burd, B.J., Fanning, M.L., Olson, J.,

McPherson, C.A., Chapman, M.K., McKinnon, S., Burd, B.J., Fanning, M.L., Olson, J., prepared for the Greater Vancouver Regional District by EVS Consultants Ltd., Burnaby, B.C., 99 pp. + appendices. Hamilton, M.C., Chen, F., 2005a. Iona Deep-sea Outfall, 2004 Environmental monitoring program: Sediment effects survey, prepared for the Greater Vancouver Regional District by EVS Consultants Ltd., Burnaby, B.C., 222 pp. + appendices. Hamilton, M.C., Chen, F., 2006a. Iona Deep-sea Outfall, 2005 Environmental monitoring program: Sediment effects survey, prepared for the Greater Vancouver Regional District by EVS Consultants Ltd., Burnaby, B.C., 262 pp. + appendices.

McPherson, C.A., Chapman, M.K., McKinnon, S., Burd, B.J., Fanning, M.L., Olson, J., Hamilton, M.C., Chen, F., 2007a. Iona Deep-sea Outfall, 2006 Environmental monitoring program: Sediment effects survey, prepared for the Greater Vancouver Regional District by EVS Consultants Ltd., Burnaby, B.C., 240 pp. + appendices.

McPherson, C.A., Chapman, P.M., McKinnon, S.J., Burd, B.J., Fanning, M.L., Olson, J., Markovic-Mirovic, N, 2006b. Lions Gate Outfall, 2005 Sediment Effects Survey. Final Report prepared for the Greater Vancouver Regional District (GVRD), Burnaby, BC by Golder Associates Ltd. North Vancouver, BC. 222 pp. + appendices. 
2962

2963

2964

2965

2966

2967

2968

2969

2970

2971

2972

2973

2974

2975

2976

2977

2978

2979

2980

2981

2982

2983

2984

McPherson, C.A., Chapman, P.M., McKinnon, S.J., Burd, B.J., Fanning, M.L., Olson, J., RossEaston, H., Brooks, G., 2007b. Lions Gate Outfall, 2006 Sediment Effects Survey. Prepared for the Greater Vancouver Regional District (GVRD), Burnaby, BC by Golder Associates Ltd. North Vancouver, BC. 238 pp. + appendices.

McPherson, C.A., Chapman, M.K., McKinnon, S.J., Fanning, M.L., Burd, B.J., Olson, J., Chen, F., Brooks, G., 2005b. Lions Gate Outfall, 2004 Sediment Effects Survey, Prepared for the Greater Vancouver Regional District by EVS Consultants Ltd, Burnaby, BC, 212 pp.+ appendices.

Møller, M.M., Nielsen, L.P., Jørgensen, B.B., 1985. Oxygen responses and mat formation by Beggiatoa spp. Applied and Environmental Microbiology 50, 373-382.

Mosher, D.C., Currie, R.G., Sullivan, D., 1997. Monitoring of ocean disposal using side-scan mosaicing. Leading Edge 16, 1667-1669.

MWLAP, 2002. Protocols for Marine environmental monitoring in support of finfish aquaculture waste control regulations, Ministry of Water Land and Parks, Environmental Protection Division, Victoria, B.C., 29 pp.

NEMP, 2002. Final report of the log storage working group, prepared for the Nanaimo Estuary Management Plan Steering Committee, Ministry of Integrated Land and Management Bureau, Government of British Columbia, 27 pp.

Newell, R. C., Seiderer, L. J., Hitchcock, D. R., 1998. The impact of dredging works in coastal waters: a review of the sensitivity to disturbance and subsequent recovery of biological resources on the sea bed. Oceanography and Marine Biology: An Annual Review 36, $127-178$. 
2985 Nickel, L.A., Atkinson, R.J.A., 1995. Functional morphology of burrows and trophic modes of

2986

2987

2988

2989

2990

2991

2992

2993

2994

2995

2996

2997

2998

2999

3000

3001

3002

3003

3004

3005 three thalassinidean shrimp species and a new approach to classification of thalassinidean burrow morphology. Marine Ecology Progress Series 128, 181-197.

Orvain, F., Le Hir, P., Sauriau, P.-G., 2003. A model of fluff layer erosion and subsequence bed erosion in the presence of the bioturbator, Hydrobia ulvae. Journal of Marine Research $61,823-851$.

Otte, G., Levings, C.D., 1975. Distribution of macroinvertebrates communities on mudflat influenced by sewage. Fraser River Estuary, British Columbia. Fisheries Marine Series Technical Report 476, 78 pp.

Paine, Ledge and Associates, 2004. Analyses of Macaulay Point sediment quality data: 19902003. Prepared for Capital Region District, Environmental Services, 137 pp. Paine, Ledge and Associates (PLA). North Vancouver, British Columbia.

Paine, M.D., 2003. Environmental significance of sediment quality and tissue residue monitoring data for the GVRD Iona and Lions Gate outfall study areas. Draft Report, Prepared for the Greater Vancouver Regional District (GVRD) by Paine, Ledge and Associates (PLA), North Vancouver, 31 pp. + Tables + Figures.

Paine, R.T., Vadas, R.L., 1969. The effects of grazing by sea urchins. Strongylocentrous spp., on benthic algal populations. Limnology and Oceanography 14, 710-719.

Palsson, W.A., Hoffmann, S., Clarke, P., Beam, J., 2003. Results from the 2001 transboundary trawl survey of the southern Strait of Georgia, San Juan Archipelago and adjacent waters, Report for the Washington Department of Fish and Wildlife, $117 \mathrm{pp.}$ 
3006

3007

3008

3009

3010

3011

3012

3013

3014

3015

3016

3017

3018

3019

3020

3021

3022

3023

3024

3025

3026

3027

3028

Parsons, T.R., Stronach, J., Borstad, G.A., Louttit, G., Perry, R.I., 1981. Biological fronts in the Strait of Georgia, British Columbia, and their relation to recent measurements of primary productivity. Marine Ecology Progress Series 6, 237-242.

Pawlowicz, R., 2001. A tracer method for determining transport in two-layer systems, applied to the Strait of Georgia/Haro Strait/Juan de Fuca Strait estuarine system. Estuarine, Coastal and Shelf Science 52, 491-503.

Pawlowicz, R., 2002. Observations and linear analysis of estuarine flow and sill-generated internal tides in Haro Strait. Journal of Geophysical Research 107, [np], DOI: 10.1029/2000JC000504.

Pearson, T.H., Rosenberg, R., 1978. Macrobenthic succession in relation to organic enrichment and pollution of the marine environment. Oceanography and Marine Biology Annual Review 16, 229-311.

PICES (Ed.), 2001. Environmental assessment of Vancouver Harbour data report for the PICES practical workshop, North Pacific Marine Sciences Organization (PICES) Secretariat, PICES, Sidney, B.C., 203 pp.

Pickard, G.L., Giovando, L.F., 1960. Some observations of turbidity in British Columbia inlets. Limnology and Oceanography 5, 162-170.

Pohle, G., Frost, B., Findlay, R., 2001. Assessment of regional benthic impact of salmon mariculture within the Letang Inlet, Bay of Fundy. ICES Journal of Marine Science 58, $417-426$.

Post, A.L., Wassenberg, T.J., Passlow, V., 2006. Physical surrogates for macrofaunal distributions and abundance in a tropical gulf. Marine and Freswater Research 57, 469483. 
3029 Prior, D.B., Bornhold, B.D., Wiseman, W.J.J., Lowe, D.R., 1987. Turbidity current activity in a $3030 \quad$ British Columbia fjord. Science 237, 1330-1333.

3031 Probert, P.K., 1984. Disturbance, sediment stability, and trophic structure of soft-bottom 3032 communities. Journal of Marine Research 42, 893-921.

3033 Ragnarsson, S.A., Raffaelli, D., 1999. Effects of the mussel Mytilus edulis L. on the 3034 invertebrate fauna of sediments. J. Exp. Mar. Biol. Ecol. 241, 31-43.

3035 Reid, B.J., Baumann, J., 1985. Preliminary laboratory study of the effects of burial by AMAX/Kitsault mine tailings on marine invertebrates. Canadian Manuscript Report of Fisheries and Aquatic Sciences 1781, 45 pp.

Rescan Environmental Services Ltd., 1988. Preliminary environmental overview of proposed

Rhoads, D.C., Young, D.K., 1970. Influence of deposit-feeding organisms on sediment stabiity and community tropic structure. Journal of Marine Research 28, 150-178.

3043 Roegner, C., Andre, C., Lindegarth, M., Eckman, J.E., Grant, J., 1995. Transport of recently settled soft-shell clams (Mya arenaria L.) in laboratory flume flow. Journal of 'Total' sediment biomass and preliminary estimates of organic carbon residence time in deep-sea benthos. Marine Ecology Progress Series 79, 99-114.

3049 Samis, S.C., Liu, S.D., Wernick, B.G., Nassichuk, M.D., 1999. Mitigation of fisheries impacts from the use and disposal of wood residue in British Columbia and the Yukon. Canadian Technical Report of Fisheries and Aquatic Sciences 2296, viii + 91 pp. 
3052 Schwinghamer, P., 1981. Characteristic size distributions of integral benthic communities.

3053 Canadian Journal of Fisheries and Aquatic Sciences 38, 1255-1263.

3054 Schwinghamer, P., 1983. Generating ecological hypotheses from biomass spectra using causal 3055 analysis: A benthic example. Marine Ecology Progress Series 13, 151-166.

3056 Seacology, Pacific Marine Life Surveys Inc., Tera Environmental Consutants (Alta.) Ltd., 2001.

3057 Biological survey and assessment of benthic habitats for a proposed Manley Creek

3058 pipeline landfall at Boatswain Bank, British Columbia-July 2000, prepared for Georgia

3059 Strait Crossing Pipeline Ltd., 47 pp. + appendices.

3060 Seed, R., Suchanek, T.H., 1972. Population and community ecology of Mytilus, in: Gosling, E.M., (Ed.), The Mussel Mytilus: Ecology, Physiology, Genetics, Culture, Amsterdam,

3063

3064

3065

3066

3067

3068

3069

3070

3071

3072

3073

3074 Elsevier Scientific, pp. 87-169.

Shang, D.Y., Macdonald, R.W., Ikonomu, M.G., 1999. Persistence of nonylphenol and ethyoxylate surfactants and their principle primary degradation products in sediments from near a municipal outfall in the Strait of Georgia, British Columbia, Canada. Environmental Science \& Technology 33, 1366-1372.

Sibert, J.R., 1979. Detritus and juvenile salmon production in the Nanaimo Estuary: 2. Meiofauna available as food to juvenile chum salmon (Oncorhynchus keta). Journal of the Fisheries Research Board of Canada 36, 497-503.

Sibert, J.R., 1981. Intertidal hyperbenthic populations in the Nanaimo Estuary. Marine Biology $64,259-265$.

Sibert, J.R., Brown, T.J., Harpham, V.J., Kask, B.J., 1979. Meiofauna counts in relation to intertidal log storage on the Nanaimo River delta: Spring 1978. Fisheries and Marine Service Data Report 149, 105 pp. 
3075

3076

3077

3078

3079

3080

3081

3082

3083

3084

3085

3086

3087

3088

3089

3090

3091

3092

3093

3094

3095

3096

Sibert, J.R., Harpham, V.J., 1979. Effects of intertidal log storge on the meiofauna and interstitital environment of the Nanaimo River delta. Technical Report of the Fisheries Marine Service (Canada) 833, 31 pp.

Smith, A.L., 1981. Comparison of macrofaunal invertebrates in sand dollar (Dendraster excentricus) beds and in adjacent areas free of sand dollars. Marine Biology 65, 191-198.

Smith, J.R., Fong, P., Ambrose, R. F., 2006. Dramatic declines in mussel bed community diversity : Response to climate change? Ecology 87, 1153-1161.

Snyder, S.W., Hale, W.R., Kontrovitz, M., 1990. Assessment of Postmortem Transportation of Modern Benthic Foraminifera of the Washington Continental Shelf. Micropaleontology, $36,259-282$.

Spaulding, H., Foster, M.S., Heine, J.N., 2003. Composition, distribution, and abundance of deep-water (>30 m) macroalgae in central California. Journal of Phycology 39, 273-284.

Stacey, M.W., Pond, S., 2003. The dependence of the currents and the density on the spring-neap cycle and the diurnal-inequality in Burrard Inlet, British Columbia: simulations and observations. Journal of Physical Oceanography 33, 2366-2374.

Stacey, M.W., Pond, S., LeBlonde, P.H., 1991. Flow dynamics in the Strait of Georgia, British Columbia. Atmosphere-Ocean 29, 1-13.

Stehr, C.M., Horiguchi, T., (Eds.), 2001. Environmental assessment of Vancouver Harbour, data report for the PICES practical workshop 16, North Pacific Marine Sciences Organization (PICES) Secretariat, 205 pp.

Stephenson, T.A., Stephenson, A., 1961a. Life between tidemarks in North America. IVA. Vancouver Island II. Journal of Ecology, 49, 1-29. 
Stephenson, T.A., Stephenson, A., 1961a. Life between tidemarks in North America. IVB. Vancouver Island II. Journal of Ecology, 49, 227-243.

Stephenson, T.A., Stephenson, A., 1972. Life between tidemarks on rocky shores. Freeman, USA, $425 \mathrm{pp}$.

Stockner, J.G., Cliff, D.D., Shortreed, K.R.S., 1979. Phytoplankton ecology of the Strait of Georgia, British Columbia. Journal of the Fisheries Research Board of Canada 36, 657666.

Striplin, P., 1996. Development of reference value ranges for benthic infauna assessment endpoints in Puget Sound, Washington, State Department of Ecology Sediment Management Unit, 44 pp. + appendices.

Stubblefield, W.A., Servos, M., Gersberg, R.M., Riley, C., Simpson, D., Smith, D., Wells, P., 2006. Scientific and technical review. Capital Regional District core area Liquid Waste Management Plan, Submitted to the Capital Regional District, Victoria B.C. by the Scientific and Technical Review Panel, $131 \mathrm{pp}$.

Stucchi, D.J., Sutherland, T., Levings, C., Higgs, D., 2005. Near-field depositional model for salmon aquaculture waste, in: Hargrave, B.T., (Ed.), Handbook of Environmental Chemistry: The Environmental Effects of Marine Finfish Aquaculture, Volume 5, Part M, Springer-Verlag, Berlin, pp. 157-179.

Suchanek, T.H., 1979. The Mytilus californianus community: studies on the composition, structure, organization and dynamics of a mussel bed, University of Washington, Ph.D. thesis, $286 \mathrm{pp}$.

Swinbanks, D.D., Murray, J.W., 1981. Biosedimentiological zonation of Boundary Bay tidal flats, Fraser River Delta, British Columbia. Sedimentology 28, 201-237. 
Taylor, F.J.R., Haigh, R., Sutherland, T.H., 1994. Phytoplankton ecology of Sechelt Inlet, a fjord system on Britisyh Columbia coast. II. Potentially harmful species. Marine Ecology Progress Series 103, 151-164.

Thompson, D., Cooke, W., 1991. Enhancement of hardshell clam habitat by beach gravelling, in: Puget Sound Water Quality Action Team (Eds.), Puget Sound Research '91. Seattle, Washington, Proceedings, pp 521-527.

Thomson, R.E., 1976. Tidal currents and estuarine-type circulation in Johnstone Strait, British Columbia. Journal of the Fisheries Research Board of Canada 33, 2242-2264.

Thomson, R.E., 1977. Currents in Johnstone Strait, British Columbia: supplementary data on the Vancouver Island side. Journal of the Fisheries Research Board of Canada, 34 697-703.

Thomson, R.E., 1981. Oceanography of the British Columbia Coast. Canadian Special Publication of Fisheries and Aquatic Sciences 56, 235-258.

Thomson, R.E., 1994. Physical oceanography of the Strait of Georgia-Puget Sound-Juan de Fuca Strait system, in: Wilson, R.C.H., Beamish, R.J., Aitkens, F., Bell, J., (Eds.), Review of the Marine Environment and Biota of Strait of Georgia, Puget Sound and Juan de Fuca Strait. Canadian Technical Report of Fisheries and Aquatic Sciences 1948, 36-100.

Thomson, R.E., 1998. Ecosystem classification of the Strait of Georgia: Physical oceanographic delineation, in: Levings, C.D., Pringle, J.D., Aikens, F., (Eds.), Approaches to Marine Ecosystem Delineation in the Strait of Georgia. Proceedings from a DFO Workshop, Sidney, B.C. November, 1997. Canadian Technical Report of Fisheries and Aquatic Sciences 2247, 112-123. 
3141 Thomson, R.E., Foreman, M.G.G., 1998. Basin areas and volumes of coastal southwest British

3142 Columbia and northwest Washington. Canadian Technical Report of Fisheries and

$3143 \quad$ Aquatic Sciences 196, 17 pp.

3144 Thomson, R.E., Huggett, W.S., 1980. M2 baroclinic tides in Johnstone Strait, British Columbia.

3145 Journal of Physical Oceanography 10, 1509-1539.

3146 Thomson, R.E., Huggett, W.S., Kuwahara, L.S.C., 1980a. Data record of current observations

3147 Vol. VIII Discovery Passage, Johnstone Strait and Queen Charlotte Strait, Part 1 - water

$3148 \quad$ property observations, 1976, 1977, 1978, 1979. Institute of Ocean Sciences, Sidney, B.C.,

$3149262 \mathrm{pp}$.

3150 Thomson, R.E., Huggett, W.S., Kuwahara, L.S.C., 1980b. Data record of current observations

$3151 \quad$ Vol. VIII, Discovery Passage, Johnstone Strait and Queen Charlotte Strait, Part 2-

3152 appendices A to E, Institute of Ocean Sciences, Sidney, B.C., 809 pp.

3153 Thomson, R.E., Mihaly, S.F., Kulikov, E.A., 2007. Estuarine versus transient flow regimes in

3154 Juan de Fuca Strait. Jounal of Geophysical Research-Oceans 112, doi:

$3155 \quad 10.1029 / 2006 J C 003925$.

3156 Tito de Morais, L., Bodiou, J.Y., 1984. Predation on meiofauna by juvenile fish in a western

3157 Mediterranean flatfish nursery ground. Marine Biology 82, 209-215.

3158 Tunnicliffe, V., 1981. High species diversity and abundance of the epibenthic community in an

$3159 \quad$ oxygen-deficient basin. Nature 294, 354-356.

3160 Tunnicliffe, V., 2000. A fine-scale record of 130 years of organic carbon deposition in an anoxic

3161 fjord, Saanich Inlet, British Columbia. Limnology and Oceanography 45, 1380-1387.

3162 Tunnicliffe, V., Syvitski, J.P.M., 1983. Corals move boulders: An unusual mechanism of

3163 sediment transport. Limnology and Oceanography 28, 564-568. 
3164 Tunnicliffe, V., Wilson, K., 1988. Brachipod populations: distribution in fjords of British Columbia (Canada) and tolerance of low oxygen concentrations. Marine Ecology Progress Series 47, 117-128.

Wainwright, P., Harper, J.R., Searing, G.F., Howes, D., 1995. Ecological classification within

Waldichuk, M., 1957. Physical oceanography of the Strait of Georgia, British Columbia. Journal of the Fisheries Research Board of Canada 14, 321-486.

Watling, L., Norse, E.A., 1998. Disturbance of the seabed by mobile fishing gear: A comparison

Warwick, R.M., Dshfield, S.L., Somerfield, P.J., 2006. The integral structure of a benthic marine macrobenthic community data. Marine Ecology Progress Series 92, 221-231. to forest clearcutting. Conservation Biology 12, 1180-1197.

Wang, F., Chapman, P.M., 1999. Biological implications of sulfide in sediment-a review focusing on sediment toxicology. Environmental Toxicology and Chemistry 18, 25262532.

Warwick, R.M., Clarke, K.R., 1993. Comparing the severity of disturbance: A meta-analysis of infaunal assemblage. Journal of Experimental Marine Biology and Ecology 330, 12-18. 
Delineation in the Strait of Georgia, Proceedings from a DFO Workshop, Sidney, B.C. November, 1997. Canadian Technical Report of Fisheries and Aquatic Sciences 2247, 371.

West, P., Fyles, T.M., King, B., Peeler, D.C., 1994. The effects of human activity on the marine environment of the Georgia basin: Present waste loadings and future trends, in: Wilson, R.C.H., Beamish, R.J., Aitkens, F., Bell, J. (Eds.), Review of the Marine Environment and Biota of Strait of Georgia, Puget Sound and Juan de Fuca Strait. Canadian Technical Report of Fisheries and Aquatic Sciences 1948, 9-35.

Whiteley, J., Bendell-Young, L.I., 2007. Ecological implications of intertidal mariculture: observed differences in bivalve community structure between farm and reference sites. Journal of Applied Ecology 44, 495-505.

Williams, G.L. \& Associates Ltd., 1991. Coastal habitat inventory, in: The town of Bamberton Review Process. VII. II. Technical Background South Island, Prepared for the Ministry of Environment, Lands and Parks, Water Quality Branch, Government of British Columbia, pp. 113-120.

Wilson, R.C.H., Beamish, R.J., Aikens, F., Bell, J., 1994. Review of the marine environment and biota of the Strait of Georgia, Puget Sound and Juan de Fuca Strait. Proceedings of the BC/Washington Symposium on the Marine Environment, January 13 \& 14, 1994. Canadian Technical Report of Fisheries and Aquatic Sciences 1948, 390 pp.

Wilson, R.C.H., McKinnon, S.J., 2003. The Point Grey ocean disposal site, 1975-200: A 25-Year Review, Prepared for the Disposal At Sea Program, Environment Canada, Victoria, B.C., $118 \mathrm{pp}$. 
Wlodarska-Kowalczuk, M., Pearson, T.H., Kendall, M.A., 2005. Benthic response to chronic natural physical disturbance by glacial sedimentation in an Arctic fjord. Marine Ecology Progress Series 303, 31-41.

Wright, C.A., Johannessen, S.C., Macdonald, R.W., Burd, B.J., Hill, P.R., van Roodselaar, A., Bertold, S., In press. The Strait of Georgia ambient monitoring program, phase I 20022007: Sediment and benthos. Canadian Data Report of Fisheries and Aquatic Sciences, $\mathrm{XX}, \mathrm{xx}$.

Wright, C.A., Pringle, J.D., 2001. Race Rocks pilot marine protected area: An ecological Overview. Canadian Technical Report of Fisheries and Aquatic Sciences 2353, 93 pp.

Wright, C., Taekema, B., Burd, B., McGreer, E., 2007a. Salmon aquaculture environmenal monitoring data report. Results of sampling program for year 2000, prepared for the Ministry of the Environment, province of British Columbia, Nanaimo, B.C. abstract only URL: http://www.elp.gov.bc.ca/epd/industrial/aquaculture/salmon_farming.htm.

Wright, C., Taekema, B., Burd, B., McGreer, E., 2007b. Salmon aquaculture environmenal monitoring data report. Results of sampling program for year 2001, prepared for the Ministry of the Environment, province of British Columbia, Nanaimo, B.C. abstract only URL: http://www.elp.gov.bc.ca/epd/industrial/aquaculture/salmon_farming.htm.

Wright, C., Taekema, B., Burd, B., McGreer, E.R., 2007c. Salmon aquaculture environmenal monitoring data report. Results of sampling program for year 2002, prepared for the Ministry of the Environment, province of British Columbia, Nanaimo, B.C. abstract only URL: http://www.elp.gov.bc.ca/epd/industrial/aquaculture/salmon_farming.htm.

Wright, C., Taekema, B., Burd, B., McGreer, E.R., 2007d. Salmon aquaculture environmenal monitoring data report. Results of sampling program for year 2003, prepared for the 
Ministry of the Environment, province of British Columbia, Nanaimo, B.C. abstract only URL: http://www.elp.gov.bc.ca/epd/industrial/aquaculture/salmon_farming.htm.

3234 Wright, C., Taekema, B., Burd, B., McGreer, E.R., 2007e. Salmon aquaculture environmenal

Yunker, M.B., 2000. Sediment PAH signatures in the IONA receiving environment, in: Greater

Yeats, P.A., 2002. Trace metal tracers of fish farm wastes. 2002. In: Hargrave, B.T., (Ed.). monitoring data report. Results of sampling program for year 2004, prepared for the Ministry of the Environment, province of British Columbia, Nanaimo, B.C. abstract only URL: http://www.elp.gov.bc.ca/epd/industrial/aquaculture/salmon_farming.htm Environmental Studies for Sustainable Aquaculture (ESSA): 2002 Workshop Report. Canadian Technical Report of Fisheries and Aquatic Sciences 2411, 82-85. Vancouver Regional District, (Ed.), Development of a Receiving Environment Monitoring Approach to Liquid Waste Management: Progress Workshop 2, Chapter 3$23 \mathrm{pp}$.

Yunker, M.B., Macdonald, R.W., Brewer, R., Sylvestre, S., Tuominen, T., Sekela, M., Mitchell, R.H., Paton, D.W., Fowler, B.R., Gray, C., Goyette, D., Sullivan, D., 2000. Assessment of natural and anthropogenic hydrocarbon inputs using PAHs as tracers. The Fraser River Basin and Strait of Georgia (1987-1997), Aquatic and Atmospheric Sciences Division, Environmental Conservation Branch, Pacific and Yukon Region, Environment Canada, Vancouver, B. C., 128 pp.

Yunker, M.B., Macdonald, R.W., Goyette, D., Paton, D.W., Fowler, B.R., Sullivan, D., Boyd, J., 1999. Natural and anthropogenic inputs of hydrocarbons to the Strait of Georgia. Science of the Total Environment 225, 181-209. 
3254 Zacharias, M.A., Howes, D.E., 1998. An analysis of marine protected areas in British Columbia,

3255 Canada, using a marine ecological classification. Natural Areas Journal 18, 4-13.

3256 Zacharias, M.A., Howes, D.E., Harper, J.R., Wainwright, P., 1998a. The British Columbia

3257 marine ecosystem classification: Rationale, development, and verification. Coastal

$3258 \quad$ Management 26, 105-124.

3259 Zacharias, M.A., Howes, D., Ogborne, C., 1998b. A biophysical habitat classification for

3260 intertidal environments in the Strait of Georgia, in: Levings, C.D., Pringle, J.D., Aikens,

3261 F., (Eds.), Approaches to Marine Ecosystem Delineation in the Strait of Georgia.

3262 Proceedings from a DFO Workshop, Sidney, B.C. November, 1997. Canadian Technical

3263 Report of Fisheries and Aquatic Sciences 2247, 105-111.

3264 Zacharias, M.A., Morris, M.C., Howes, D.E., 1999. Large scale characterization of intertidal

3265 communities using a predictive model. Journal of Experimental Marine Biology and

3266 Ecology 239, 223-242.

3267 Zacharias, M.A., Roff, J.C., 2001. Explanations of patterns of intertidal diversity at regional

3268 scales. Journal of Biogeography 28, 471-483.

3269 Ziervogel, K., Forster, S., 2006. Do benthic diatoms influence erosion thresholds on coastal

$3270 \quad$ subtidal sediments? Journal of Sea Research 51, 43-53.

3271 Zis, T., Ronningen, V., Scrosat, R., 2004. Minor improvement for intertidal seaweeds and

3272 invertebrates after acid mine drainage diversion at Britannica Beach, Pacific Canada.

3273 Marine Pollution Bulletin, 48, 1040-4047.

3274 Zorn, M.E., Lalonde, S.W., Gingras, M.K., Pemberton, S.G., Konhauser, K.O., 2006. Microscale

3275 oxygen distribution in variousl invertebrate burrow walls. Geobiology 4, 137-145.

3276 


\section{Figure Captions}

3279 Figure 1. The Strait of Georgia, including depth contours from multibeam imagery (see also Fig.

3280 3), locations of important geographic units and discharge sources described herein, and

3281 theoretical boundaries of north, middle and southern oceanographic regimes within the main 3282 basin.

3283

3284 Figure 2. Physical parameters used to develop ecounits (Modified from the Ministry of

3285 Sustainable Resource Management (http://ilmbwww.gov.bc.ca/risc/). Substrate = mud, sand, 3286 hard $(\mathrm{M}, \mathrm{S}, \mathrm{H})$; Exposure = high, moderate, low $(\mathrm{H}, \mathrm{M}, \mathrm{L})$; Current $=$ High $>3 \mathrm{knots}$, low $<3$ knots

$3287(\mathrm{H}, \mathrm{L}) ;$ Slope $=$ Flat 0-5\%, sloping 5-20\%, Steep $>20 \%(\mathrm{~F}, \mathrm{~S}, \mathrm{~S})$; Depth $=$ Shallow 0-20m; photic 3288 20-50m, mid-depth 50-200m, deep 200-1000m; Temperature $=$ warm $9-15^{\circ} \mathrm{C}$, cold $<9^{\circ} \mathrm{C}$; Relief $3289=$ low 0-1, medium 2, high 3-4. For example: ecounit = M/L/L/F/M/C/L: Substrate = mud;

3290 Exposure $=$ low Current $=$ low Slope $=$ flat Depth $=$ mid-depth Bottom Temperature $=$ cold;

3291 Relief $=$ low.

3292

3293 Figure 3. Multibeam imagery from the southern Strait of Georgia showing bottom relief and 3294 type, courtesy of Natural Resources Canada, Pacific Geoscience Center, Sidney, BC.

3296 Figure 4. Plot of sediment percent fines (silt/clay $<63 \mu \mathrm{m}$ particle size) to illustrate sediment 3297 types in the Strait of Georgia (data from Burd, 2006; and courtesy of Natural Resources Canada, 3298 Pacific Geoscience Center, Sidney, BC). 
3300 Figure 5. MERIS satellite taken 2007/07/10 (copyright, European Space Agency). True colour 3301 image, Courtesty of Jim Gover and Stephanie King, Institute of Ocean Sciences, Canadian 3302 Department of Fisheries and Oceans, Sidney, BC.

3303

3304 Figure 6. Shorekeepers' Program sites in the Strait of Georgia, BC.

3305 (http://www.shim.bc.ca/atlases/sk/main.htm).

3306

3307 Figure 7. Habitat (beach) suitability maps for Pacific oysters and Manila clams and a 3308 corresponding area map for kelp and eelgrass habitat as generated by the Internet. Framework 3309 Mapping tool provided by the Provincial Ministry of the Environment (http://maps.gov.bc.ca/). 
3311 Table 1. Gross features of the Strait of Georgia, B.C. (from England et al. 1996, Thomson 1998, 3312 and Thomson and Foreman 1998).

\begin{tabular}{|c|c|}
\hline Feature & Measure \\
\hline Surface Area & $6515 \mathrm{~km}^{2}$ \\
\hline Area at 100m depth & $4374 \mathrm{~km}^{2}$ \\
\hline Volume & $1050 \mathrm{~km}^{3}$ \\
\hline Mean Depth & $155 \mathrm{~m}$ \\
\hline Maximum Depth & $420 \mathrm{~m}(\mathrm{~S} \mathrm{Texada} \mathrm{Island})$ \\
\hline Annual Mean Runoff & $5650 \pm 3500 \mathrm{~m}^{3} / \mathrm{s}$ \\
\hline Drainage Area & $286,890 \mathrm{~km}^{2}$ \\
\hline Sill Depth - Haro Strait & $90 \mathrm{~m}$ \\
\hline Sill Depth - Rosario Strait & $50 \mathrm{~m}$ \\
\hline Summer Basin Flushing & $50-75 \mathrm{days}$ \\
\hline Winter Basin Flushing & $100-200 \mathrm{days}$ \\
\hline
\end{tabular}

3313

3314

3315 
Figure 1

3317

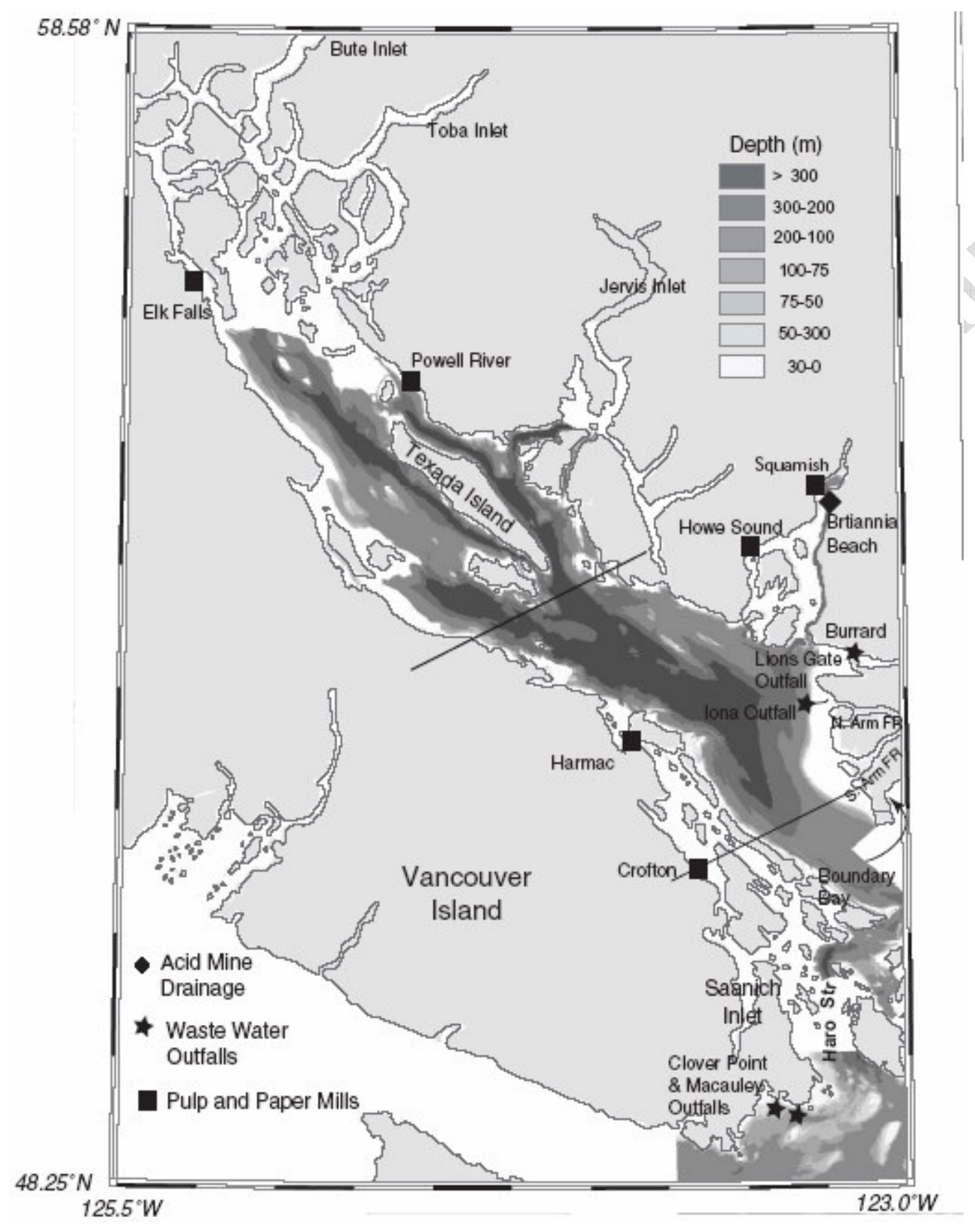




\section{Figure 2}

3320

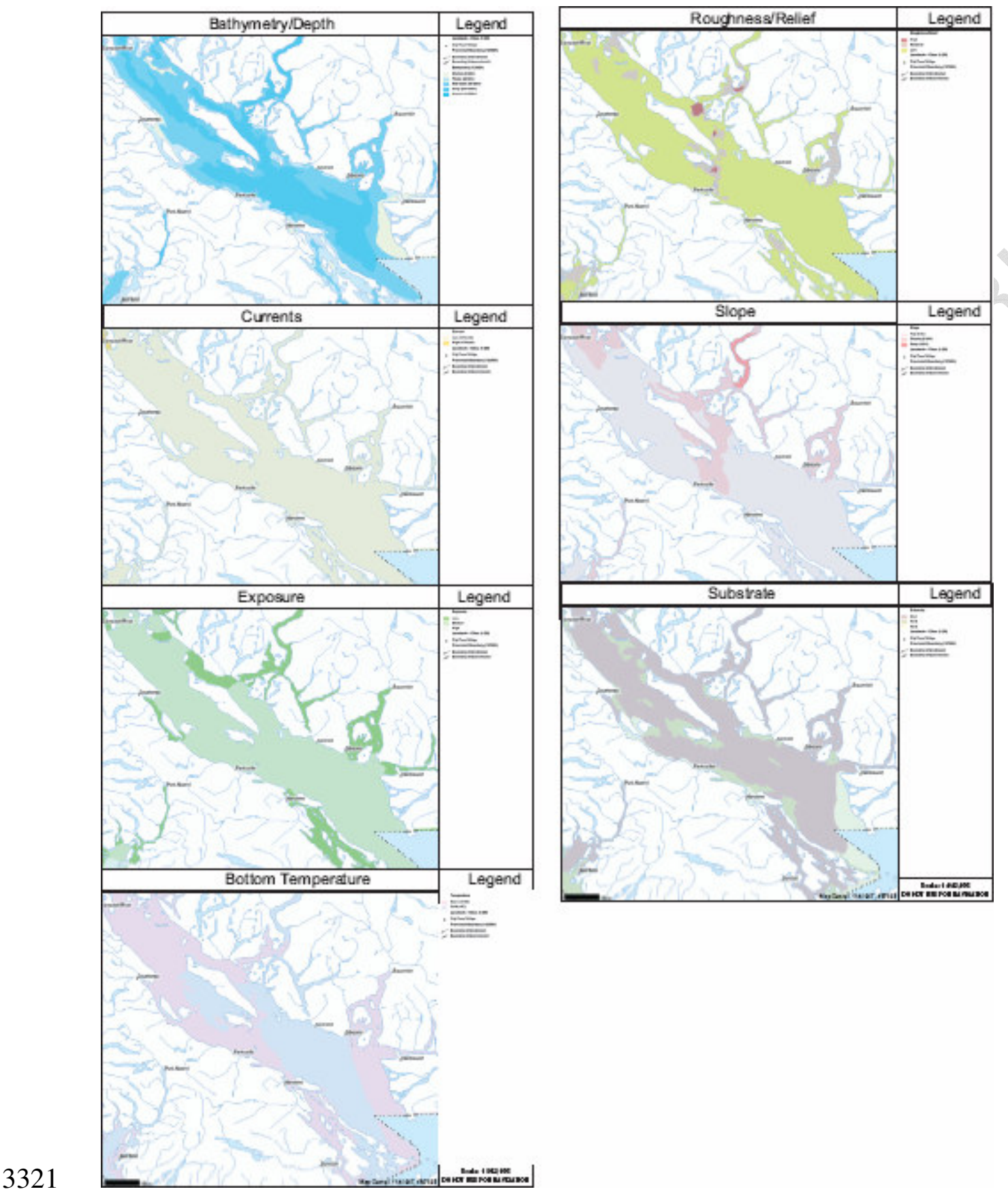


3322 Figure 3

3323

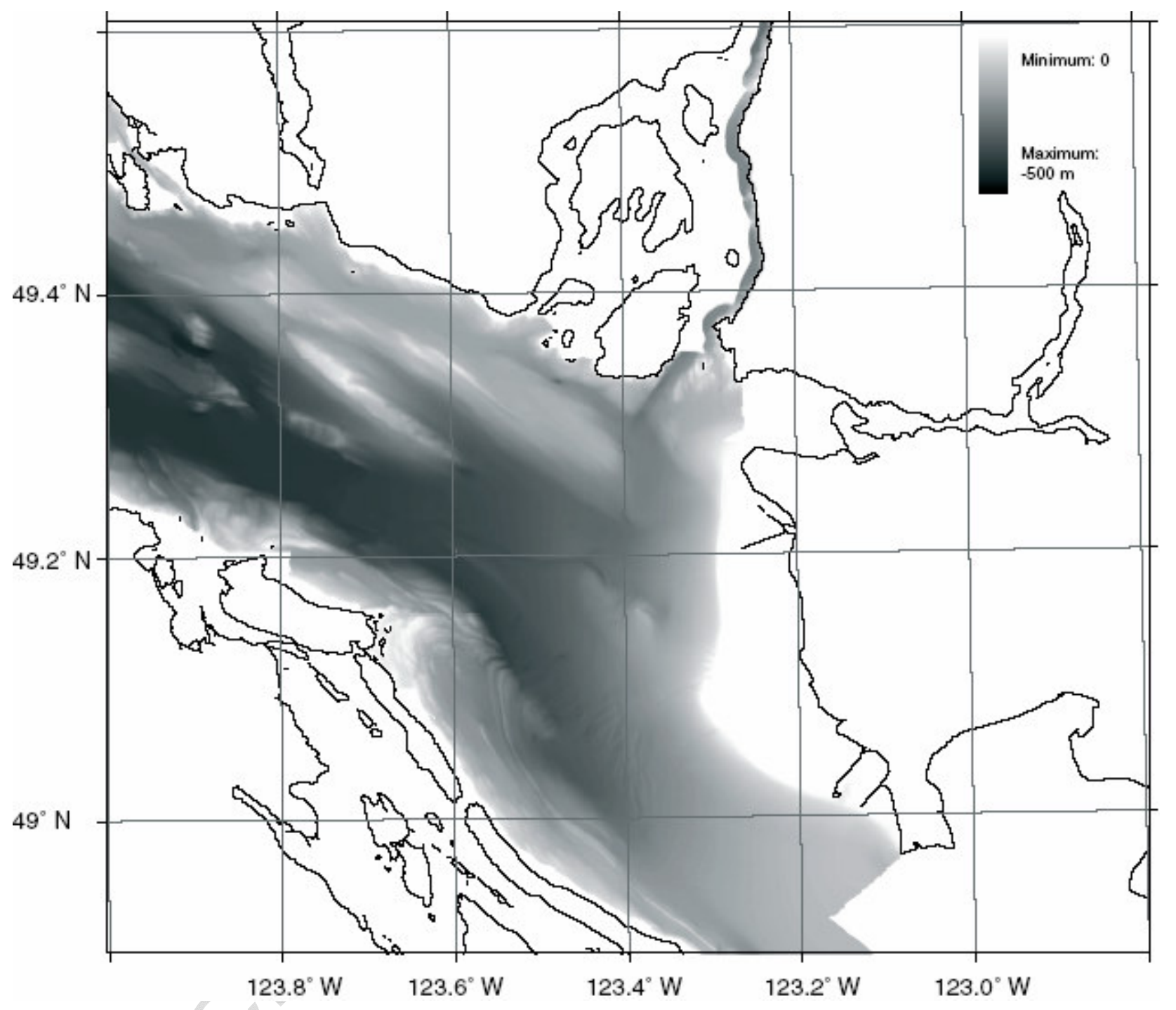


Figure 4

3326

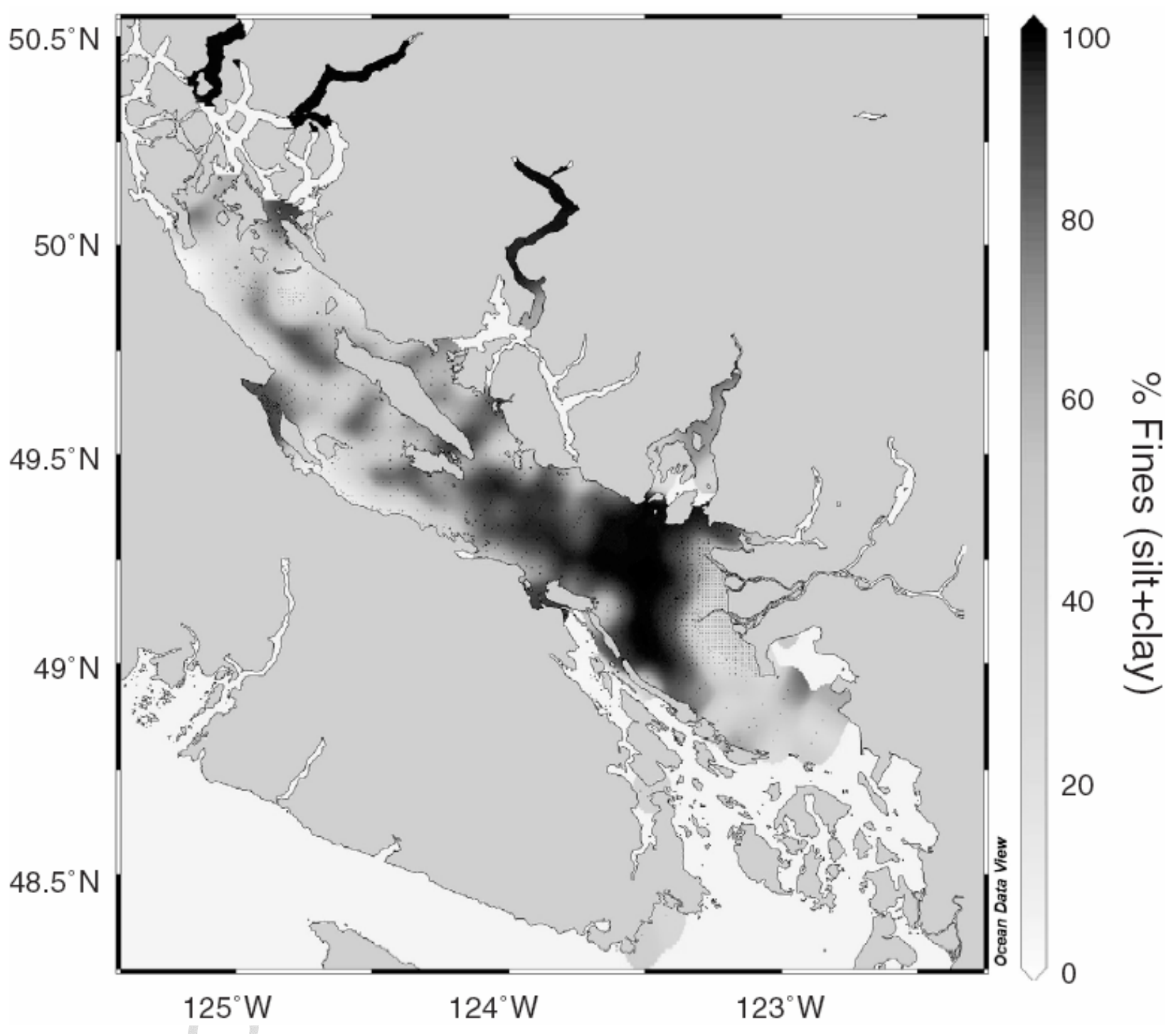


3328 Figure 5

3329

3330

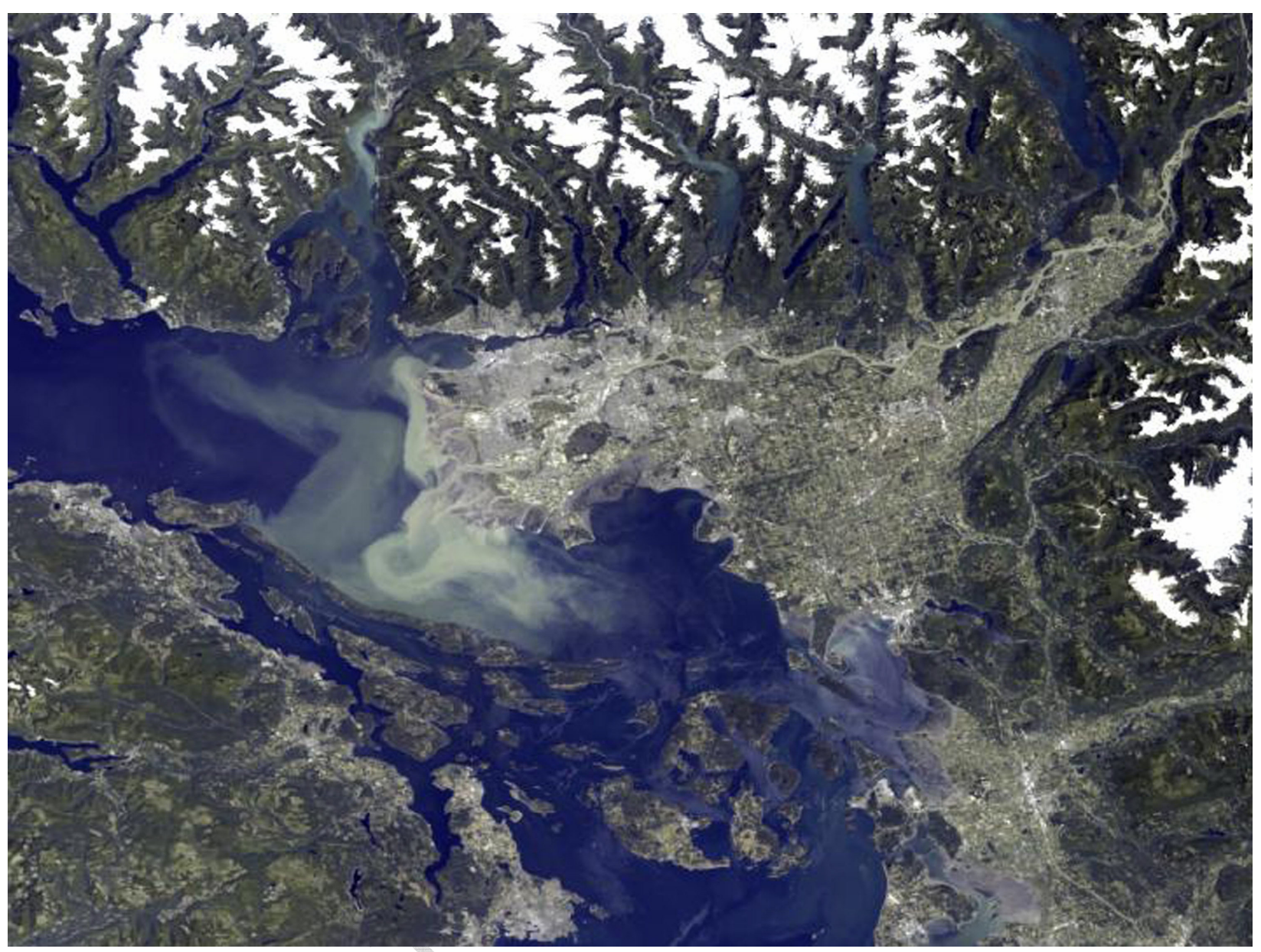




\section{$3331 \quad$ Figure 6}

3332

3333

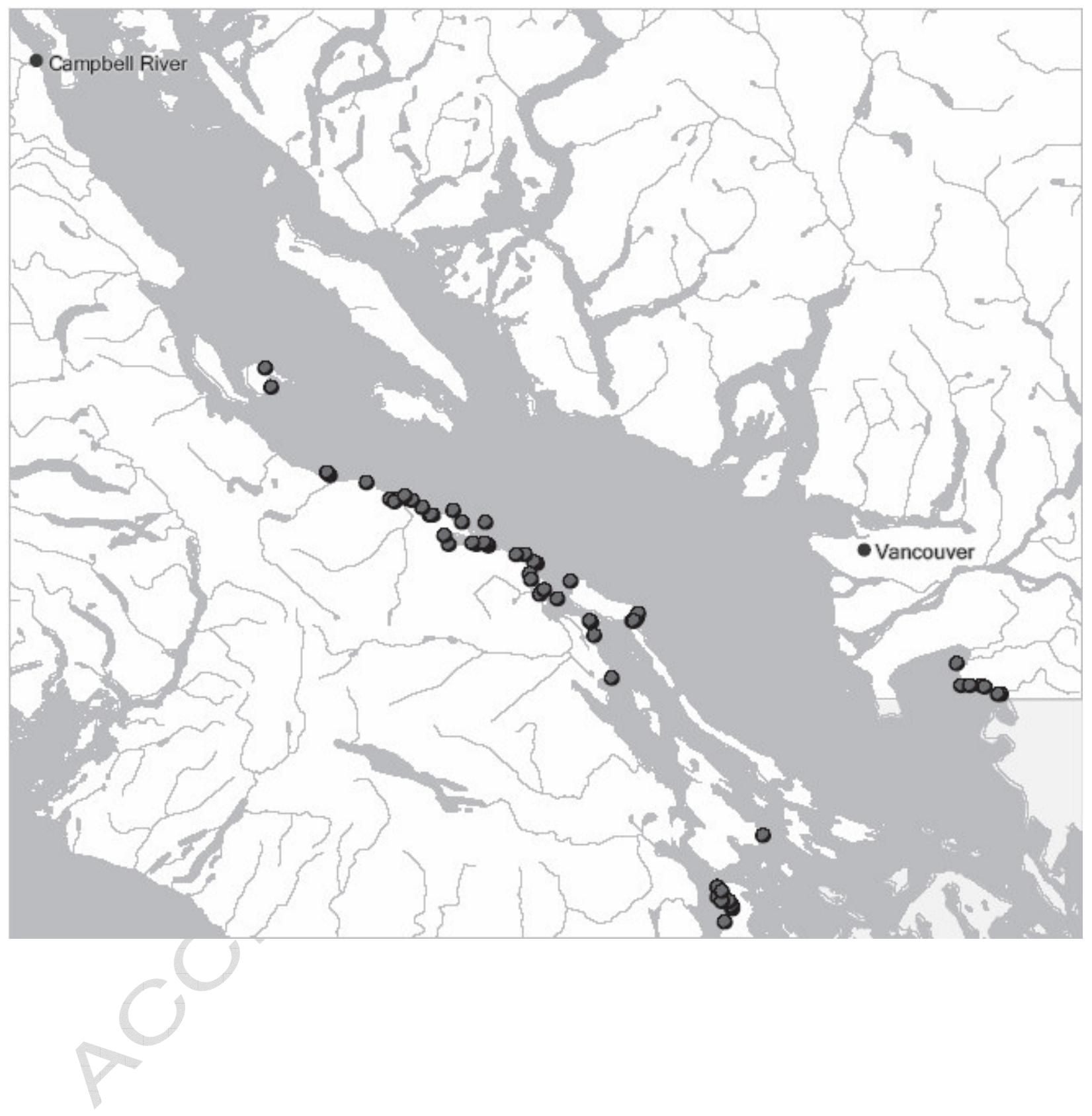


Figure 7

3335

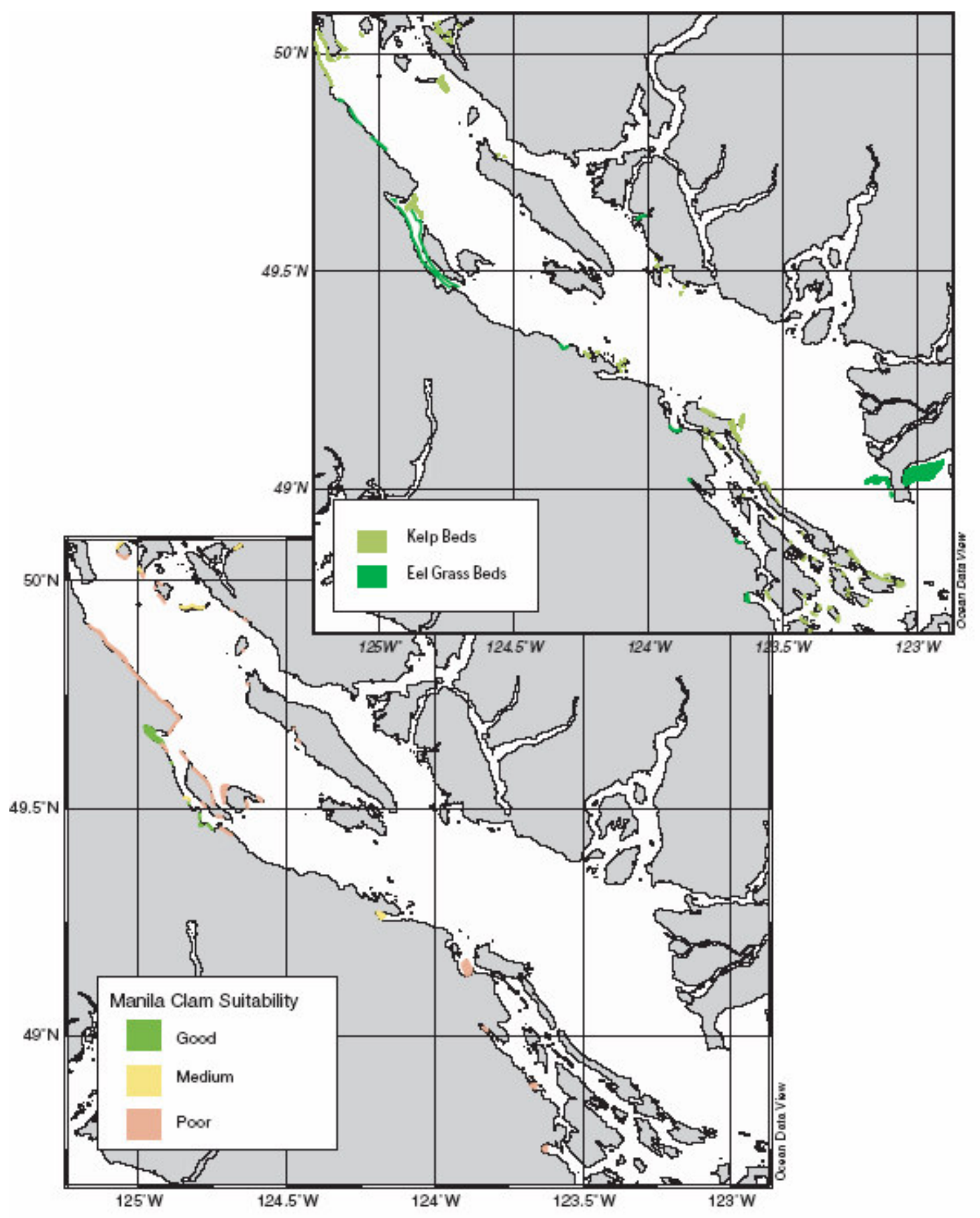

